\title{
Government spending in dynamic general equilibrium models
}

Citation for published version (APA):

Kuehn, S. (2011). Government spending in dynamic general equilibrium models. [Doctoral Thesis, Maastricht University]. Universiteit Maastricht. https://doi.org/10.26481/dis.20110218sk

Document status and date:

Published: 01/01/2011

DOI:

10.26481/dis.20110218sk

Document Version:

Publisher's PDF, also known as Version of record

\section{Please check the document version of this publication:}

- A submitted manuscript is the version of the article upon submission and before peer-review. There can be important differences between the submitted version and the official published version of record.

People interested in the research are advised to contact the author for the final version of the publication, or visit the DOI to the publisher's website.

- The final author version and the galley proof are versions of the publication after peer review.

- The final published version features the final layout of the paper including the volume, issue and page numbers.

Link to publication

\footnotetext{
General rights rights.

- You may freely distribute the URL identifying the publication in the public portal. please follow below link for the End User Agreement:

www.umlib.nl/taverne-license

Take down policy

If you believe that this document breaches copyright please contact us at:

repository@maastrichtuniversity.nl

providing details and we will investigate your claim.
}

Copyright and moral rights for the publications made accessible in the public portal are retained by the authors and/or other copyright owners and it is a condition of accessing publications that users recognise and abide by the legal requirements associated with these

- Users may download and print one copy of any publication from the public portal for the purpose of private study or research.

- You may not further distribute the material or use it for any profit-making activity or commercial gain

If the publication is distributed under the terms of Article $25 \mathrm{fa}$ of the Dutch Copyright Act, indicated by the "Taverne" license above, 


\section{Government Spending in Dynamic General Equilibrium Models}


(c) Stefan Kühn, Maastricht 2010

This book was typeset by the author using $\mathrm{IAT}_{\mathrm{E}} \mathrm{X}$.

Universitaire Pers Maastricht

ISBN 978-94-6159-027-5

Printed in the Netherlands by Datawyse Maastricht 


\title{
Government Spending in Dynamic General Equilibrium Models
}

\author{
Proefschrift
}

ter verkrijging van de graad van doctor aan de Universiteit Maastricht, op gezag van de Rector Magnificus, Prof. mr. G.P.M.F. Mols, volgens het besluit van het College van Decanen, in het openbaar te verdedigen op vrijdag 18 februari 2011 om 12.00 uur

door

Stefan Kühn

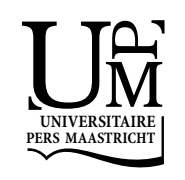




\section{Promotores:}

Prof. dr. J. Muysken

Prof. dr. A.P. van Veen (Maastricht University/ Nyenrode Business

Universiteit)

\section{Beoordelingscommissie:}

Prof. dr. B. Verspagen (voorzitter)

Prof. dr. F. Palm

Prof. dr. F. Smets (European Central Bank/ University of Groningen)

Dit onderzoek werd gefinancieerd door de Maastricht Research School of Economics of Technology and Organizations (METEOR). 


\section{Acknowledgements}

Having completed this book is a great feeling. Four years ago there was only some vague idea existing about what should eventually be in it. Completion seemed to be at the end of a very long road, and I couldn't see the end, not even the first milestone. Fortunately, I didn't have to go down this road alone but had lots of people guiding, helping or entertaining me along the way. I owe thanks to these people not only because of the book they helped me to complete in some way or another, but also because they were part of a great and significant period of my life.

First of all, I would like to thank my supervisors, Joan Muysken and Tom van Veen, for their continuous support throughout the whole time. You gave me a lot of freedom as to what I do while at the same time managing to challenge me to think further and develop new ideas. Furthermore, your advise was invaluable when it came to structuring my findings into papers that are understandable for people reading them. I highly appreciated the fact that your doors were always open and very much liked the pleasant atmosphere at our meetings.

Next, I'd like to thank the members of the assessment committee, Prof. Dr. Bart Verspagen, Prof. Dr. Franz Palm and Prof. Dr. Frank Smets. Receiving qualified comments not only helps to improve the outcome of 
research but also serves as a sign of appreciation for the work done so far. In this respect, I also want to thank other members and former members of the department for their help. I furthermore thank Lenard for giving me a crash-course on VAR methodology and Robert for perfecting my Dutch summary. Further thanks also go to the great administrative staff of our department, Sylvia, Silvana and Fleur.

Even though I worked for four years on this one project named $\mathrm{PhD}$, the time flew by fast thanks to the fantastic people that were always around. First of all, there are my officemates Nils Holinski, Lenard Lieb, Jeroen van den Berg and Jan Piplack. You also made the time in between lunch breaks fly by quickly, which in themselves provided a great forum for any kind of discussion thanks to numerous people at the faculty. I also want to thank my friends from volleyball in- and outside Fyrfad for making my life outside the university building so enjoyable.

My parents and my brother deserve special thanks. They always supported me and opened lots of opportunities in my life, which allowed me to get to the point I am at now. I owe them greatly for that. Finally, I thank Ania for enriching my life in the best way possible. 


\section{Contents}

Contents vii

List of Tables $\quad$ xi

List of Figures $\quad$ xiii

1 Introduction $\quad \mathbf{1}$

1.1 Aim of the Dissertation . . . . . . . . . . . . . 1

1.2 Outline of Dissertation . . . . . . . . . . . . 5

2 Literature Review $\quad 9$

2.1 Introduction . . . . . . . . . . . . . . . . . 9

2.2 Empirical Survey ................... . 10

2.2.1 Survey Results . . . . . . . . . . . . . 11

2.2.2 SVAR versus Dummy Approach . . . . . . . . 16

2.3 Government Spending in NK Models . . . . . . . . . . . . . 18

2.3.1 The basic New Keynesian Model . . . . . . . . . 18

2.3.2 Models fixed to show Consumption Crowding in . . 19

2.3.3 Government Spending under the Zero Interest Bound 22

2.4 Persistent Effects of Temporary Shocks . . . . . . . . . 25 
2.4.1 A Survey of Endogenous Growth Models . . . . . . . 27

2.4.2 Empirical Evidence on the Productivity of Government Spending . . . . . . . . . . . . . . 29

2.5 New Keynesian Endogenous Growth Models . . . . . . . . . 30

2.5.1 The Natural Real Rate of Interest and the Taylor Rule 31

2.5.2 Determinacy and the Taylor Principle . . . . . . . 33

2.6 Conclusion . . . . . . . . . . . . . . . . . . 34

3 Systematic Analysis $\quad 35$

3.1 The Baseline Model . . . . . . . . . . . . . . . . 35

3.2 Government Spending in a standard NK Model . . . . . . . 40

3.3 Demand Side Modifications . . . . . . . . . . . . . . . . . 41

3.4 Short Run Response to Long Run Effects . . . . . . . . . . 45

3.5 Conclusion . . . . . . . . . . . . . . . 47

3.A Mathematical Appendix . . . . . . . . . . . . 47

3.A.1 The standard New Keynesian Model . . . . . . . . . 48

3.A.2 Demand Side Modifications . . . . . . . . . . . . 49

4 Government Spending in an EG Model 53

4.1 Introduction . . . . . . . . . . . . . . . 53

4.2 Endogenous Growth Model . . . . . . . . . . . . . . 54

4.2.1 Endogenous Growth Specification . . . . . . . . . 54

4.2 .2 Production . . . . . . . . . . . . . . . 55

4.2 .3 The Firms . . . . . . . . . . . . . . . . 56

4.2 .4 Households . . . . . . . . . . . . . . . . 57

4.2.5 The Complete Model . . . . . . . . . . . . . . 59

4.3 Flex Price Model . . . . . . . . . . . . . . . . . . . . 60

4.3 .1 Steady State . . . . . . . . . . . . 60 60

4.3.2 Dynamics around the Steady State . . . . . . . . . 61

4.3.3 The Impact of Increased Government Spending . . . 64

4.3 .4 Discussion . . . . . . . . . . . . . . . 68

4.4 Taylor Rule . . . . . . . . . . . . . . . . . . . . . . . 69

4.4.1 The Natural Real Rate of Interest . . . . . . . . . 69

4.4 .2 Monetary Policy . . . . . . . . . . . . . . 70

4.4.3 The Taylor Rule . . . . . . . . . . . . . . . . 72 
4.5 The Sticky Price Model . . . . . . . . . . . . . . . . 74

4.5.1 Sticky Price Extension . . . . . . . . . . . 75

4.5 .2 The Full Model . . . . . . . . . . . . . . . 76

4.5 .3 Sticky Price Dynamics . . . . . . . . . . . . . . . . . . 77

4.6 Simulation . . . . . . . . . . . . . . . . . . . . . . . . . 79

4.7 Conclusion . . . . . . . . . . . . . . . . . 82

4.A NK Phillips Curve for Growing Economy . . . . . . . . 83

4.B Appendix Flex Price model . . . . . . . . . . . . . . 85

4.C Appendix Sticky Price Model . . . . . . . . . . . . . 88

5 Persistence of Shocks $\quad 95$

5.1 Introduction . . . . . . . . . . . . . . . . . . . 95

5.2 The Model . . . . . . . . . . . . . . . . . . 97

5.2.1 Investment Demand in Endogenous Growth Models 97

5.2.2 The Endogenous Growth Specification . . . . . . . 98

5.2.3 Source and Strength of Endogenous Growth . . . . . 99

5.2 .4 Firms . . . . . . . . . . . . . . . 100

5.2 .5 Households . . . . . . . . . . . . . . . . . . 102

5.2 .6 Equilibrium . . . . . . . . . . . . . . . . . 104

5.2 .7 Policy . . . . . . . . . . . . . . . . . . 105

5.2 .8 Steady State . . . . . . . . . . . . . . 105

5.3 Methodology . . . . . . . . . . . . . . . . . . . 107

5.3 .1 Calibration . . . . . . . . . . . . 107

5.3 .2 Analysed Scenarios . . . . . . . . . . . . . . . . 109

5.4 Results . . . . . . . . . . . . . . . . . . . . 110

5.4.1 Illustration of Exogenous versus Endogenous Growth 111

5.4 .2 Consumption Crowding-in . . . . . . . . . . . . . 112

5.4.3 Long Run Policy Implications of Monetary Policy . 115

5.4.4 The Zero Bound: One's Losses, Other's Gains . . . . 119

5.4.5 The Paradox of Thrift . . . . . . . . . . . . . . . 121

5.4.6 Robustness . . . . . . . . . . . . . . . . 123

5.5 Conclusion . . . . . . . . . . . . . . . . . 123

5.A Lower Zero Bound: Solution Strategy . . . . . . . . . 125 
$\begin{array}{lll}6 & \text { Implications } & 127\end{array}$

6.1 Implications for Future Research . . . . . . . . . . . . 127

6.2 Policy Implications . . . . . . . . . . . . . . . 128

$\begin{array}{ll}\text { Bibliography } & 131\end{array}$

Nederlandse Samenvatting (Summary in Dutch) 141

$\begin{array}{ll}\text { Short Curriculum Vitae } & 145\end{array}$ 


\section{List of TABles}

2.1 Estimates of responses to a government spending shock. . . 11

4.1 Calibrated Parameters for Quarterly Periods . . . . . . . 80

5.1 Calibrated Parameters for Quarterly Periods . . . . . . 108 



\section{List OF FiguRES}

1.1 Government consumption as $\%$ of GDP . . . . . . . 2

2.1 Stylised representation of concerns of economics schools . . 25

3.1 The intratemporal household consumption leisure decision and the resulting output consumption line . . . . . . . . 37

3.2 General Equilibrium . . . . . . . . . . . . . . . 38

3.3 The basic New Keynesian model with variable real wage . . 40

3.4 The New Keynesian model with a share $\lambda$ of rule of thumb consumers . . . . . . . . . . . . . . . 44

3.5 Response of private consumption to a government spending shock in the period of impact depending on $\lambda \ldots \ldots$. . . 45

3.6 Model with permanent effect of productive government spending . . . . . . . . . . . . . . 46

4.1 Phase diagrams of endogenous growth model . . . . . . . 62

4.2 Regions of increases growth . . . . . . . . . . . 66

4.3 Impulse Response in endogenous growth model . . . . . . . 81

5.1 The response of output to an investment shock and a research shock. . . . . . . . . . . . . . . . 111 
5.2 The response to a government spending shock using $\gamma=0 . \quad 113$

5.3 The response to a government spending shock using $\gamma=0.1 .114$

5.4 The response of output to a negative interest rate shock. . . 116

5.5 Negative productivity shock with $\rho_{y}=0.1 \ldots \ldots \ldots . . . .117$

5.6 Negative productivity shock with $\rho_{y}=0.5 \ldots \ldots . \ldots 118$

5.7 Impact of the zero bound . . . . . . . . . . . . 120

5.8 Government spending in presence of a zero bound . . . . . 121

5.9 The response to a savings shock. . . . . . . . . . . . . 122

5.10 The response to a savings shock with persistence $\rho=0.8$. $\quad 122$ 


\section{1}

\section{Introduction}

\subsection{Aim of the Dissertation}

In democratic societies, we vote for a government also based on its expenditure decisions. This makes government expenditures a topic of very high interest. Naturally, this interest has also sparked a vast amount of research by economists. For economists, government expenditures can be seen from three broad angles. The first is the provision of public goods and services, the second is the redistributive role via transfers and the third is the stabilising role of government spending over the business cycle.

This dissertation deals with the third role, the impact of government spending shocks on the economy. This allows an analysis of the impact government spending has when used as a tool to deal with business cycle fluctuations. Such a role was not foreseen in the neo-classical school of thought, which states that only supply factors determine output. Government spending should seek to maximise the supply and growth potential of the economy, thus focusing on the first role. This view was seriously challenged in the great depression, which resulted in the birth of Keynesian economics.

This school of macroeconomics (formalised in the textbook IS/LM model) argues that business cycle downturns are the result of a lack of demand and therefore prescribes the use of government spending to generate that demand. In this model, government spending shocks increase 
household's income and thereby consumption. Figure 1.1 shows the development of government consumption as a share of GDP over the last 50 years for selected countries. The most recognisable changes are the large increases in the government spending share in the beginning of the 70's as well as in the last year. These increases occurred in response to large economic crises and are examples of the Keynesian notion that government has to provide the demand the private sector lacks in large downturns.

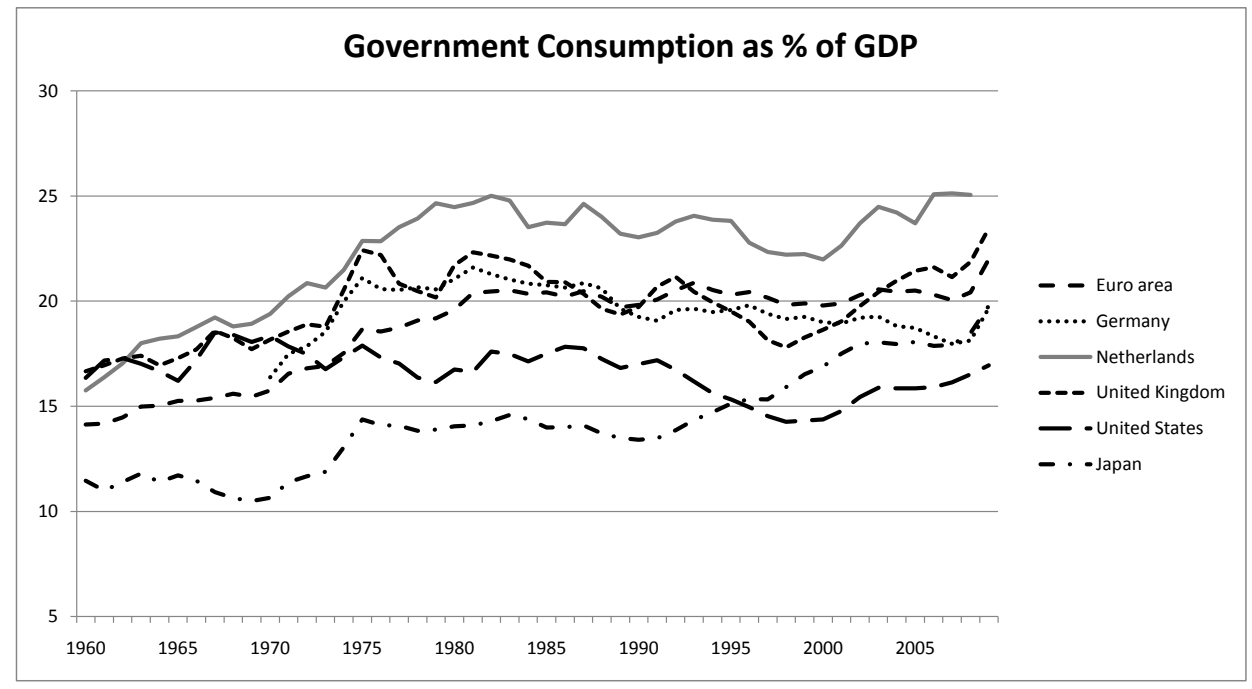

Figure 1.1: Government Consumption as \% of GDP for selected Countries. (Source: World Bank World dataBank, Series: NE.CON.GOVT.ZS)

The period of stagflation of the 1970's seemed to prove the ineffectiveness of Keynesian demand management and prompted a revival of classical economics. This came in the form of new-classical macroeconomics with its focus on microeconomic foundations for macroeconomic relationships. Infinitely living households maximise their lifetime utility over consumption and leisure. This leads to a completely supply-determined dynamic general equilibrium (DGE) model. The real business cycle (RBC) literature uses this model to claim that economic fluctuations are the efficient response to fluctuations in technology (Kydland and Prescott, 1982). Government spending in such models is a pure waste of resources with its only effect being to make households poorer (Baxter and King, 1993). 
In a parallel development, the 70's saw a revival of disequilibrium economics. Markets do not have to clear in order for transactions to be possible. This allows involuntary unemployment caused by a lack of demand (Barro and Grossman, 1971) and consequently advocates a significant role for government spending (Drèze and Malinvaud, 1994). However, this approach was criticised by mainstream dynamic general equilibrium economists for its lack of microfoundations.

New Keynesian literature revived the role of policy intervention in face of economic shocks, focussing on monetary policy. While the basic structure is still a supply determined new classical model, nominal rigidities imply that the short run equilibrium can be different to the efficient flexible price level (Smets and Wouters, 2003). Thereby, it is similar to its namesake of traditional Keynesian models in that excess demand can exist and will increase inflation, where an increase in the interest rate through monetary policy will restore equilibrium. A large part of New Keynesian literature has dealt with the optimal monetary policy, which should push the economy as close as possible to the flexible price equilibrium (Woodford, 2003).

This dissertation will make clear that the role of government spending in New Keynesian models is still far away from the role it has in the Keynesian school. While government spending creates demand, equilibrium in the New Keynesian model is still largely supply determined. Government spending represents a reduction of household resources, meaning that consumption demand will fall. Nevertheless, government spending creates excess demand that pulls output above its flexible price level.

Recent empirical research using vector autoregression (VAR) methodology (for example Blanchard and Perotti, 2002) provided a puzzle for the New Keynesian model's prediction of the effect of government spending. It turns out that private consumption actually rises in response to such a spending shock, while the New Keynesian model predicts a fall - the socalled crowding-in puzzle. This puzzle is due to the fact that consumption demand in the New Keynesian model does not increase as it does in the IS/LM model, thereby disallowing consumption crowding-in. This has evoked a large amount of literature trying to amend the New Keynesian model with factors that allow crowding-in. Chapter 3 reviews these attempts and discusses their weaknesses. 
This dissertation solves the crowding-in puzzle in a novel way. This solution utilises the persistence (discussed by Comin and Gertler, 2006) of the impact of temporary shocks, meaning that short run fluctuations in output cause permanent changes in the level of output. In other words, output has a unit root. The key mechanism, which is the novel contribution of this dissertation, is that higher economic activity due to government spending leads to higher long run output and consumption, which increases consumption demand in the short run so much that consumption is crowded in. The large demand increase allows the New Keynesian model to have an output response so far above its flexible price level despite the use of the supply-determined new-classical base model.

The dissertation takes an analytical approach to motivate amendments to the New Keynesian model. Once these are made, parameters are calibrated using existing results from other papers. With these parameters, the model's implications can either be calculated directly or simulated using a computer program. The usual representation of results is an impulse response graph, where the development over time of a variable in response to a shock is shown.

New Keynesian models are frequently called dynamic stochastic general equilibrium (DSGE) models. The idea is that shocks hitting the economy are unknown in advance and happen stochastically. This allows the modelling not only of first but also of second moments of economic relationships. However, in line with the literature we only model the first moment of macroeconomic variables' reactions to a government spending shock using a linear model. This means, that we will investigate the difference between future expected values of variables of interest between a scenario with and without a certain shock.

In a linear model, this difference in expected values using a stochastic model is equal to the difference in actual values using a deterministic model. Therefore, using a stochastic model does not add any value to our analysis. For this reason, we only show the results of deterministic simulations, thereby following the literature making impulse response analysis to shocks. 


\subsection{Outline of Dissertation}

In Chapter 2 empirical papers analysing the effect of government spending on macroeconomic variables are surveyed. The survey focuses on papers using vector autoregressions since these are suited best to describe the interrelated dynamics of many macroeconomic variables. Next, Chapter 2 surveys existing papers on New Keynesian models and their response to a government spending shock from a theoretical perspective.

In Chapter 3, we use a graphical analysis to explain why the basic New Keynesian model predicts consumption crowding-out. Furthermore, this graphical apparatus is used to show how the different existing approaches to obtain consumption crowding-in work and what their weaknesses are. Finally, this graphical apparatus is used to outline the novel approach introduced in this dissertation: consumption crowding-in due to demand pull from a positive long-run effect of government spending.

Section 2.4 in the literature review discusses papers that show persistent effects of temporary shocks. In essence, output is path dependent. This path dependence can be introduced into a New-Keynesian model using elements of endogenous growth. Therefore, section 2.4.1 of the literature review surveys the part of the endogenous growth literature that we will use in the New Keynesian model. Chapter 4 theoretically develops such an endogenous growth model and analytically derives the effects temporary government spending has on growth. Furthermore, this chapter introduces price stickiness into an endogenous growth model and shows the added dynamics in response to a government spending shock.

The main findings of Chapter 4 are that temporary spending primarily causes households to reduce their savings to counter the negative wealth effect induced by government spending. Furthermore, it finds a number of channels that induce households to increase their savings, or that provide additional resources, so that in the end growth could actually increase in response to a temporary government spending shock. These channels are caused by productive government spending, increasing labour supply and through through a direct increase in resources as well as an increase in the real interest rate. Price stickiness enhances these effects even more, so that significant growth increases are possible. 
The endogenous growth model of Chapter 4 is not a true New Keynesian model since investment is determined as a residual by savings, thus disallowing excess demand. Chapter 5 enhances the endogenous growth determination so that the model allows investment demand and thus excess demand in the New Keynesian tradition. With this specification, the chapter shows that consumption crowding-in as described in Chapter 3 can occur. Additionally, the introduction of endogenous growth increases the government spending multiplier without the need to increase the degree of price stickiness.

The New Keynesian endogenous growth model allows many more interesting discoveries. A short run stimulation of the economy through monetary policy leads to a permanent effect on long run supply factors of the economy. This means that the neutrality of money is only partially correct. Furthermore, an economy facing a liquidity trap, which is introduced in the form of a zero interest bound in New Keynesian models, faces a larger temporary and permanent output effect than the standard New Keynesian model due to the additional fall in demand caused by lower growth. On the upside, this also means that demand induced through government spending when facing a zero bound leads to higher multipliers. Government spending becomes very effective when monetary policy looses its power. Finally, a fall in consumption demand, which essentially should be a savings shock, can reduce output and growth so much that investment actually falls. Thus, the paradox of thrift can actually exist in a New Keynesian endogenous growth model.

Households saving, which depends on the real interest rate, is a key determinant of the long run rate of growth of an economy. Furthermore, the natural real rate of interest is of vital importance for inflation stability in a monetary policy rule such as the Taylor rule. This requires a closer investigation of the monetary policy reaction function for an endogenous growth model. Section 4.4 shows that by reacting to fluctuations in output from a target level a central bank also reacts to fluctuations in the natural real rate of interest, which is needed for inflation stability. Stated differently, even central banks that claim to only care about inflation stability will appear to react to output fluctuations, thus explaining the findings of significant output gap parameters for both the Bundesbank and 
the ECB by many authors.

With the use of endogenous growth elements a new potential solution to the crowding-in puzzle could be found. Additionally, this dissertation provides a New Keynesian endogenous growth model allowing the study of both short and medium run cycles for alternative monetary policy rules, including a liquidity constrained economy. Finally, this dissertation also provides an answer as to why inflation targeting central banks seem to follow a standard Taylor rule. 



\section{2}

\section{Literature Review}

\section{$2.1 \quad$ Introduction}

This chapter surveys the existing literature relevant for this dissertation. While doing that, it reveals open problems which this dissertation will solve. Therefore, the survey lays the foundations on which later chapters are built and also explains the connections between the chapters.

The first section deals with empirical evidence on the macroeconomic effects of government spending. While we do not perform our own empirical analysis, these results provide the yardstick for a theoretical model. After all, a useful model should be able to explain reality.

Section 2.3 surveys the literature dealing with the theoretical prediction of the impact of government spending on private consumption in New Keynesian models, comparing it with the empirical observation. In Section 2.4, the link to the literature asserting a permanent effect of temporary shocks is made. More specifically, endogenous growth literature using a growth determination relevant for this dissertation is surveyed.

Finally, Section 2.5 surveys existing New Keynesian endogenous growth models and their conclusions. Furthermore, this section discusses literature dealing with the natural real rate of interest and the Taylor rule. 


\subsection{Empirical Evidence on the Effects of Govern- ment Spending}

Stock and Watson (2001) conclude that 'vector autoregressions (VARs) are powerful and reliable tools when describing and forecasting data'. Therefore, modern macroeconometrics uses VAR's to estimate economic time series. However, policy analysis is much more difficult since it requires a differentiation between correlation and causation, which the authors call the 'identification problem'. This of course also holds true for the analysis of government spending effects.

In current literature three main approaches to the identification of fiscal policy shocks are seen. The first is a straightforward dummy approach, first followed by Ramey and Shapiro (1998). The great military build-ups in the postwar history of the USA are tagged with a dummy to show that these are times of government spending expansions. The dummy is 1 in the quarter of announcement of the military spending increase (obtained from newspaper articles). It is then included with a number of lags (4 in Ramey, 2009) in the VAR regression. The identification then uses this dummy ordered first in a Choleski decomposition to construct the impulse response functions.

A basic structural VAR approach would estimate a VAR and then construct the identification matrix by a Choleski decomposition with government spending ordered first. The intuition is that changes in government spending are exogenous in a given quarter since there is a decision and implementation lag of policy in response to current economic conditions. Blanchard and Perotti (2002) refine this approach by first using institutional information on tax and spending elasticities to set some parameters, and then estimating the VAR, followed by a Choleski decomposition with government spending ordered first to identify shocks.

The third approach, described among others in Mountford and Uhlig (2009), uses sign restrictions on impulse response curves to select viable identification matrices. In this method, a large number of orthogonal identification matrices is used to retrieve the structural shocks from the VAR residuals. Out of all the possible impulse response functions obtained, only the ones that satisfy certain sign restrictions on the impulse response, after removing business cycle shocks, qualify as responses to a government 
spending shock. The reported impulse response function is then an average of the whole set of impulse response functions identified as government spending shocks.

\subsubsection{Survey Results}

Table 2.1 shows an overview over the predicted response of selected variables estimated by various authors as well as the methodology used by them. Unless otherwise stated, the results are for post-war US data. The arrows indicate the qualitative response at impact as well as at a horizon of 8 and 20 quarters. ${ }^{1}$ When available, the output multiplier is also presented.

Table 2.1: Estimates of responses to a government spending shock.

\begin{tabular}{|c|c|c|c|c|c|c|c|}
\hline Author & Variable & & Resl & onse & Mult & plier & Source \\
\hline (Method) & & $1 \mathrm{Q}$ & $8 \mathrm{Q}$ & $20 \mathrm{Q}$ & $1 \mathrm{Q}$ & $8 \mathrm{Q}$ & \\
\hline Bamov ond & $\mathrm{Y}$ & $\uparrow$ & $\uparrow$ & $\rightarrow$ & & & Figure $6 \mathrm{~A}$ \\
\hline Shaniro (1908) & $\mathrm{C}$ & $\uparrow$ & $\downarrow$ & $\downarrow$ & & & \\
\hline Snapiro (1998) & $\mathrm{I}(\mathrm{r})$ & $\downarrow$ & $\downarrow$ & $\uparrow$ & & & \\
\hline & $\mathrm{I}(\mathrm{nr})$ & $\uparrow$ & $\uparrow$ & $\rightarrow$ & & & \\
\hline & $\mathrm{Y}$ & $\uparrow$ & $\uparrow$ & $\uparrow \uparrow$ & & & Figure 2 \\
\hline Burnside et al. & $\mathrm{C}$ & $\rightarrow$ & $\rightarrow$ & $\uparrow$ & & & \\
\hline$(2004)$ & I & $\uparrow$ & $\rightarrow$ & $\rightarrow$ & & & \\
\hline (Dummy) & $\mathrm{w}$ & $\downarrow$ & $\downarrow$ & $\downarrow$ & & & \\
\hline & $\mathrm{H}$ & $\uparrow$ & $\uparrow$ & $\uparrow$ & & & \\
\hline & $\mathrm{Y}$ & $\uparrow$ & $\rightarrow$ & $\rightarrow$ & & & Figure 2 \\
\hline (Dummy) & $\mathrm{C}$ & $\downarrow$ & $\downarrow$ & $\rightarrow$ & & & column 1 \\
\hline & I & $\rightarrow$ & $\downarrow$ & $\rightarrow$ & & & \\
\hline Monacelli and & $\mathrm{Y}$ & $\uparrow$ & $\uparrow$ & $\uparrow$ & & & Figure 1 \\
\hline Perotti (2008) & $\mathrm{C}$ & $\rightarrow$ & $\uparrow$ & $\uparrow$ & & & column 4 \\
\hline (Dummy) & I & $\uparrow$ & $\uparrow$ & $\rightarrow$ & & & \\
\hline Hall (2009) & $\mathrm{Y}$ & $\uparrow$ & & & 0.47 & & Table 1 \\
\hline (Dummy) & $\mathrm{C}$ & $\downarrow$ & & & -0.12 & & \\
\hline
\end{tabular}

\footnotetext{
${ }^{1}$ It is common practice in the literature to show $68 \%$ confidence bounds (Ramey, 2009, comments on that). We believe that a critical evaluation of results requires more than $68 \%$ significance. Therefore, we refrain from showing any stars on the arrows. Directions shown are based on verbal claims of the authors, when available.
} 
Table 2.1: - continued-

\begin{tabular}{|c|c|c|c|c|c|c|c|}
\hline \multirow{2}{*}{$\begin{array}{l}\text { Author } \\
\text { (Method) }\end{array}$} & \multirow[t]{2}{*}{ Variable } & \multicolumn{3}{|c|}{ Sign Response } & \multicolumn{2}{|c|}{ Multiplier } & \multirow[t]{2}{*}{ Source } \\
\hline & & $1 \mathrm{Q}$ & $8 \mathrm{Q}$ & $20 \mathrm{Q}$ & $1 \mathrm{Q}$ & $8 \mathrm{Q}$ & \\
\hline \multirow{5}{*}{$\begin{array}{l}\text { Ramey (2009) } \\
\text { (Dummy) }\end{array}$} & Y & $\uparrow$ & $\uparrow$ & $\downarrow$ & & & \multirow[t]{5}{*}{ Figure $4 \mathrm{~A}$} \\
\hline & $\mathrm{C}$ & $\downarrow$ & $\downarrow$ & $\downarrow$ & & & \\
\hline & I & $\uparrow$ & $\downarrow$ & $\downarrow$ & & & \\
\hline & $\mathrm{w}$ & $\downarrow$ & $\downarrow$ & $\downarrow$ & & & \\
\hline & $\mathrm{H}$ & $\uparrow$ & $\uparrow$ & $\rightarrow$ & & & \\
\hline Blanchard and & $\mathrm{Y}$ & $\uparrow$ & $\uparrow$ & $\uparrow$ & 0.9 & 0.65 & \multirow[t]{3}{*}{ Table VI } \\
\hline Perotti (2002) & $\mathrm{C}$ & $\uparrow$ & $\uparrow$ & $\uparrow$ & 0.33 & 0.42 & \\
\hline (SVAR, ST) & I & $\rightarrow$ & $\downarrow$ & $\downarrow$ & 0.02 & -0.97 & \\
\hline Fatas and & $\mathrm{Y}$ & $\uparrow$ & $\uparrow$ & $\uparrow$ & & \multirow[t]{4}{*}{1.5} & Figure 1 \\
\hline Mihov (2001) & $\mathrm{C}$ & $\uparrow$ & $\uparrow$ & $\uparrow$ & & & Figure 2 \\
\hline \multirow[t]{2}{*}{ (SVAR) } & I & $\uparrow$ & $\uparrow$ & $\uparrow$ & & & Figure 2 \\
\hline & $\mathrm{w}$ & $\rightarrow$ & $\uparrow$ & $\rightarrow$ & & & Figure 3 \\
\hline Castro (2006) & $\mathrm{Y}$ & $\uparrow$ & $\rightarrow$ & $\downarrow$ & & \multirow[t]{3}{*}{$1.04^{c}$} & \multirow{3}{*}{$\begin{array}{l}\text { Figure } 1 \\
\text { and } \\
\text { Table } 2\end{array}$} \\
\hline general G & $\mathrm{C}$ & $\uparrow$ & $\uparrow$ & $\downarrow$ & & & \\
\hline (SVAR, Spain) & I & $\rightarrow$ & $\uparrow$ & $\downarrow$ & & & \\
\hline Castro (2006) & $\mathrm{Y}$ & $\uparrow$ & $\rightarrow$ & $\downarrow$ & & \multirow[t]{3}{*}{$2.15^{c}$} & \multirow{3}{*}{$\begin{array}{l}\text { Figure } 2 \\
\text { and } \\
\text { Table } 2\end{array}$} \\
\hline goods \& services & $\mathrm{C}$ & $\uparrow$ & $\uparrow$ & $\rightarrow$ & & & \\
\hline (SVAR, Spain) & $\mathrm{I}$ & $\uparrow$ & $\rightarrow$ & $\downarrow$ & & & \\
\hline Tenhofen and & $\mathrm{C}^{g}$ & $\downarrow$ & $\downarrow$ & $\downarrow$ & & & Figure 3 \\
\hline Wolff (2007) & $\mathrm{C}^{n g}$ & $\uparrow$ & $\uparrow$ & $\uparrow$ & & & Figure 4 \\
\hline$(\mathrm{SVAR}, \mathrm{DT})$ & & & & & & & \\
\hline \multirow{5}{*}{$\begin{array}{l}\text { Galí et al. } \\
\text { (2007) (SVAR) }\end{array}$} & $\mathrm{Y}$ & $\uparrow$ & $\uparrow$ & $\bar{\uparrow}$ & 0.74 & 1.22 & \multirow{5}{*}{$\begin{array}{l}\text { Figure 1 } \\
\text { baseline } \\
\text { 1954-2003 } \\
\text { small VAR }\end{array}$} \\
\hline & $\mathrm{C}$ & $\uparrow$ & $\uparrow$ & $\uparrow$ & 0.14 & 0.73 & \\
\hline & I & $\downarrow$ & $\uparrow$ & $\rightarrow$ & & & \\
\hline & $\mathrm{w}$ & $\rightarrow$ & $\uparrow$ & $\uparrow$ & & & \\
\hline & $\mathrm{H}$ & $\rightarrow$ & $\uparrow$ & $\rightarrow$ & & & \\
\hline \multirow{3}{*}{$\begin{array}{l}\text { Perotti (2007) } \\
\text { (SVAR) US }\end{array}$} & Y & $\uparrow$ & $\uparrow$ & $\rightarrow$ & 0.7 & 1.2 & \multirow{3}{*}{$\begin{array}{l}\text { Figure 3, } \\
\text { 1947, LT }\end{array}$} \\
\hline & $\mathrm{C}$ & $\uparrow$ & $\uparrow$ & $\uparrow$ & 0.1 & 0.4 & \\
\hline & I & $\downarrow$ & $\rightarrow$ & $\rightarrow$ & -0.4 & 0.0 & \\
\hline \multirow[t]{2}{*}{ AUS } & $\mathrm{Y}$ & $\uparrow$ & $\uparrow$ & $\uparrow$ & & & \multirow{4}{*}{$\begin{array}{l}\text { Figure } \\
14, \mathrm{LT}\end{array}$} \\
\hline & $\mathrm{C}$ & $\uparrow$ & $\uparrow$ & $\rightarrow$ & & & \\
\hline \multirow[t]{2}{*}{ CAN } & Y & $\uparrow$ & $\rightarrow$ & $\uparrow$ & & & \\
\hline & $\mathrm{C}$ & $\rightarrow$ & $\rightarrow$ & $\rightarrow$ & & & \\
\hline
\end{tabular}


Table 2.1: - continued-

\begin{tabular}{|c|c|c|c|c|c|c|c|}
\hline \multirow{2}{*}{$\begin{array}{l}\text { Author } \\
\text { (Method) }\end{array}$} & \multirow[t]{2}{*}{ Variable } & \multicolumn{3}{|c|}{ Sign Response } & \multicolumn{2}{|c|}{ Multiplier } & \multirow[t]{2}{*}{ Source } \\
\hline & & $1 \mathrm{Q}$ & $8 \mathrm{Q}$ & $20 \mathrm{Q}$ & $1 \mathrm{Q}$ & $8 \mathrm{Q}$ & \\
\hline \multirow[t]{3}{*}{ GBR } & $\mathrm{Y}$ & $\uparrow$ & $\rightarrow$ & $\downarrow$ & & & \\
\hline & $\mathrm{C}$ & $\uparrow$ & $\rightarrow$ & $\downarrow$ & & & \\
\hline & $\mathrm{Y}$ & $\uparrow$ & $\uparrow$ & $\uparrow$ & $1.2^{c}$ & $2.8^{c}$ & Fig 5 and 11 \\
\hline \multirow{5}{*}{$\begin{array}{l}\text { Giordano et al. } \\
\text { (2007) (SVAR) } \\
\text { Italy }\end{array}$} & $\mathrm{C}$ & $\rightarrow$ & $\uparrow$ & $\rightarrow$ & & & Figure 11 \\
\hline & I & $\uparrow$ & $\uparrow$ & $\uparrow$ & & & Figure 11 \\
\hline & $\mathrm{H}$ & $\rightarrow$ & $\uparrow$ & $\rightarrow$ & & & Figure 3 \\
\hline & $\mathrm{i}$ & $\downarrow$ & $\rightarrow$ & $\rightarrow$ & & & Figure 3 \\
\hline & $\pi$ & $\uparrow$ & $\rightarrow$ & $\rightarrow$ & & & Figure 3 \\
\hline \multirow{3}{*}{$\begin{array}{l}\text { Monacelli and } \\
\text { Perotti (2008) } \\
\text { (SVAR) }\end{array}$} & $\mathrm{Y}$ & $\uparrow$ & $\uparrow$ & $\uparrow$ & & & Figure 1 \\
\hline & $\mathrm{C}$ & $\uparrow$ & $\uparrow$ & $\uparrow$ & & & column 2 \\
\hline & I & $\downarrow$ & $\rightarrow$ & $\rightarrow$ & & & \\
\hline \multirow{5}{*}{$\begin{array}{l}\text { Ramey (2009) } \\
\text { (SVAR) }\end{array}$} & $\mathrm{Y}$ & $\uparrow$ & $\uparrow$ & $\rightarrow$ & & & Figure $4 \mathrm{~A}$ \\
\hline & $\mathrm{C}$ & $\uparrow$ & $\uparrow$ & $\rightarrow$ & & & \\
\hline & I & $\downarrow$ & $\downarrow$ & $\downarrow$ & & & \\
\hline & $\mathrm{w}$ & $\rightarrow$ & $\uparrow$ & $\uparrow$ & & & \\
\hline & $\mathrm{H}$ & $\uparrow$ & $\uparrow$ & $\downarrow$ & & & \\
\hline Mertens and & $\mathrm{Y}$ & $\uparrow$ & $\uparrow$ & $\uparrow$ & & & Figure 6 \\
\hline $\begin{array}{l}\text { Ravn (2010) } \\
\text { (SVAR) }\end{array}$ & $\mathrm{C}$ & $\uparrow$ & $\uparrow$ & $\uparrow$ & & & \\
\hline \multirow{4}{*}{$\begin{array}{l}\text { Monacelli and } \\
\text { Perotti (2010) } \\
\text { (SVAR) US }\end{array}$} & $\mathrm{Y}$ & $\uparrow$ & $\uparrow$ & $\rightarrow$ & & & Figure 3 \\
\hline & $\mathrm{C}$ & $\uparrow$ & $\uparrow$ & $\rightarrow$ & & & \\
\hline & TB & $\downarrow$ & $\rightarrow$ & $\uparrow$ & & & \\
\hline & RER & $\uparrow$ & $\uparrow$ & $\rightarrow$ & & & \\
\hline \multirow{4}{*}{ AUS } & $\mathrm{Y}$ & $\uparrow$ & $\rightarrow$ & $\rightarrow$ & & & Figure 6 \\
\hline & $\mathrm{C}$ & $\uparrow$ & $\rightarrow$ & $\rightarrow$ & & & \\
\hline & $\mathrm{TB}$ & $\rightarrow$ & $\rightarrow$ & $\rightarrow$ & & & \\
\hline & RER & $\uparrow$ & $\uparrow$ & $\rightarrow$ & & & \\
\hline \multirow{4}{*}{ CAN } & $\mathrm{Y}$ & $\rightarrow$ & $\rightarrow$ & $\rightarrow$ & & & Figure 6 \\
\hline & $\mathrm{C}$ & $\downarrow$ & $\rightarrow$ & $\rightarrow$ & & & \\
\hline & TB & $\rightarrow$ & $\rightarrow$ & $\downarrow$ & & & \\
\hline & RER & $\rightarrow$ & $\rightarrow$ & $\downarrow$ & & & \\
\hline
\end{tabular}


Table 2.1: - continued-

\begin{tabular}{|c|c|c|c|c|c|c|}
\hline \multirow{2}{*}{$\begin{array}{l}\text { Author } \\
\text { (Method) }\end{array}$} & \multirow[t]{2}{*}{ Variable } & \multicolumn{3}{|c|}{ Sign Response } & Multiplier & \multirow[t]{2}{*}{ Source } \\
\hline & & $1 \mathrm{Q}$ & $8 \mathrm{Q}$ & $20 \mathrm{Q}$ & $1 \mathrm{Q} \quad 8 \mathrm{Q}$ & \\
\hline \multirow{4}{*}{ GBR } & $\mathrm{Y}$ & $\uparrow$ & $\uparrow$ & $\rightarrow$ & & Figure 6 \\
\hline & $\mathrm{C}$ & $\rightarrow$ & $\uparrow$ & $\rightarrow$ & & \\
\hline & $\mathrm{TB}$ & $\downarrow$ & $\downarrow$ & $\rightarrow$ & & \\
\hline & RER & $\uparrow$ & $\uparrow$ & $\rightarrow$ & & \\
\hline \multirow{2}{*}{$\begin{array}{l}\text { Pappa (2005) } \\
\text { (Sign Restr.) }\end{array}$} & $\mathrm{w}$ & $\uparrow$ & $\rightarrow$ & & & Figure 4 \\
\hline & $\mathrm{H}$ & $\uparrow$ & $\uparrow$ & & & \\
\hline \multirow{4}{*}{$\begin{array}{l}\text { Mountford and } \\
\text { Uhlig (2009) } \\
\text { (Sign Restr.) }\end{array}$} & $\mathrm{Y}$ & $\uparrow$ & $\uparrow$ & $\uparrow$ & & Figure 8 \\
\hline & C & $\rightarrow$ & $\uparrow$ & $\uparrow$ & & (antici- \\
\hline & I & $\uparrow$ & $\rightarrow$ & $\rightarrow$ & & pated \\
\hline & $\mathrm{w}$ & $\rightarrow$ & $\rightarrow$ & $\rightarrow$ & & shock) \\
\hline \multirow{5}{*}{$\begin{array}{l}\text { Kriwoluzky } \\
\text { (2009) (Sign } \\
\text { Restr.) }\end{array}$} & $\mathrm{Y}$ & $\downarrow^{p 1}$ & $\uparrow^{p 2}$ & $\rightarrow^{p 3}$ & & Figure 5 \\
\hline & $\mathrm{C}$ & $\downarrow^{p 1}$ & $\uparrow p 2$ & $\rightarrow^{p 3}$ & & \\
\hline & I & $\downarrow^{p 1}$ & $\downarrow^{p 2}$ & $\uparrow^{p 3}$ & & \\
\hline & $\mathrm{w}$ & $\uparrow^{p 1}$ & $\rightarrow^{p 2}$ & $\downarrow^{p 3}$ & & \\
\hline & $\mathrm{H}$ & $\downarrow^{p 1}$ & $\rightarrow^{p 2}$ & $\uparrow p 3$ & & \\
\hline \multirow{4}{*}{$\begin{array}{l}\text { Candelon and } \\
\text { Lieb (2010) } \\
\text { (Sign Restr.) } \\
\text { normal times }\end{array}$} & $\mathrm{Y}$ & $\uparrow$ & $\uparrow^{q 6}$ & & & Figure 4 \\
\hline & $\mathrm{C}$ & $\rightarrow$ & $\rightarrow^{q 6}$ & & & \\
\hline & I & $\rightarrow$ & $\rightarrow_{q 6}^{q 6}$ & & & \\
\hline & $\mathrm{w}$ & $\uparrow$ & $\uparrow q 6$ & & & \\
\hline \multirow{4}{*}{ recession } & $\mathrm{Y}$ & $\uparrow$ & $\uparrow^{q 6}$ & & & Figure 4 \\
\hline & $\mathrm{C}$ & $\uparrow$ & $\uparrow q 6$ & & & \\
\hline & I & $\downarrow$ & $\rightarrow^{q 6}$ & & & \\
\hline & $\mathrm{w}$ & $\rightarrow$ & $\rightarrow^{q 6}$ & & & \\
\hline
\end{tabular}


Table 2.1: - continued-

\begin{tabular}{l}
\hline \hline Author $\quad$ Sariable Response \\
(Method) \\
Notes:
\end{tabular}

Output always increases on impact. This result is not surprising and coherent with any theory. The response of output is still mostly positive at the 8 quarter horizon, while there is no coherent finding for the long-run response. The estimated increase in hours worked is another unanimous result by all authors. This is not surprising since one should expect a positive relationship between output and hours worked.

Perotti (2004) finds that the large output multipliers found in, for example Blanchard and Perotti (2002), are a specific feature of US data. He claims that for the US post-1980 multipliers are much smaller, as they are for other OECD countries (Australia, Canada, UK). However, in Perotti (2007) investigating the same topic, the author does not mention this dependence on the estimated time period, although he still mentions lower multipliers in other countries than the US. In Giordano et al. (2007), the authors find high multipliers in the post-1980 period for Italy. The reader should be aware of this uncertainty and ongoing research on multipliers.

The response of the real wage is an interesting aspect since there is a difference in the theoretical response between RBC models (as in Baxter and King, 1993) and New Keynesian models. In RBC models, the increase in labour supply due to the negative wealth effect lowers the marginal product of labour, while in New Keynesian models the additional increase in demand caused by government spending can lead to a rise in real wages 
(Linnemann and Schabert, 2003b). The empirical evidence on that matter is inconclusive. While authors using the dummy variable approach find a falling real wage, the opposite holds true for authors using the SVAR approach. Finally, authors using sign restriction find both a falling real wage (Kriwoluzky, 2009) or a rising real wage (Pappa, 2005). There is no explanation in the literature as to why these different approaches yield different results.

The response of private investment is also empirically inconclusive. In contrast to real wages, there is no separation along methodology in this matter. Therefore, a verdict on the response of private investment requires further research.

The response of private consumption to a government spending shock has induced a vast amount of literature discussing it. As can be seen in Table 2.1, most authors actually find an increase in private consumption, crowding-in. This contradicts the prediction of both the new-classical (as in Baxter and King, 1993) as well as the New Keynesian model, while it is in line with the "out of fashion" Keynesian model. Section 2.3 as well as Chapter 3 deal with this theoretical discussion. However, there is also a discussion on the grounds of empirical methodology, reviewed in Section 2.2.2.

A very recent innovation is the analysis of state-dependent responses of macroeconomic variables to fiscal shocks using a VAR. Results by Candelon and Lieb (2010), obtained using a threshold model and the sign restriction identification, indicate that impact multipliers of government spending on output are larger in times of recession than in normal times. Furthermore, consumption is crowded in only in recession times. However, consumption crowding out is never observed, showing that taking state-dependency into account does not remove the contradiction of empirical results with theoretical models.

\subsubsection{SVAR versus Dummy Approach}

Table 2.1 shows that estimates using the dummy variable approach favour crowding-out of private consumption, while the SVAR approach favours crowding-in. Ramey (2009) proposes that the implementation lag of fiscal 
policy can explain this difference. In a standard new-classical model, the announcement of higher government spending immediately lowers private consumption due to the negative wealth effect. Afterwards, private consumption increases back to its steady state. Ramey (2009) claims that by the time government spending actually occurs (which is the timing of the shock in the SVAR methodology), consumption is increasing. She shows by estimating simulated data from a theoretical model that the SVAR approach finds an increase in consumption in this case. She furthermore performs a dummy approach regression where the war dates are shifted back by 4 periods and finds that private consumption is crowded in.

Perotti (2007) discusses the problem of the implementation lag. He finds that OECD forecasts of government spending mostly do not predict the government spending shocks identified by the SVAR. In contrast, Ramey (2009) shows that war dates Granger-cause SVAR shocks while SVAR shocks do not Granger-cause war dates. However, Perotti (2007) argues that even the presence of the implementation lag does not discredit the SVAR approach. The estimation of simulated data from a new-classical model with habit persistence using the SVAR approach will show crowding out of consumption, not crowding in.

Mertens and Ravn (2010) show theoretically that anticipation effects in VAR's could pose serious problems due to non-invertible roots in the MA representation of the time series processes. They propose the use of a Blaschke matrix to flip these roots and identify this matrix using longrun restrictions on government spending. This restricts their analysis to permanent government spending shocks, but allows a proper treatment of anticipation effects. They find, even with anticipation, that private consumption rises significantly in response to a government spending shock.

Kriwoluzky (2009), using sign restrictions, identifies pre-announced shocks using the predicted response from a DSGE model. A pre-announced shock occurs when during the period of pre-announcement investment rises and consumption falls, while on impact of the shock government spending is restricted to be positive. He finds that on impact of the shock, private consumption rises, even though it falls during pre-announcement by construction. The findings of these authors suggests that the rise in consumption is a robust feature even in face of the presence of 
announcement effects.

Perotti (2007) also argues that the use of a dummy variable creates too many restrictions. First, there is large uncertainty about the actual path of government spending on the onset of a spending period. Nobody expected the Iraq war to become as expensive as it actually became in the end. Second, there are only 4 identified spending periods, where each was very different in terms of relative spending size and macroeconomic environment. In fact, Perotti (2007) does not find crowding out of consumption when allowing for differences between the different spending periods.

While the discussion on the empirical methodology is not over, the results so far lead us to believe that private consumption is not crowded out by government spending, and is probably crowded in. As already stated, this stands in stark contrast to the prediction of the new-classical as well as the New Keynesian model and has induced a large amount of literature. This dissertation contributes to that theoretical literature by providing new insights into how private consumption can increase after a government spending shock when extending a New Keynesian model setup.

\subsection{New Keynesian Models and their Response to Government Spending}

This section surveys the theoretical literature dealing with government spending in New Keynesian models. Section 2.3.1 will show that the basic New Keynesian model predicts that private consumption falls after a government spending shock. Section 2.3.2 surveys papers that attempted to change the New Keynesian model so that consumption does not fall in response to a government spending increase. Section 2.3.3 covers the literature dealing with the effect of government spending in a situation where the zero interest rate is binding.

\subsubsection{The basic New Keynesian Model}

Baxter and King (1993) show in a new-classical model that the negative wealth effect of government spending is the driving force influencing private consumption in reaction to a government spending shock, causing it to 
fall. With the fall in consumption households also reduce leisure time, thereby increasing labour supply. Investment rises in face of a permanent government spending increase since the increase in labour supply raises the marginal product of capital permanently. When a government spending shock is temporary, investment decreases since the consumption smoothing motive of households causes them to temporarily dissave, raising the real interest rate.

One of the most popular New Keynesian models is the one by Smets and Wouters (2003). In this model a government spending shock always leads to a fall in private consumption, as will be shown in Chapter 3 . Linnemann and Schabert (2003b) investigate this issue further and find that the response of real wages to a government spending shock depends on the interest rate reaction of the central bank. If it is not too strong, demand induced by government spending can actually raise real wages. However, consumption and investment still fall.

Hall (2009) discusses the importance of the markup variability for the size of the output and consumption multiplier to a government spending shock. A New Keynesian model achieves its deviations of output from the efficient flexible price level since either firms or workers temporarily have a lower than optimal mark-up, thereby allowing more employment and output. This means that large countercyclical markups are crucial to obtain government spending multipliers close to one, like they are found in empirical research. Hall (2009) finds that a model using Calvo (1983) pricing with a quarterly probability of sticky prices of 0.89 as the only nominal rigidity implies an elasticity of the markup ratio of 0.75 , which yields the desired output multiplier. The consumption multiplier is still slightly negative. These findings on output multipliers and the degree of price stickiness will be used in Chapter 5 .

\subsubsection{Models fixed to show Consumption Crowding in}

In response to the empirical finding of consumption crowding in after a government spending shock a number of approaches have been proposed to explain this phenomenon using a New Keynesian model. This section shortly reviews each of these, while Chapter 3 provides a systematic analysis 
of some of these approaches.

Bénassy (2007) constructs an overlapping generations model where taxes are levied only on the young and prices are predetermined. A deficit spending shock increases demand in the IS-LM tradition, meaning that the multiplier on output is above unity, thus allowing consumption crowdingin. The rise in production is caused by a rise in the real wage, and thus in firm's marginal costs. However, this has no further effects in the model except to reduce firms' profits, thereby not influencing inflation and the interest rate as it should in New Keynesian models.

Linnemann (2004) goes a different route by investigating tax base effects of balanced budget fiscal policy. An increase of government spending increases labour supply and thus tax income. The tax rate could fall despite the additional funding requirement of the extra spending. If there is an additional reduction in unemployment benefits paid out, Linnemann (2004) finds that consumption could actually be crowded in. The conditions needed to be met for crowding-in also reverse the stability results of the New Keynesian model by requiring a passive monetary policy. While technically interesting, this proposed approach seems implausible to be responsible for crowding in since it disregards the demand effects of government spending and works purely through supply effects.

Monacelli and Perotti (2008) discuss the importance of the complementarity between hours worked and consumption. When a government spending shock leads to a rise in real wage, the following rise in labour supply will also increase consumption demand when hours worked and consumption are complements. This could potentially lead to consumption crowding-in. However, they find the crowding-out effects of government spending too strong when simulating a commonly used specification of the model.

Since consumption crowding in is a Keynesian result, it is only logical that a New Keynesian model should be extended with Keynesian features. A popular "Keynesian" addition has been the "rule-of-thumb" consumers in Galí et al. (2007). A fraction of consumers does not smooth consumption but rather only consumes their real labour income. If a government spending increase induces a rise in real wages due to excess demand, then this can lead to a spiral which eventually increases overall consumption 
demand sufficiently to induce consumption crowding in. Coenen and Straub (2005) find that the share of rule-of-thumb consumers needed to generate crowding-in is implausibly large and cannot be justified by empirical facts. Furlanetto and Seneca (2009) also consider that problem and propose a combination of habit persistence, non-constant elasticity of demand as well as firm-specific capital to increase real rigidities so that the degree of price stickiness as well as the share of rule-of-thumb consumers needed for crowding-in is lower.

Colciago (2005) and Bartolomeo and Manzo (2007) discuss the problem of determinacy in the model of Galí et al. (2007). They find that either introducing sticky wages or a balanced budget fiscal policy based on tax distortions restores the determinacy results of standard New Keynesian models even in face of rule-of-thumb consumers. These additions remove the chance for sunspot driven fluctuations, but also for consumption crowding-in.

Linnemann and Schabert (2003a) introduce government spending into household's preferences to raise labour supply when government spending is increased. The mechanism is to have complementarity between private and public consumption so that an increase in public consumption raises the marginal utility of private consumption, which in turn requires households to raise their marginal utility of leisure. This implies an increase in labour supply. When this effect is sufficiently strong, government spending crowds in private consumption. Bouakez and Rebei (2007) copy this approach and estimate the parameters of their model using US data. Not surprisingly, they find a strong degree of complementarity between private and public consumption, since this is the measure that allows consumption crowding-in in their model.

The approach of complementarity between private and public consumption suffers from a lack of empirical backing. Ni (1995) surveys literature where estimates range from strong substitution to complementarity, while he also conducts own estimations only to find that results are highly sensitive to changes in specification. Intuitively, the idea that consuming government goods lowers leisure demand is suspicious, although not implausible.

In another paper Linnemann and Schabert (2006) introduce productive 
government spending in a basic New Keynesian model. Government spending will produce some of its own resource use directly. Furthermore, it raises the marginal product of labour, real wages and labour supply, thus leading to an additional effect on output. Therefore, the authors conclude that sufficiently productive government spending coupled with flexible labour supply can lead to a rise in private consumption. Tervala (2009) concludes in response to this article that for any realistic values government spending productivity is not sufficient to generate consumption crowding in.

Devereux et al. (1996) and Ravn et al. (2006) use alternative approaches, which are similar in technical aspects. The former specify a production function where the total factor productivity increases with the number of intermediate inputs used. The latter introduce deep habits, so that temporary changes in firm's sales have permanent effects. In both cases demand induced by government spending leads to large countercyclical markups, which increases the output effect of a government spending shock. Nevertheless, the implied markup variability needed for consumption crowding-in by these models is very large.

The discussion shows that none of the approaches can explain consumption crowding-in on their own. Nevertheless, they can be included in a model since they help to increase private consumption by some amount. Rule of thumb consumers is a very interesting concept. However, Chapter 3 will show that at parameter settings where they actually matter, the model becomes very sensitive to parameter changes. However, there is empirical evidence (reviewed in Section 2.4.2) that government spending is actually productive. For this reason, we will use this approach in addition to the main transmission channel introduced in this dissertation.

\subsubsection{Government Spending under the Zero Interest Bound}

The IS/LM model's prediction about the effect of government spending changes drastically when in a liquidity trap. The government spending multiplier is much higher since the interest rate does not increase. Even though the New Keynesian model does not necessarily contain money, a liquidity trap can still be introduced in the form of a zero bound on the 
nominal interest rate. We will show that government spending multipliers are also much higher in the New Keynesian model when the zero bound holds.

This inclusion of a zero bound on the nominal interest rate in DSGE models is a relatively recent phenomenon. Sine the zero bound is a restriction on monetary policy, the topic has received most attention in the literature on optimal monetary policy (Reifschneider and Williams, 2000; Eggertsson and Woodford, 2003; Nakov, 2008). The first observation is that an economy facing a liquidity trap falls into a deflationary spiral since a lack of demand, leading to falling marginal costs and deflation, cannot be countered by lower real interest rates. For an open economy Bodenstein et al. (2009) find that the effects of foreign demand shocks on the home economy are substantially stronger when the home economy is constrained by a zero bound. A general conclusion from this literature is that monetary policy should create additional inflation expectations for a period after the deflationary period so that deflation is reduced.

Christiano et al. (2009) investigate the size of the government spending multiplier under conditions when the zero bound holds. They find that in economies where the output cost of a zero bound is large, meaning where the deflationary spiral is more severe, the government spending multiplier becomes larger as well. The reason behind this is that the deflationary spiral is fuelled by a lack of demand, so that demand induced by government spending can offset this spiral. While under normal conditions government spending crowds out private consumption by raising the real interest rate, it crowds in private consumption under a zero bound by lowering the real interest rate through its weakening of the deflationary spiral. They furthermore show that the government spending multiplier under the zero bound is very sensitive to parameter changes. Finally, they show that in a linear model the effect does not differ between a situation where the economy hits the zero bound or where the interest rate is held fixed, since in both situations the effect of government spending on the change in the real interest rate will be the same.

Both Christiano et al. (2009) as well as Cogan et al. (2010) estimate a government spending multiplier using estimated medium scale DSGE models where the interest rate is held fixed for 2 years. Using the simulated 
model of the US economy by Smets and Wouters (2007), Cogan et al. (2010) find an output multiplier of unity on impact when subjecting the model to a permanent government spending shock. Christiano et al. (2009) subject the model by Altig et al. (2005) to government spending shocks of varying length. When the shocks duration is 1 year, the multiplier is just above 1. A duration of 8 periods gives an impact multiplier of above 2, while a shock of 24 periods gives an impact multiplier of only 0.5 .

These results on government spending multipliers under a zero bound using theoretic models shows that they are sensitive to both the duration of the spending increase as well as to the model's parameters. The reason lies in that future government spending creates inflation expectations, which is very important in a liquidity trap. Unfortunately, as Christiano et al. (2009) state, empirical evidence on government spending multipliers in a liquidity trap does not yet exist and could be impossible to come by.

Government deficits have an effect similar to the zero bound case when using the fiscal theory of the price level (FTPL). In this theory the price level reacts to changes in spending or taxes since it is assumed to equilibrate the present real value of debt with the present value of primary surpluses (Bassetto, 2008). This implies that an increase in the interest rate raises the present value of debt and requires an increase in price level to retain equilibrium. A debt financed increase in government spending raises the present value of debt, and furthermore has to be met by a passive interest rate rule. Given this setup, its effect will be similar to a government spending shock under a zero bound, as in both cases the real interest rate falls (Sims, 2008).

The fiscal theory of the price level is highly controversial. Buiter (2002) argues that "this theory is fatally flawed". It suffers from an overidentification problem, which, simply stated, means that there are too many equations for the variables. In a standard general equilibrium model the process of spending or taxes is left endogenous to allow the fulfillment of the government solvency constraint. These processes are fixed in FTPL, resulting in the over-identification. 


\subsection{Persistent Effects of Temporary Shocks}

Campbell and Mankiw (1987) pose the interesting question why macroeconomics essentially seems to be concerned with fluctuations of output around a trend, which in itself is more or less fixed (see line (a) in Figure 2.1). The New Keynesian literature additionally uses monetary policy to refine these movements around that trend. However, policy does not have long-run consequences. In contrast to that, growth economists are concerned with the transition to that trend, or, in endogenous growth theory, with the determination of the slope of that trend (see line (b) in Figure 2.1). This strict separation is unappropriate. This section argues that a macroeconomic model should not only deal with short run fluctuations, but also with their impact on the medium run potential output (represented by line (c) in Figure 2.1).

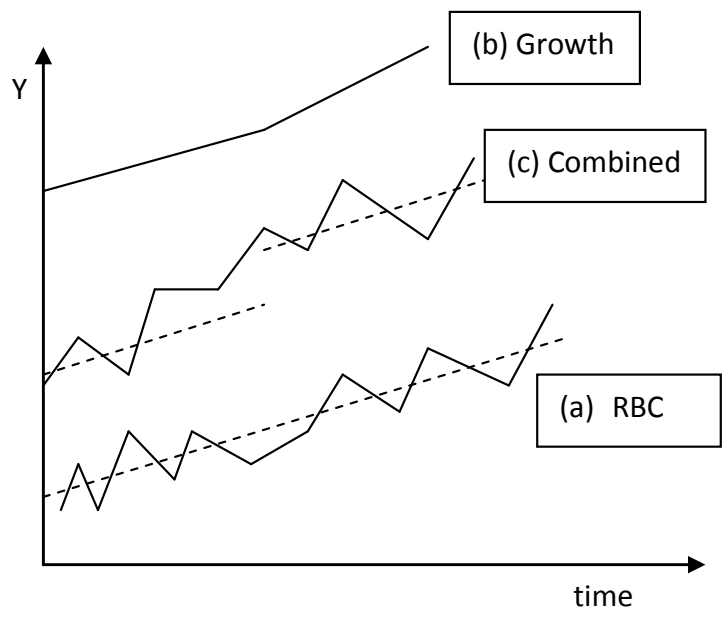

Figure 2.1: Stylised representation of concerns of economics schools

Steindl and Tichy (2009) provide a comprehensive survey of literature where cycles and growth are regarded jointly. Apart from the classical literature (Schumpeter, 1939), they state that Nelson and Plosser (1982) started a discussion on the nature of dynamics of economic time series. This led Campbell and Mankiw (1987) to argue that output has a unit root and that a $1 \%$ short run change in output will lead lead to a more 
than $1 \%$ change in long run output. While their estimates of the size of the effects have to be taken with care, as also shown by Diebold and Rudebusch (1989), the general idea was also confirmed recently by Murray and Nelson (2002).

The apparent non-stationarity of output prompted further theoretical contributions. Blanchard and Quah (1989) argue that economic shocks can be decomposed into demand and supply shocks, where the former do not have a permanent effect on output while the latter do. They show using postwar $U S$ data of output and unemployment that supply and demand shocks influence unemployment the way that a textbook AS/AD model would prescribe. Stadler (1990) goes one step further and proposes that in a monetary model with endogenous technical change even demand shocks, in form of monetary policy, will have a permanent impact on output. In contrast, Comin and Gertler (2006) propose a real business cycle model with endogenous technical change where supply shocks (a wage markup shock in their case) generate not only short run but also medium run fluctuations. This makes the classic source of business cycle fluctuations, technology shocks, endogenous.

The discussion makes clear that the combination of business cycle and growth analysis can yield new insights on the short and medium run consequences of policy decisions. Surprisingly, the New Keynesian literature with price stickiness and a monetary policy rule largely ignored this field thus far. Section 2.5 presents the papers known to us that incorporate endogenous growth into a New Keynesian model. We intent to add to that field by analytically showing the effects of a temporary government spending shock in an endogenous growth model with price stickiness in Chapter 4. Furthermore, Chapter 5 presents the effects of a variety of shocks in a New Keynesian endogenous growth model, which exhibits flexibility as to the source as well as strength of endogenous growth and thus yields different effects. This model not only allows supply but also demand shocks to have permanent effects, which is a Post-Keynesian idea and was introduced in a stylised way by Lavoie (2006) into a New Keynesian model.

Since endogenous growth theory is of vital importance, the following Section 2.4.1 gives an overview over the field of endogenous growth 
literature which we will employ. Furthermore, Section 2.4.2 reviews empirical studies on the productive effects of government spending as these play an important role in endogenous growth models.

\subsubsection{A Survey of Endogenous Growth Models}

The field of endogenous growth is very large. A complete survey would go beyond the scope of this dissertation and is unnecessary. Therefore, this survey focuses on the type of endogenous growth models that employ the knowledge creation function used in Chapters 4 and 5 .

Endogenous growth models are characterised by allowing continued growth of economic variables without facing decreasing returns on any of these. This means that the marginal return to capital is not allowed to fall even when the labour force does not grow. This is achieved by having labour augmenting technical progress, which is endogenously determined and grows at the steady state rate of all variables.

One way to achieve this is by having technology evolve as a result of learning-by-doing, which in its simplest form is represented by the $Y=A K$ model (Romer, 1986, models along this line). A similar type of model is obtained when technological progress is specified as the outcome of economic action by some market participants, for example R\&D or human capital accumulation (Romer, 1990). A second way to introduce endogenous growth is to assume that productive government spending, which is growing with output, provides the growing technology needed to prevent the marginal product of capital from falling (Barro, 1990). A change in government spending directly affects the return to capital. Romer (2006) provides a textbook treatment of the properties of the economy for the different specifications of the endogenous growth process.

A direct extension is the introduction of a productive government capital stock as opposed to productive government spending (flow). While the latter case implies that the economy is always on its balanced growth path upon a change in government spending, the former case introduces additional transition dynamics (Futagami et al., 1993; Turnovsky, 1997).

Turnovsky (2000) presents the determination of household labour supply when households maximise their utility over consumption and leisure 
in a model of productive government spending (flow). In such a case of endogenous labour supply the interaction of two tradeoff loci between growth and leisure determines the steady state growth and labour supply. Government spending, besides its direct productivity effect, induces a negative wealth effect, which in turn changes labour supply, the return to capital, and thus saving and growth (García-Peñalosa and Turnovsky, 2007, also show this for an endogenous growth model with learning by doing).

It is noteworthy that even though Turnovsky (1997) advocates the use of a public capital stock instead of government spending (flow) in endogenous growth models, he uses spending in Turnovsky (2000) when labour supply is endogenous due to the analytical complexity of the stock approach. Irmen and Kuehnel (2008) show (using exogenous labour supply) that most results of the balanced growth path analysis carry over from the flow approach to the stock approach. Cassou and Lansing (1998) find a way to analytically solve an endogenous growth model with both public capital stock and endogenous labour supply by introducing an alternative capital accumulation equation. However, the shares of after tax output consumed and invested by households are fixed in their model. Government investment only has the effect of changing the labour supply.

The endogenous growth models discussed thus far suffer from a scale effect, where changes in the labour force change the endogenous long-run growth rate (Jones, 1995a,b). This critique is picked up by Peretto (2003) who shows that in a model without scale effects all fiscal variables, with the exception of taxes on household asset income and corporate income, have no effects on long run growth of income per capita. However, as Jones (1995a) as well as Peretto (2003) show, the endogenous rate of growth can still change temporarily in such models, so that policy does induce level effects.

The aim of this dissertation is to have a temporary government spending shock induce permanent effects on output and consumption. For that aim, we need to introduce endogenous growth into the New Keynesian model. The desire to obtain analytical results requires the use of a model as simple as possible while having endogenous labour supply: an AKL model with productive government spending (flow). Given the fact that the focus does 
not lie in the determination of the long run growth rate ((b) in Figure 2.1), but rather on the impact of temporary shocks on changes in the short run growth rate ((c) in Figure 2.1), the Jones critique is not relevant for us.

\subsubsection{Empirical Evidence on the Productivity of Govern- ment Spending}

The previous section showed that the introduction of government spending in the production function is common practice in parts of the endogenous growth literature. This section reviews empirical evidence on the size of this alleged productivity effect.

In a seminal paper Aschauer (1989) finds a high elasticity of output with respect to public capital. However, the production function approach used was criticised on methodological issues. It was re-estimated by a number of authors making a variety of adjustments. Evans and Karras (1994b) perform a panel regression using the production function approach and find the results to be very fragile, not allowing them any conclusions with respect to the productivity of government spending. Sturm and de Haan (1995) come to a similar conclusion using first differences for the production function. Kamps (2004) also applies the production function approach and finds an elasticity of output with respect to public capital of 0.31 for a panel of 22 OECD countries.

Another approach to estimate the productive effect of government activity is through the use of a VAR model. Kamps (2004) finds mostly positive or insignificant responses of GDP to a shock to public capital in the analysis of 22 OECD countries. The long run elasticity estimates of output with respect to public capital range from - -77 to 1.77 , with 12 out of 22 being significantly positive, and 1 being significantly negative. Mittnik and Neumann (2001) find a positive effect of public investment on growth and private investment. Alfonso and Alegre (2008) also find a strong crowding-in effect of public investment on private investment using a panel of $27 \mathrm{EU}$ countries. Furthermore, they identify a negative impact of public consumption and social security contributions on economic growth.

Romp and de Haan (2007) survey the various approaches available to estimate the productive effect of government activity. They conclude 
that newer literature has some consensus that public capital is growthenhancing. Furthermore, they find that the effect of public investment differs across countries, regions and sectors. Bom and Lighthart (2008) perform a Meta-analysis of all existing empirical studies and find an average output elasticity of public capital of 0.08 . Therefore, one can conclude that public capital is indeed productive.

As mentioned in the previous section, this dissertation will use productive government flow spending instead of a productive government capital stock for the sake of analytical tractability. Unfortunately, no Meta-analysis study exists for the effects of productive flow spending. However, Evans and Karras (1994a); Devarajan et al. (1996) and Kneller et al. (1999) perform a cross-section analysis to directly test the impact of various variables on growth. They find that current productive government expenditure has a positive effect on growth. They also find that non-productive government spending has a negative effect on growth. This shows that the basic mechanism of productive government flow expenditure used in this dissertation exists, even though our calibration is, in line with the literature, stylised.

\subsection{New Keynesian Endogenous Growth Models}

The discussion thus far makes clear that the extension of a New Keynesian model with elements of endogenous growth is a relevant addition. It allows to study the impact of monetary policy not only on short run fluctuations but also on long run variables. Nevertheless, only very few papers exist that actually engage that task using a New Keynesian setup of Calvo (1983) price stickiness as well as a Taylor rule type monetary policy. One of these papers is by Hiroki (2009), who investigates the growth and welfare effects of Taylor type monetary policy. The model setup features human capital formation as the driving force of endogenous growth and can therefore be represented as a learning-by-doing model. Using simulations, the author finds that optimal monetary policy should react strongly to inflation and mutely to real activity. He furthermore finds that growth maximising monetary policy is not identical to welfare maximising policy and that welfare costs of responding to real activity are larger than in an exogenous 
growth New Keynesian model.

Rannenberg (2009) proposes the introduction of a time-variable NAIRU in a New Keynesian endogenous growth model with learning-by-doing technological progress. He finds that a negative productivity shock has a much more persistent effect on the NAIRU with endogenous growth than with exogenous growth. The reason lies in the fact that higher unemployment also lowers growth in the economy, which in turn slows down the recovery of the NAIRU. He finds that the inflation stabilisation policy of the 70's by European central banks with its depressing effect on output led to persistent increases of the natural rate of unemployment. He furthermore finds, in contrast to Hiroki (2009), that a Taylor rule with a stronger focus on output would have lowered the NAIRU for many years compared to what actually occurred.

The results of Hiroki (2009) and Rannenberg (2009) seem to be at odds concerning the output parameter of the Taylor rule. However, in Hiroki (2009) price distortion is the only inefficiency from a flexible price economy, so that its elimination through a high coefficient in the Taylor rule is the optimal policy. In contrast, Rannenberg (2009) firstly does not consider optimal policy and secondly has real rigidities, which also change the optimal monetary policy in standard New Keynesian models to allow a higher inflation variability.

In Chapter 5, we do not perform optimal monetary policy analysis but rather follow Rannenberg (2009) by showing the long run consequences of a variety of temporary shocks. The idea is to show the channels through which endogenous growth enhances New Keynesian models. However, the model follows more closely that of Hiroki (2009) in that there are no real rigidities and price stickiness is the only monetary distortion. This also adds to obtain a clear view of how endogenous growth changes the New Keynesian model.

\subsubsection{The Natural Real Rate of Interest and the Taylor Rule}

Endogenous growth models usually do not contain an interest rate rule like the Taylor rule. Nevertheless, the interest rate is very important in such models as it determines savings and thus growth. This calls for a thorough 
investigation of the Taylor rule in such models. The Taylor rule received its name after Taylor (1993) found that interest rate setting by the FED seems to follow a remarkably simple rule of reacting to gaps in inflation and output relative to a target. Since then, many authors have estimated the Taylor rule for many countries. An interesting result is that a reaction of the nominal interest rate to deviations in the output gap is always found, even for central banks that allegedly only care for inflation, like the ECB (see for example Gorter et al., 2008).

Woodford (2001) makes the point that theoretically a central bank interest rate rule consistent with inflation and output gap stabilisation requires knowledge about the Wicksellian natural real rate of interest (NRRI) as well as natural output. Since the natural rates are defined as the rates at which there is price stability, monetary policy conducted under misinformed knowledge of these rates cannot guarantee inflation stability. An unnoticed fall in the NRRI will cause the interest rate to be too high, leading to an adjustment via inflation.

The major problem in the monetary policy literature is that the NRRI as well as natural output are unobservable. Furthermore, estimates of a time-varying NRRI suffer from an endogeneity problem and are imprecise when a non-model based approach is used (Laubach and Williams, 2003; Msonnier and Renne, 2007). Giammarioli and Valla (2004) investigate the concept of the natural rate from three angles: empirical based on time series, theoretical based on dynamic general equilibrium models and financial based on the yield curve and asset pricing models. They conclude that due to the different concepts and estimates of the natural rate more substantial research is needed if monetary policy is to use the natural rate reliably in its actions.

To conclude, knowledge of the natural real rate of interest is of high importance but unfortunately impossible to obtain in a timely manner. In Section 4.4 we utilise the co-movement between natural output and the NRRI in the context of an endogenous growth model to show why purely inflation targeting central banks seem to follow a standard Taylor rule. At the same time, this highlights the importance of using the output gap in a Taylor rule. 


\subsubsection{Determinacy and the Taylor Principle}

The monetary policy parameter on inflation is also not innocuous. The commonly accepted notion that the Taylor principle (nominal interest rate increases by more than inflation) is sufficient for determinacy (Woodford, 2001) was questioned by Dupor (2001). He finds using a continuous time model with capital accumulation that the results on determinacy are reversed, in the sense that a passive monetary policy is needed. The intuition is that the real interest rate set by the central bank has to equal the net return on capital. An inflation shock where the central bank increases the real interest rate has to be met by an increased return to capital, which, given the predetermined capital stock, requires an increase in output and marginal costs, leading to more inflation, thus causing instability.

Carlstrom and Fuerst (2005) investigate this issue closer using a discrete time setup. They find that the key issue lies with the horizon of the central bank. All forward looking interest rules suffer from the problem described by Dupor (2001), where forward looking means that the interest rate set for bonds held from the current period to the next is determined using the inflation rate from the current to the next period. The introduction of capital adjustment costs, when sufficiently strong, breaks down the direct relationship between the real interest rate and the return to capital. Furthermore, an interest rate rule where the interest rate is set using inflation from last to current period also reinstates the Taylor principle as a determinacy requirement.

Kurozumi and Zandweghe (2008) extend the analysis of Carlstrom and Fuerst (2005) by showing that even a forward looking monetary policy rule can deliver determinacy if it reacts sufficiently strong to output or contains sufficiently strong interest rate smoothing. New Keynesian models featuring investment actually use both, investment adjustment cost as well as appropriate timing, in order to allow models with an active monetary policy parameter on inflation. 


\subsection{Conclusion}

Given the ongoing discussion on empirical estimation methodology, there is not yet a definite answer as to the response of macroeconomic variables to a government spending shock. Nevertheless, amalgamating existing results, there is strong evidence that private consumption does not fall, and even may rise after a government spending shock. This result conflicts with the prediction of the basic New Keynesian model, which states that private consumption falls due to the negative wealth effect induced. This is the crowding-in puzzle.

Over the last years, the crowding-in puzzle has provoked a number of contributions, where the New Keynesian model has been extended by some mechanisms so that crowding-in is possible. However, none of these mechanisms provides a satisfactory answer. This dissertation's contribution lies in exploring the novel mechanism of the feedback effect of long run effects of government spending on short run private consumption. This necessitates an extension of the New Keynesian model to actually allow for long run effects.

The basic New Keynesian model is able to generate short run fluctuations, while in the medium run all variables return to their steady state and no shock will have any influence on the variables. Section 2.4 shows that this restriction is inappropriate. It also shows that some dynamic general equilibrium models exist where temporary shocks cause medium run cycles. These utilise elements from the theory of endogenous growth. The survey also finds that there are very few New Keynesian endogenous growth models, which furthermore do not discuss fiscal policy.

To conclude, there are two reasons for investigating government spending in a New Keynesian endogenous growth model. The first is that we identified it as a possible channel to obtain consumption crowding in. The second is that a model able to show short run as well as medium run cycles is more appropriate. Since government spending has not been analysed in such a model, this dissertation will do that. 


\section{3}

\section{A Systematic Analysis of Government Spending in New Keynesian Models}

This chapter provides, using a graphical framework, a systematic analysis of the effects of government spending in a New Keynesian model and its extensions. ${ }^{1}$ Section 3.1 shows the determination of output given the the resource constraint, the production function as well as the leisureconsumption tradeoff of households. Section 3.2 shows the additional effects of New Keynesian price stickiness and also explains why consumption is always crowded out in response to a government spending shock. Section 3.3 analytically evaluates the modifications presented in Section 2.3.2. Finally, Section 3.4 proposes the use of long run effects of government spending to induce short run consumption crowding-in.

\subsection{The Baseline Model}

Current state of the art macroeconomic models employ a framework of inter- and intratemporal utility maximising households and firms operating under monopolistic competition. ${ }^{2}$ General equilibrium is obtained when the labour market, the goods market and the financial market are in equilibrium.

\footnotetext{
${ }^{1}$ This chapter is based on Kühn et al. (2010), forthcoming in Metroeconomica.

${ }^{2}$ See Goodfriend and King (1997) for a survey on this type of model.
} 
We assume a simple production function $Y=L$, with $Y$ being output and $L$ being labour employed, since a constant equilibrium real wage makes our graphical analysis more intuitive. ${ }^{3}$ Goods are produced in a setup of monopolistic competition of firms, each facing a downward sloping demand curve. This implies that firms want to charge a gross markup $\mu$ over nominal marginal costs, which are simply the nominal wage $W$. Therefore, each firm $i$ wants to set a price $P^{i}=\mu W$. In the symmetric equilibrium, assuming flexible prices, all firms charge the same price and the equilibrium real wage is $w^{*}=1 / \mu$ at any labour demanded, and profits of $\Pi$ result.

Households maximise their intertemporal utility subject to a budget constraint. Appendix 3.A.1 shows that due to the closed economy assumption, this budget constraint is equal to the resource constraint $C=w L+\Pi-G=Y-G$, where $C$ is household consumption and $G$ is government consumption. The reason is that any resources that the government uses, irrespective of deficit or tax financing, have to come from the households, who earn all the income from production and have to buy government bonds issued. This makes Ricardian equivalence a central aspect of the New Keynesian model and allows us to disregard the question of government financing in this paper. ${ }^{4}$

In an intratemporal context, households simultaneously choose consumption $C$ and leisure $\Lambda$, and the real wage is the relative price between both. Figure 3.1 shows this decision using indifference curves in quadrant I. The expansion path $E P\left(w^{*}\right)$ shows the optimal combinations of leisure and consumption for a given real wage $w^{*}{ }^{5}$ Quadrant 4 translates the leisure decision to output produced, since $L=1-\Lambda$, where we assume equilibrium on the labour market and full-time labour supply is normalised to 1 . In Quadrant III the $Y C\left(w^{*}\right)$ line shows the combinations of consumption and output that are consistent with intratemporal household optimisation

\footnotetext{
${ }^{3}$ This implies a horizontal labour demand curve. Qualitatively, all our results also hold for a downward sloping labour demand curve.

${ }^{4}$ The notion of Ricardian equivalence implies that a shift in the budget constraint due to increased government spending will happen irrespective of whether this spending is financed by (lump-sum) taxes or by issuing bonds. In the latter case, the households anticipate an increase in government debt, which will have to be repaid by future taxes and will therefore save an amount equal to the taxes they would have to pay otherwise. These savings are realised by buying the bonds issued by the government.

${ }^{5}$ The line $E P(w)$ shows the expansion path for a higher real wage $\hat{w}$.
} 


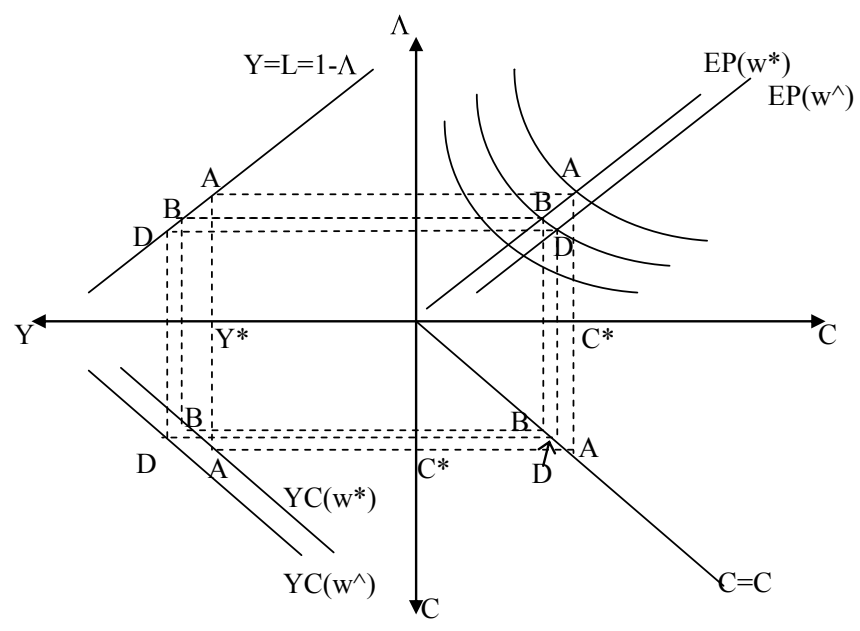

Figure 3.1: The intratemporal household consumption leisure decision and the resulting output consumption line

behaviour given the real wage $w^{*}$. At a certain government spending $G^{*}$ and real wage $w^{*}$, the equilibrium consumption output combination is $C^{*}, Y^{*}$. This is represented in Figure 3.1 by point $A$.

In Figure 3.2, we reproduce the $Y C\left(w^{*}\right)$ curve and combine it with the resource constraint $\left(R C\left(G^{*}\right): Y=C+G^{*}\right)$. The intersection of the $Y C$ and $R C$ curve at point $A$ then corresponds to point $A$ in Figure 3.1. It represents the economy's output supply $Y^{*}$ conditional on the real wage $w^{*}$ and government expenditures $G^{*}$.

In an intertemporal context, households aim at smoothing consumption over time, consistent with their subjective rate of time preference. The households react to changing circumstances by buying or selling bonds on the financial market, where the price is set by the real interest rate. In a steady state with constant output and government spending, households want to have a constant consumption path, and the steady state real interest rate $r^{*}$ equals the inverse of the rate of time preference. A higher interest rate would induce households to buy bonds to shift consumption to the future and consume less today.

When government spending increases permanently from $G^{*}$ to $G^{\prime}$, households see their lifetime budget fall, thus incurring a negative wealth 


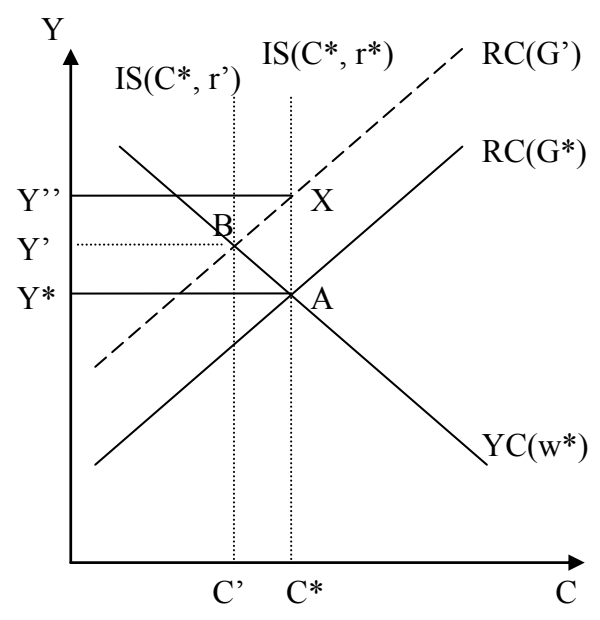

Figure 3.2: General equilibrium, combining the intratemporal optimality condition $Y C$ with the intertemporal condition $I S$ and the resource constraint $R C$

effect, and want to cut consumption in each period evenly. Thus, deficit financed government spending will be met by households wanting to save the full amount of the deficit at the steady state real interest rate $r^{*}$. The budget line in Figure 3.1 shifts inwards, and the economy jumps immediately from point $A$ to point $B$. Similarly, the resource constraint in Figure 3.2 shifts outwards, and the corresponding point $B$ in Figure 3.2 is obtained. In the new equilibrium consumption and income permanently settle at $C^{\prime}$ and $Y^{\prime}$, respectively. The economy's output supply $Y^{\prime}$ is higher because consumption of leisure is reduced after the fall in household resources.

A temporary government spending increase from $G^{*}$ to $G^{\prime}$ also induces a negative wealth effect, and given the steady state real interest rate $r^{*}$, households would like to smooth this fall in resources until infinity. Consumption smoothing occurs through borrowing in the case of taxfinanced expenditures, or by not buying the full amount of government bonds issued each period in case of a deficit financing. However, due to the closed economy resource constraint, this leads to excess demand for goods as well as an excess supply of bonds, either by households or by 
the government-compare point $X$ in Figure 3.2, which shows that output demand is at $Y$ ". The disequilibrium on the financial market leads to a rise in the real interest rate, which reduces current consumption demand. As a consequence households want to have an upward sloping consumption path, thereby reinstating equilibrium in the financial and goods market at point $B$. As the spending shock fades away, the economy moves gradually from point $B$ to point $A$.

We introduce the intertemporal aspect of household optimisation in Figure 3.2 through the $I S\left(C^{*}, r^{*}\right)$ curve, which shows current consumption demand given future consumption $C^{*}$ and the real interest rate $r^{*}{ }^{6}$ The intersection of the $I S$ and the $R C$ curves then depicts output demand. A disequilibrium between output supply ( $Y C$ - $R C$ intersection) and output demand automatically also implies a disequilibrium in the financial market. In the flexible price model, the real interest rate rises to reinstate equilibrium, while the real wage stays fixed at $w^{*}$. This is depicted in Figure 3.2 by an increase of the real interest rate to $r^{\prime}$, which shifts the $I S$ curve to the left, consistent with consumption $C^{\prime}$. The subsequent fading out of the spending shock leads to a gradual decline in the real interest rate as well as a gradual shift of the $I S$ curve back to its original position at $I S\left(C^{*}, r^{*}\right)$. This shift is consistent with the economy moving along the $Y C\left(w^{*}\right)$ curve from point $B$ to point $A$.

Our analysis shows that crowding out occurs in the baseline model. For private consumption to increase in response to increased government spending, the $Y C$ curve has to shift outwards beyond point $X$ in Figure 3.2. This requires either a rightward shift of the $E P$ curve in the first quadrant of Figure 3.1, or an outward shift of the production function in the second quadrant. We systematically discuss these possibilities in the following sections and will conclude that none of the existing approaches in the literature satisfactorily solves the crowding in puzzle.

\footnotetext{
${ }^{6}$ Appendix A.1 shows the mathematical derivation.
} 


\subsection{Government Spending in a Standard New Keynesian Model}

The New Keynesian model deviates from our baseline model since it allows for price stickiness. This causes the real wage to deviate from its flexible price level. Hence, government expenditures will affect household decisions differently. We analyse why this does not open up the possibility for crowding in.

Temporary government spending creates a situation of excess demand indicated by the distance $\overline{X B}$ in Figure 3.2, as explained above. Firms wanting to meet that excess demand see their nominal wages rise due to pressure on the labour market. In a setup of Calvo (1983) price stickiness, not all firms can readjust their price to this rise in marginal costs and thus see their mark-up fall. Consequently, the aggregate ratio of nominal wages

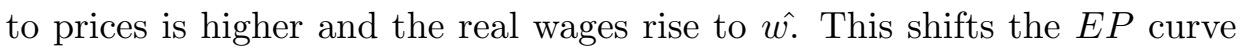
in Figure 3.1 right to $E P(w)$, and therefore implies an upward shift of the $Y C$ curve in Figure 3.3 to $Y C(w)$. Thus, excess demand leads to a rise in output supply.

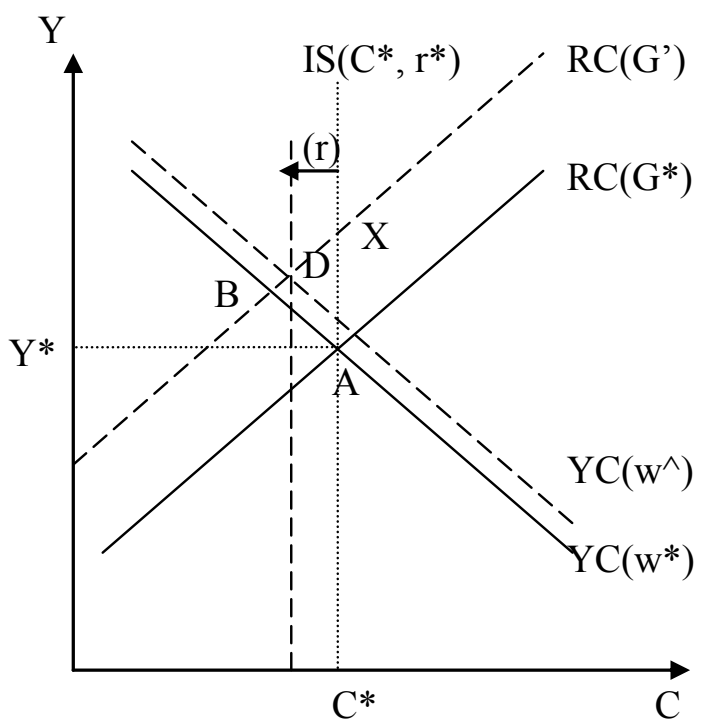

Figure 3.3: The basic New Keynesian model with variable real wage 
In setting their price, firms take into account both current and future marginal costs. This notion underlies the New Keynesian Phillips curve, as derived by Galí and Gertler (1999). It shows that higher marginal costs lead to inflation. In line with the literature, we assume the presence of a central bank that increases the nominal interest rate by more than one for one in response to inflation ${ }^{7}$. Consequently, inflation triggers a rise in the real interest rate. This rise in the real interest rate following a situation of excess demand leads to a fall in consumption demand, represented by a leftward shift of the $I S$ curve.

The New Keynesian adjustment mechanism allows excess demand induced by temporary government spending to be eliminated not only through a rise in the real interest rate but also through a rise in real wages, labour supply, and output. Thus, the $Y C$ and the $I S$ curve immediately move towards each other and intersect in the initial equilibrium point $D$ along the $R C\left(G^{\prime}\right)$ curve. Importantly, this point can never be to the right of point $X$. Therefore, the standard New Keynesian model cannot generate a realistic response of private consumption to a government spending shock. The next section investigates New Keynesian extensions that imply further shifts of the $I S$ or $Y C$ curves.

\subsection{Demand Side Modifications and Government Spending}

Section 2.3.2 in the previous chapter reviews approaches taken in the literature to obtain a New Keynesian model that shows crowding-in. This section analyses these approaches with the help of the framework developed above.

Productive government spending introduced by Linnemann and Schabert (2006) shifts the production line in the upper left quadrant of Figure 3.1 outwards and makes it flatter. Furthermore, the increase in real wages shifts the EP line right. Thus, output increases due to a direct productivity effect as well as a labour supply effect caused by the higher worker productivity. This implies that the $Y C$ curve in Figure 3.2 shifts

\footnotetext{
${ }^{7}$ This is called the Taylor principle and is needed to ensure determinacy (Woodford, 2003)
} 
up and becomes steeper in reaction to a government spending shock. If the productive effect of government spending is strong enough to counter the shift of the resource constraint, consumption could be crowded in. However, Tervala (2009) show that this is not the case for realistic parameters.

In Linnemann and Schabert (2003a), government spending enters the household utility function in a way such that marginal utility of private consumption is raised when government spending increases. The first consequence is that current consumption demand increases with government spending (the $I S$ curve depends positively on $G$ ). Given the temporary nature of the government spending shock, current consumption has to be higher than future consumption to equalise marginal utility as required by intertemporal consumption smoothing. The second consequence is that the marginal rate of substitution between consumption and leisure increases at all points, making the indifference curves in quadrant I steeper. This shifts the $E P$ curve for a given real wage right. Therefore, the $Y C$ curve shifts upward with an increase in $G$, as well as with the increase in $w$ caused by excess demand. The mathematical derivation is shown in Appendix 3.A.2.

This approach thus works through a combination of an upward shift of the $Y C$ curve as well as a rightward shift of the $I S$ curve. When the complementary effect of utility from government consumption on utility from private consumption is large enough to counter the negative wealth effect, the $Y C$ curve shifts up far enough to allow an increase in private consumption and output upon a government spending shock. Such a strong complementarity effect required for crowding in is contradicted by empirical studies, which find no significant complementarity effect (See Ni, 1995; Amano and Wirjanto, 1998; Kwan, 2006, for empirical evidence). Therefore, this approach is unsuitable as a practical explanation for crowding in.

Monacelli and Perotti (2008) discuss the importance of the degree of complementarity or substitutability between labour supply and consumption. Under the commonly used separable utility function a change in labour supply has no effect on the marginal utility of consumption. If an increase in labour supply induced by the negative wealth effect of government spending were to increase the marginal utility of consumption, then the $I S$ curve would be shifted right by such a shock. This creates 
additional demand, which could therefore cause consumption crowdingin. This approach is similar to the preceding one, even though it misses the additional effect on the $Y C$ curve. However, Monacelli and Perotti (2008) find using usual parameters that this effect is not strong enough and crowding-out prevails.

Galí et al. (2007) use the idea also proposed by Mankiw (2000) of having savers and spenders in an economy, also called "optimising" and "rule of thumb" consumers. The latter do not participate in financial markets but rather only consume their current income, which depends on real wage. An economy consisting only of rule of thumb consumers has no financial markets, and therefore the equilibrium occurs at the intersection of $R C$ and $Y C\left(w^{*}\right)$, without an $I S$ curve. However, consider an economy with a certain share $\lambda$ of rule of thumb consumers. Excess demand induced by optimising consumers in response to a temporary government spending shock induces more excess demand by rule of thumb consumers as they see their real wages rise. Consequently, the IS curve in Figure 3.4 is amended with the real wage as a shift factor whose strength depends on $\lambda$. Appendix 3.A.2 also includes this derivation.

Higher real wages increase demand with larger $\lambda$. They also increase inflation, and thus the real interest rate, which in turn reduces demandalbeit decreasingly with larger $\lambda$. This implies that there is a certain level of $\lambda$ for which higher real wages increase consumption demand and shift $I S$ right instead of left. When that is the case, excess demand caused by temporary government spending shifts both $I S$ and $Y C$ right to the point at which they both intersect $R C^{\prime}$ in the same point above $X$, and consumption crowding in occurs.

The weakness of the model lies in the fact that higher real wages increase consumption demand of rule of thumb consumers one for one, while they do not increase output supply on a one for one basis. When the moderating impact of the real interest rate on consumption demand through optimising consumers falls as $\lambda$ increases, $I S$ shifts further than $Y C$ when the real wage increases. Thus excess demand leads to more excess demand; the model is explosive and does not reach an equilibrium. Galí et al. (2007) call this the region of indeterminacy.

Figure 3.5 illustrates how sensitive the model is to parameter choice in 


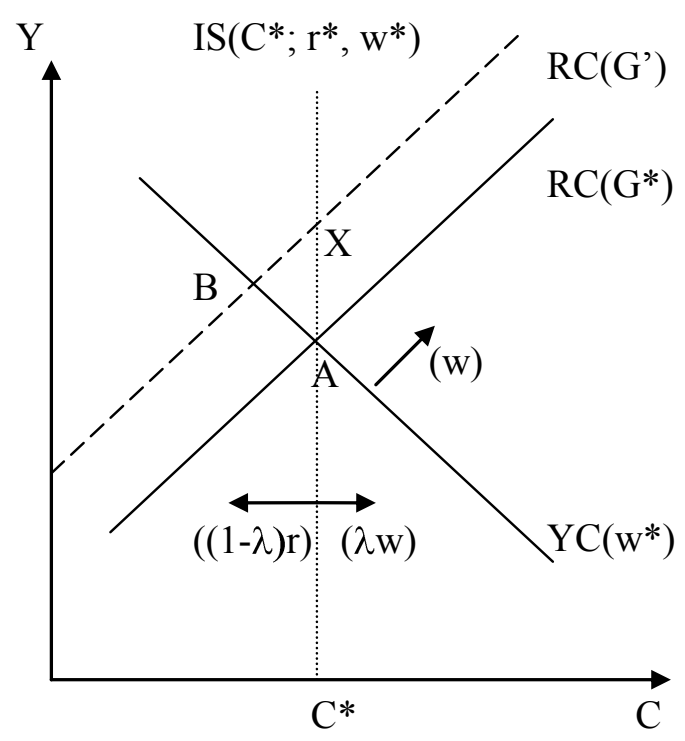

Figure 3.4: The New Keynesian model with a share $\lambda$ of rule of thumb consumers

the region in which crowding in occurs. Considering a standard choice in the literature of price stickiness of $\phi=0.75$, a share of rule of thumb consumers of $\lambda=0.85$ is required to obtain crowding in at point $A$. Looking at point $B$, one can see that small changes in the degree of price stickiness or the share of rule of thumb consumers change the response of the economy to crowding out or indeterminacy. As discussed in the literature review, Colciago (2005) and Bartolomeo and Manzo (2007) find that sticky wages or a balanced budget policy based on tax distortions restore standard determinacy results, but also deprive the model of its ability to introduce consumption crowdingin.

Another problematic aspect lies with the required high share of ruleof-thumb consumers that Galí et al. (2007) have to use despite their use of a high degree of price stickiness as well as their high elasticity of labour supply. Coenen and Straub (2005) find that the rule of thumb consumer approach does raise private consumption compared to the basic New Keynesian model, but only by small amounts. They conclude that consumption crowding in is unlikely, since it requires a very small range 


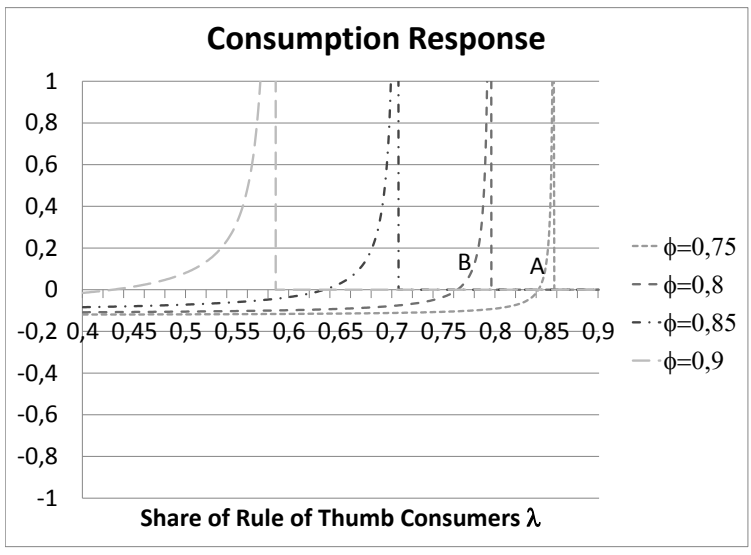

Figure 3.5: Response of private consumption to a government spending shock in the period of impact depending on $\lambda$

of share of rule of thumb consumers to be viable. Finally, Furlanetto and Seneca (2009) propose a combination of habit persistence, non-constant elasticity of demand as well as firm-specific capital to increase real rigidities so that the degree of price stickiness as well as the share of rule-of-thumb consumers needed for crowding-in is lower. This results in a consumption response similar to the case $\phi=0.9$ in Figure 3.5, with the same problem of determinacy present.

\subsection{Short Run Response to Long Run Effects}

The previous section reviewed a number of approaches present in the literature that aim to affect the $Y C$ or the $I S$ curve. However, none of these approaches can provide a satisfactory answer to the crowding-in puzzle. This section outlines a new approach based on shifting the $I S$ curve using long run effects of temporary government spending.

The basic idea relies on temporary policy changes having permanent effects. Section 2.4 discusses literature that shows and also uses this idea in economic models. This section's proposal is to utilise the increased 
economic growth in response to government spending and its effect on the $I S$ curve. Higher future consumption will directly shift the $I S$ curve right and thereby increase current consumption demand.

Another aspect used in endogenous growth literature, and also by Barro (1990), is productive government spending. Even though productive spending on its own is not sufficient to induce crowding-in (see Section 3.3), its effect, when combined with the long run effect, could potentially lead to an increase in consumption.

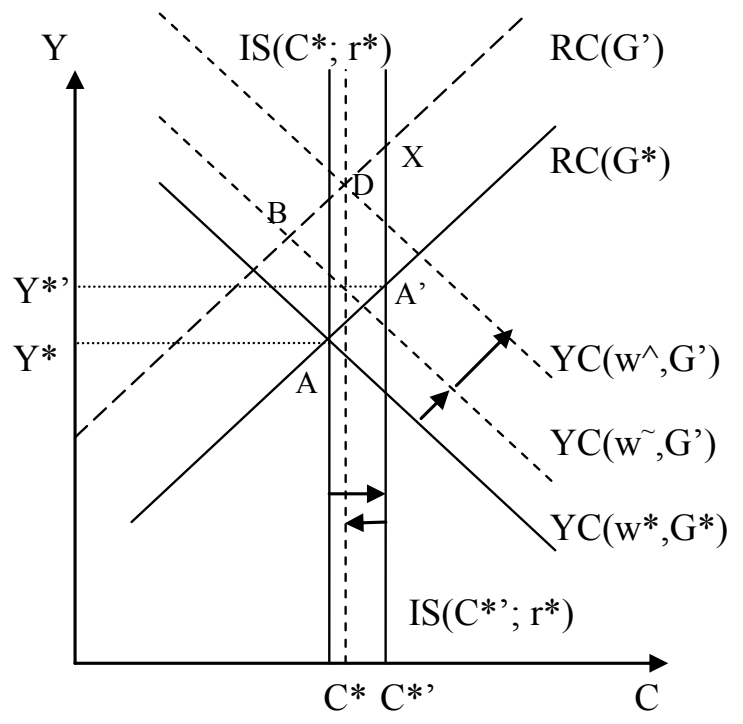

Figure 3.6: Model with permanent effect of productive government spending

Without becoming too specific, we sketch in Figure 3.6 how our model could incorporate these ideas. Increased government spending shifts the $R C$ curve up to $R C\left(G^{\prime}\right)$. Due to the productivity effect of government spending as well as the change in real wage, the $Y C$ curve experiences an upward shift to $Y C\left(G^{\prime}, w\right)$. Thus $Y C$ shifts to point $B$ in Figure 3.6. The permanent productivity effects also cause the IS curve to shift to the right to $I S\left(C^{*^{\prime}}, r^{*}\right)$, consistent with the higher long run consumption of $C^{*^{\prime}}$. In response to the resulting excess demand of size $\overline{X B}$, real wages rise to $\hat{w}$. Inflation and the real interest rate also rise and cause a left shift of $I S$ to 
the dashed $I S$ curve. Thus the short run equilibrium is at $D$.

The aim of the remaining chapters is to closely investigate the effect of government spending in an endogenous growth model to see whether the prediction made here is actually feasible.

\subsection{Conclusion}

Empirical research finds the Keynesian effect that private consumption rises in the face of a temporary government spending shock. Paradoxically, a class of models labelled New Keynesian produces the opposite effect. Although price stickiness allows output to deviate from its natural level, consumption demand simply does not rise in the face of a government spending shock, hence disallowing any crowding in. In fact, consumption is crowded out.

This chapter provides a simple analytical framework to analyse the effect of government spending on consumption. Using this framework, it analyses a number of approaches proposed in recent literature that aim to achieve crowding-in in a New Keynesian model. The conclusion has to be that none of these approaches is satisfactory.

Rather than discarding the neo-classical consensus, this chapter uses the framework to propose a new approach using the long run effect government spending might have on private consumption. The proposition is to use an endogenous growth model to see whether crowding-in is achievable. This analysis is the task of the following chapters.

\section{A Mathematical Appendix}

The appendix shows the basic mathematical derivation of the equations used in the figures in the text. We adhere to the standard assumption of rational expectations, but disregard stochastic shocks, thus allowing perfect foresight in our model. Furthermore, we follow the literature by using loglinearised equations, where variables are stated in their percent deviation from their steady state value, $\hat{x}_{t}=\frac{X_{t}-X}{X}$. The basic derivation of the consumption Euler equation and the labour supply equation can be found in any advanced textbook, for example in Galí (2008). We assume in line 
with the literature that the model possesses a steady state and investigate the dynamics close to the steady state when the model is subjected to a temporary autoregressive government spending shock. Since the model only possesses forward looking variables, the impulse response function of any variable is also an autoregressive process with its highest value in the period of impact, which is the one we analyse graphically in the text.

\section{A.1 The standard New Keynesian Model}

Households maximise their intertemporal utility subject to a budget constraint. The utility function is

$$
\sum_{t=1}^{\infty} \beta^{t} u_{t}
$$

The instantaneous utility function is

$$
u_{t}=\log \left(\tilde{C}_{t}\right)-\frac{1}{1+\sigma} L_{t}^{1+\sigma} \quad \sigma>0
$$

with $L_{t}$ being the period's labour supply and $\tilde{C}_{t}$ being effective consumption. The budget constraint is

$$
\underbrace{w_{t} L_{t}+\Pi_{t}}_{Y_{t}}=C_{t}+\underbrace{\tau_{t}+\frac{B_{t+1}}{P_{t+1}}-\left(1+R_{t}\right) \frac{B_{t}}{P_{t}}}_{G_{t}}
$$

$\Pi_{t}$ is the profit earned by firms, which are ultimately owned by households. This shows that a change in the real wage per se does not change households' available budgets if it cuts firms profits. $B_{t+1}$ is the nominal value of bonds held from this to the next period, savings that cannot be consumed, while $\left(1+R_{t}\right) B_{t}$ is the nominal value of bonds saved in the last period plus interest earned on them. The government can either finance its spending through taxes or by selling bonds. Because of the closed economy assumption, the only parties to buy these bonds are households. Thus the change in the real value of household bonds is the amount of government spending that is not financed by taxes. Assuming the public holds government bonds, the interest payments are a transfer from the 
government to the public and have to be financed by taxes that cannot be used for government consumption. Therefore, the household budget constraint also represents the aggregate resource constraint of the economy, which we label the $R C$ curve.

$$
R C: \quad \hat{y}_{t}=\frac{C}{Y} \hat{c}_{t}+\frac{G}{Y} \hat{g}_{t}
$$

When $\tilde{C}_{t}=C_{t}$ and $Y_{t}=L_{t}$, the $Y C$ shows the trade-off between consumption and leisure.

$$
Y C: \quad \hat{y}_{t}=\hat{l}_{t}=\frac{1}{\sigma} \hat{w}_{t}-\frac{1}{\sigma} \hat{c}_{t}
$$

The New Keynesian $I S$ curve can be derived from the intertemporal Euler equation.

$$
I S: \quad \hat{c}_{t}=\hat{c}_{t+1}-\left(\hat{R}_{t+1}-\hat{\pi}_{t+1}\right)
$$

$\pi_{t+1}=\frac{P_{t+1}}{P_{t}}$ is the gross price inflation. Substituting forward, and defining the deviation of the real interest rate from its steady state level as $\hat{r}_{t+1}=$ $\hat{R}_{t+1}-\hat{\pi}_{t+1}$, we obtain

$$
I S: \quad \hat{c}_{t}=\hat{c}_{L R}-\sum_{i=t+1}^{\infty} \hat{r}_{i}
$$

In this chapter we assume that the New Keynesian Phillips curve causes higher inflation when marginal costs, or real wages, increase. The derivation of the NK Phillips curve can be seen for example in Galí and Gertler (1999).

\section{A.2 Demand Side Modifications}

\section{Useful Government Spending}

By redefining effective consumption to include government spending as was done by Linnemann and Schabert (2003a), consumption has an impact on the utility function.

$$
\tilde{C}_{t}=\left(\alpha C_{t}^{\zeta}+(1-\alpha) G_{t}^{\zeta}\right)^{\frac{1}{\zeta}} \quad \zeta \in(-\infty, 1), \quad \alpha \in(0,1)
$$


The parameter $\zeta$ determines the impact government spending has on the marginal utility of private consumption. When $\zeta<0$, this impact is positive, and private and public consumption are complements. The IScurve solved forward for this model is

$$
I S: \quad \hat{c}_{t}=\hat{c}_{L R}+\frac{\psi_{2}}{\psi_{1}}\left(\hat{g}_{t}-\hat{g}_{L R}\right)-\frac{1}{\psi_{1}} \sum_{i=t+1}^{\infty} \hat{r}_{i}
$$

where $\psi_{1}=(1-\zeta)\left(1-\eta_{c}\right)+\eta_{c}>0$ and $\psi_{2}=-\zeta \eta_{g}$. The steady state elasticity of $\tilde{C}$ with respect to $C_{t}$ is defined as $\eta_{c}=\alpha(\tilde{C} / C)^{-\zeta}>0$. For $\eta_{g}=(1-\alpha)(\tilde{C} / G)^{-\zeta}>0$ the same holds with respect to $G_{t}$. It must further hold that $\eta_{c}+\eta_{g}=1$. The $Y C$ curve changes as well to

$$
Y C: \quad \hat{y}_{t}=\frac{1}{\sigma} \hat{w}_{t}-\frac{\psi_{1}}{\sigma} \hat{c}_{t}+\frac{\psi_{2}}{\sigma} \hat{g}_{t}
$$

When government spending plays no role in private utility $(\alpha=1)$, or when it does not affect the marginal utility $(\zeta=0)$, then $\psi_{1}=1$ and $\psi_{2}=0$. The $I S$ and $Y C$ curves then collapse to their standard counterparts, equations 3.5 and 3.7 .

\section{Rule of Thumb Consumers}

To introduce rule of thumb consumers as done by Galí et al. (2007), we again assume $\tilde{C}_{t}=C_{t}$. Rule of thumb consumers have the utility function equation 3.2 but face the budget constraint:

$$
C_{t}=w_{t} L_{t}-\tau_{t}
$$

Consumption is then determined by the log-linearised budget constraint

$$
\hat{c}_{t}^{r}=\frac{w L}{C}\left(\hat{w}_{t}+\hat{l}_{t}^{r}\right)-\frac{\tau}{C} \hat{\tau}_{t}^{r}
$$

where variables with the superscript $r$ represent rule of thumb consumers. We assume that rule of thumb households make up a share $\lambda$ of all households in the economy. The log-linearised aggregate consumption and 
employment are

$$
\begin{aligned}
& \hat{c}_{t}=\lambda \hat{c}_{t}^{r}+(1-\lambda) \hat{c}_{t}^{o} \\
& \hat{l}_{t}=\lambda \hat{l}_{t}^{r}+(1-\lambda) \hat{l}_{t}^{o}
\end{aligned}
$$

Using equations 3.12 and 3.13 as well as the optimal labour supply of the households, we see that the aggregate $Y C$ curve is unchanged. The $I S$ curve solved forward is

$$
\begin{aligned}
I S: \quad \hat{c}_{t}= & \hat{c}_{L R}+\frac{\lambda(1+\sigma)}{\frac{C}{Y} \sigma+1}\left(\hat{w}_{t}-\hat{w}_{L R}\right)-\frac{\lambda \frac{\tau}{Y} \sigma}{\frac{C}{Y} \sigma+1}\left(\hat{\tau}_{t}^{r}-\hat{\tau}_{L R}^{r}\right) \\
& -(1-\lambda) \sum_{i=t+1}^{\infty} \hat{r}_{i}
\end{aligned}
$$

The model can be solved using the methods of undetermined coefficients, where $\hat{\pi}_{t}=\varphi_{1} \hat{g}_{t}$ and $\hat{c}_{t}=\varphi_{2} \hat{g}_{t}$. The calculated results in Figure 3.5 use this model solution, where

$$
\varphi_{2}=\frac{\frac{G}{Y} \sigma}{\frac{C}{Y}+\frac{1}{\sigma}} \frac{\lambda(1-\rho)(1-\beta \rho)-(1-\lambda)\left(\rho_{\pi}-1\right) \rho \chi\left(\frac{C}{Y}+\frac{1}{\sigma}\right)}{(1-\lambda(1+\sigma))(1-\rho)(1-\beta \rho)+\sigma(1-\lambda)\left(\rho_{\pi}-1\right) \rho \chi\left(\frac{C}{Y}+\frac{1}{\sigma}\right)} .
$$

Furthermore, $\frac{C}{Y}=0.8, \sigma=1$, the Taylor rule parameter is $\rho_{\pi}=1.5$, $\beta=0.99$, the autoregressive parameter of the government spending shock is $\rho=0.9$ and the Phillips curve parameter on marginal costs deviations is $\chi=\frac{(1-\phi)(1-\beta \phi)}{\phi}$, with $\phi=0.75$. 



\section{Government Spending in a Sticky Price} Endogenous Growth Model

\subsection{Introduction}

The previous chapter concluded that long run effects of government spending are needed to increase short run consumption demand to allow crowding-in. The task of this chapter is to analyse the long run consequences of a temporary government spending shock. This is done using a standard endogenous growth model.

In growth models, household savings is the primary determinant of investment and growth. This is no different in the model used in this chapter. Therefore, this chapter analyses the response of output and saving supply to a temporary government spending shock. Chapter 5 additionally takes investment demand into account. This is not included in this chapter since it does not allow an analytically tractable solution.

The chapter finds 4 primary channels in how temporary government spending affects households' saving. The first is the direct negative wealth effect, which prompts households to dissave. Opposing this effect is the increase labour supply, which combined with productive government spending directly increases output to allow for more resources for growth. Furthermore, these two effects also increase the real interest rate, thereby increasing saving. 
The fourth is uncovered when introducing sticky prices. Deviations of output from flexible price level as well as a higher real interest rate additionally increase resources to be used for growth. The next chapter will show how these supply effects work in combination with endogenous investment demand depending negatively on the real interest rate.

Sticky price models require a monetary policy rule in order to have the nominal interest rate determined. As already pointed out, government spending has an effect on the real interest rate under flexible prices. Therefore, a monetary policy rule wanting to mimic the flexible price outcome, thus achieve inflation stability, has to take these changes in the real interest rate into account.

This observation leads to an important general result concerning the use of the Taylor rule. Section 4.4 will show that a Taylor rule used in a New Keynesian model actually requires an output gap parameter in order to adjust the nominal interest rate to changes in the natural real rate of interest. Without it, inflation stability is not guaranteed. The section furthermore proposes that this aspect actually explains why even central banks that supposedly only care for inflation seem to put a significant weight on the output gap.

The chapter begins by presenting a flexible price endogenous growth model and analyses the effects of temporary increases in government spending. Then it proceeds with a theoretical discussion of the Taylor rule, before it uses it in a sticky price endogenous growth model.

\subsection{The Endogenous Growth Model}

This section presents a flexible price endogenous growth model with productive government spending. The next section analyses the model's response to a temporary government spending shock with the help of a graphical framework.

\subsubsection{The Specification of Endogenous Growth}

The endogenous growth model employed follows Romer (1986). The idea is that capital accumulation generates aggregate knowledge available for 
all firms through learning-by-doing, so that even though capital faces diminishing returns on the firm level, it exhibits constant returns on the aggregate level. Therefore, there is no limit to capital accumulation. This notion is combined with an insight of Barro (1990), who also uses a production function where firms face diminishing returns to capital, but where government spending provides productive services so that on aggregate returns to capital are constant again.

The use of productive government spending as the additional accumulated resource to generate endogenous growth is common practice in the literature. Furthermore, there is ample evidence that government activity is indeed productive - see Section 2.4.2. In accordance with the discussion in Section 2.4.1, we employ the flow approach of government spending in order to allow clear analytical results.

\subsubsection{Production}

The production function for firm $i$ in period $t$ is a Cobb-Douglas function

$$
Y_{t}^{i}=A\left(K_{t}^{i}\right)^{\alpha}\left(L_{t}^{i}\right)^{1-\alpha} T F P_{t}\left(K_{t}, G_{t}\right) .
$$

The variables $Y_{t}^{i}, K_{t}^{i}$ and $L_{t}^{i}$ represent output, capital and employment, respectively. Total factor productivity $T F P_{t}$ is identical for all firms and represents on the one hand technological spillovers (following Romer, 1986), for simplicity represented by the level of aggregate capital $K_{t}$, and on the other hand the productive effect government spending $G_{t}$ (following Barro, 1990). To simplify notation, we specify:

$$
T F P_{t}=K_{t}^{\epsilon} G_{t}^{\gamma}
$$

Government spending is a constant share $\theta$ of output, which implies the spending rule

$$
G_{t}=\theta_{t} Y_{t}
$$


Assuming identical firms, the aggregate production function is

$$
Y_{t}=\sum_{i=1}^{n} Y_{t}^{i}=\left(A \theta_{t}^{\gamma}\right)^{\frac{1}{1-\gamma}} K_{t}^{\frac{\alpha+\epsilon}{1-\gamma}} L_{t}^{\frac{1-\alpha}{1-\gamma}}
$$

Endogenous growth requires that the marginal product of the accumulated resource, capital, does not diminish as it accumulates. We therefore assume $\epsilon=1-\alpha-\gamma$ to hold.

Romp and de Haan (2007) find in their survey of the literature that the elasticity of output with respect to government spending $(\gamma)$ lies between 0 and 0.4 , where more recent research results indicate that it should be at the lower end of this margin. Bom and Lighthart (2008) estimate in their Meta analysis of different studies a $\gamma$ of 0.086 . This implies that $\gamma$ should not exceed 0.1 if one wants the model to imply a realistic productivity effect of government spending.

\subsubsection{The Firms}

Each firm i minimises costs $r_{t}^{k} K_{t}^{i}+w_{t} L_{t}^{i}$ subject to output produced. The variables $r_{t}^{k}$ and $w_{t}$ represent the return on capital in use and the wage rate, respectively, in period $t$. The firm takes $r_{t}^{k}$ and $w_{t}$ as given. Solving the Lagrangian and interpreting the Lagrange multiplier as marginal cost $m c_{t}$, we obtain the first order conditions:

$$
\begin{aligned}
r_{t}^{k} & =m c_{t} \alpha \frac{Y_{t}^{i}}{K_{t}^{i}}, \\
w_{t} & =m c_{t}(1-\alpha) \frac{Y_{t}^{i}}{L_{t}^{i}} .
\end{aligned}
$$

Aggregating across all identical firms and using equation (4.4), equations (4.5a) and (4.5b) become

$$
\begin{aligned}
& r_{t}^{k}=m c_{t} \alpha\left(A \theta^{\gamma}\right)^{\frac{1}{1-\gamma}} L_{t}^{\frac{1-\alpha}{1-\gamma}}, \\
& w_{t}=m c_{t}(1-\alpha)\left(A \theta^{\gamma}\right)^{\frac{1}{1-\gamma}} K_{t} L_{t}^{-\frac{\alpha-\gamma}{1-\gamma}} .
\end{aligned}
$$

Following a standard set-up of monopolistic competition as described 
in Woodford (2003), firms set their prices as a desired mark-up $\mu>1$ over their real marginal cost. In a flexible price steady state this mark-up is constant and depends on the elasticity of demand that firms face; a higher elasticity of demand corresponds to a lower mark-up. ${ }^{1}$ The result is that under symmetric firms

$$
m c_{t}=\frac{1}{\mu}
$$

holds.

\subsubsection{Households}

The representative household maximises its intertemporal utility over consumption $C$ and leisure $\Lambda$ subject to a budget constraint and a capital accumulation equation. This can be specified as follows:

$$
\max _{C, \Lambda} \sum_{t=0}^{\infty} \beta^{t} u_{t}(C, \Lambda),
$$

where $\beta<1$ is the time discount factor. Since the household's available time is bounded, we need the representative household to supply a constant number of hours when real wage is growing. Therefore, income and substitution effects must be exactly offsetting. We restrict our attention to the commonly used CES function with log-utility for consumption. We furthermore use the common specification of introducing labour supply $L$ directly in the utility function, where $L=1-\Lambda$ when we normalise total available time to unity. We thus obtain

$$
u_{t}=\log \left(C_{t}\right)-\frac{L_{t}^{1+\sigma}}{1+\sigma},
$$

where $\sigma>0$ is the inverse of the intertemporal elasticity of labour supply.

Utility is maximised subject to the budget constraint and the capital

\footnotetext{
${ }^{1}$ For simplicity we do not present here the full model including the distinction between an intermediate goods and a final goods sector - for the full model see Woodford (2003).
} 
accumulation identity

$$
\begin{aligned}
w_{t} L_{t}+R_{t-1} B_{t} / P_{t}+r_{t}^{k} K_{t}+\kappa_{t} & \geq C_{t}+\tau_{t}+B_{t+1} / P_{t}+I_{t}, \\
K_{t+1} & =(1-\delta) K_{t}+I_{t},
\end{aligned}
$$

where $\kappa_{t}$ are profits from firm ownership of households, $\tau_{t}$ lump sum taxes, $R_{t-1}$ is the gross nominal interest rate for bonds held from period $t-1$ to period ${ }^{2} t$ and $\delta$ is the capital depreciation rate. $C_{t}$ is consumption, $I_{t}$ is investment, $P_{t}$ is the price level and $B_{t}$ is the stock of bonds in period $t$. Government spending uses resources that are unavailable to households, either through direct taxation or indirectly by households buying government bonds. We only deal with lump sum taxation, thereby implying Ricardian equivalence. ${ }^{3}$ Thus, a fiscal financing rule is not needed.

Household optimisation leads to the following first order conditions:

$$
\begin{aligned}
C_{t} & =C_{t+1} \frac{1}{\beta} \frac{\pi_{t+1}}{R_{t}}, \\
r_{t+1}^{k} & =\frac{R_{t}}{\pi_{t+1}}+\delta-1, \\
w_{t} & =L_{t}^{\sigma} C_{t} .
\end{aligned}
$$

Equation (4.11a) is the standard Euler equation, showing the intertemporal consumption path depending on the real interest rate. $\frac{R}{\pi}$ represents the real interest rate on bonds, where $\pi_{t+1}=\frac{P_{t+1}}{P_{t}}$ is the gross inflation rate. Arbitrage ensures that the real interest rate on bonds equals the real return on capital. Condition (4.11c) shows the equality between the marginal utility of consumption and leisure, where the relative price of leisure in terms of consumption is the real wage. Inelastic labour supply then results when $\sigma \rightarrow \infty$.

\footnotetext{
${ }^{2}$ This timing is also used in Smets and Wouters (2003) and Galí et al. (2007).

${ }^{3}$ see appendix Chapter 3
} 


\subsubsection{The Complete Model}

Demand for labour and labour supply, equations (4.6b) and (4.11c) respectively, determine the labour market equilibrium. This yields: ${ }^{4}$

$$
L_{t}=\left(\frac{m c_{t}(1-\alpha)\left(A \theta^{\gamma}\right)^{\frac{1}{1-\gamma}}}{\frac{C_{t}}{K_{t}}}\right)^{\frac{1-\gamma}{\sigma+\alpha-\gamma(1+\sigma)}} .
$$

Using the resource constraint $Y=C+I+G$ as well as the definition of the gross growth rate of capital $g_{t}=\frac{K_{t}}{K_{t-1}}$, the full flexible price model then can be represented by the following system of 6 equations:

$$
\begin{aligned}
\frac{Y_{t}}{K_{t}} & =m c_{t}^{c_{1}}(1-\alpha)^{c_{1}}\left(A \theta_{t}^{\gamma}\right)^{\frac{1}{1-\gamma}\left(1+c_{1}\right)}\left(\frac{C_{t}}{K_{t}}\right)^{-c_{1}} \\
\frac{C_{t}}{K_{t}} & =\frac{C_{t+1}}{K_{t+1}} g_{t+1} \frac{1}{\beta} \frac{1}{1-\delta+r_{t+1}^{k}} \\
g_{t+1} & =\frac{I_{t}}{K_{t}}+(1-\delta) \\
\frac{I_{t}}{K_{t}} & =\left(1-\theta_{t}\right) \frac{Y_{t}}{K_{t}}-\frac{C_{t}}{K_{t}} \\
r_{t}^{k} & =m c_{t}^{1+c_{1}} \alpha(1-\alpha)^{c_{1}}\left(A \theta^{\gamma}\right)^{\frac{1}{1-\gamma}}\left(1+c_{1}\right)\left(\frac{C}{K}\right)^{-c_{1}} \\
m c_{t} & =\frac{1}{\mu}
\end{aligned}
$$

with

$$
c_{1}=\frac{1-\alpha}{\sigma+\alpha-\gamma(1+\sigma)}>0 .
$$

We analyse the dynamics of this model in the next section.

\footnotetext{
${ }^{4}$ We restrict $\gamma$ to $\gamma<\frac{\alpha+\sigma}{1+\sigma}$. Without this restriction one might find $\frac{\partial L}{\partial x} \rightarrow \infty$, where $x$ could be $m c, A$ or $\theta$. A shock increasing labour supply will increase output, which in turn increases government spending (see equation 4.3). When government spending is too productive, the following increase in labour productivity is so strong that the large rise in real wages leads to an exploding behaviour of labour supply.
} 


\subsection{Analysis of the Flexible Price Endogenous Growth Model}

We first analyse how a permanent government spending shock affects the growth rate of the economy to illustrate the mechanisms at work in the model. The impact of a temporary shock in government spending is discussed thereafter.

\subsubsection{Steady State}

The steady state is the flexible price equilibrium when $Y, K, C, I$ and $w$ all grow at a constant rate of growth, $g$. By imposing $\Delta \frac{C}{K}=0$ on equation (4.13b) and using equation (4.6a) we obtain an expression relating steady state growth to the steady state labour supply.

$$
g=\beta\left(1+\frac{\alpha}{\mu}\left(A \theta^{\gamma}\right)^{\frac{1}{1-\gamma}} L^{\frac{1-\alpha}{1-\gamma}}-\delta\right) .
$$

Steady state labour supply, as long as it is elastic (i.e. $\sigma$ is finite), can be identified implicitly as in Turnovsky (2000). Labour supply determines output as well as the return to capital, which in turn determines the steady state growth and thus investment, leaving resources available for consumption after subtracting government spending. This consumption has to be such that it induces households to supply exactly that amount of labour that delivers that consumption. The resulting consumption and leisure have to match the resource constraint. An increase in government spending share $\theta$ then increases labour supply because of the negative effect on consumption, and thus its influence on the substitution between consumption and leisure.

Lemma 1. A permanent increase of the share or government spending in output $(\theta)$ leads to a permanent increase in growth if either (a) government spending is productive $(\gamma>0)$ or $(b)$ labour supply is elastic (i.e. $\sigma$ is finite), or both (a) and (b) hold.

Proof. (a) follows immediately from equation (4.14) (and from the positive impact of $\theta$ on labour supply, as long as it is elastic). (b) follows from 
the identification of the steady state labour supply. If we make the approximation $(1-\beta)(1-\delta) \approx 0$, we can explicitly solve for steady state labour supply.

$$
L=\left(\frac{\frac{1-\alpha}{\alpha \beta}}{a_{2}-1}\right)^{\frac{1}{1+\sigma}}
$$

with

$$
a_{2}=\frac{(1-\theta) \mu}{\alpha \beta} .
$$

Equation (4.15) immediately proves point (b). ${ }^{5}$

An increase in government spending share $\theta$ increases the growth rate in two ways. On the one hand, it increases labour supply, as we argued above. This in turn raises the marginal product of capital and thus the real interest rate - this is the effect analysed in Turnovsky (2000). On the other hand, more productive government spending directly raises the return to capital. The higher interest rate induces households to save more, thus creating more steady state growth - this is the effect analysed in Barro (1990).

\subsubsection{Dynamics around the Steady State}

We first show the precise dynamic equations for the flexible price model. We reduce the flexible price model (equations $4.13 \mathrm{a}$ to $4.13 \mathrm{f}$ ) to two equations that can be represented in the $(C / K, g)$ space, see Figure 4.1a.

$$
\begin{aligned}
g_{t+1} & =\left(1-\theta_{t}\right)\left(\frac{1-\alpha}{\mu}\right)^{c_{1}}\left(A \theta_{t}^{\gamma}\right)^{\frac{1}{1-\gamma}\left(1+c_{1}\right)}\left(\frac{C_{t}}{K_{t}}\right)^{-c_{1}}-\frac{C_{t}}{K_{t}}+(1-\delta) \\
\frac{C_{t}}{K_{t}} & =\frac{C_{t+1}}{K_{t+1}} g_{t+1} \frac{1}{\beta} \frac{1}{1-\delta+\frac{\alpha}{\mu}\left(\frac{1-\alpha}{\mu}\right)^{c_{1}}\left(A \theta_{t+1}^{\gamma}\right)^{\frac{1}{1-\gamma}\left(1+c_{1}\right)}\left(\frac{C_{t+1}}{K_{t+1}}\right)^{-c_{1}}}
\end{aligned}
$$

\footnotetext{
${ }^{5}$ We obviously need $a_{2}>1$, hence $\theta<1-\frac{\alpha \beta}{\mu}$.
} 
Equation (4.16a) reflects the intratemporal choice of consumption and labour supply as well as the resource constraint, which we represent as the $G G$ curve. A higher current level of consumption lowers labour supply via the consumption leisure trade-off. This lowers output, and thus resources available for investment and growth. Furthermore, higher consumption directly takes resources from growth. This curve is downward sloping in the $(C / K, g)$-plane and it will shift to the left when the government uses more resources. ${ }^{6}$

Figure 4.1

(a) The basic phase diagram

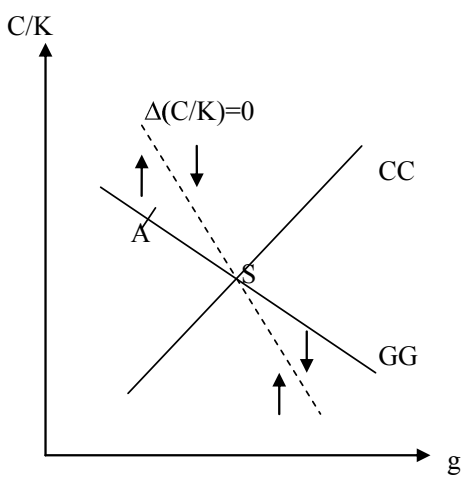

(b) A government spending shock $(\gamma=0)$

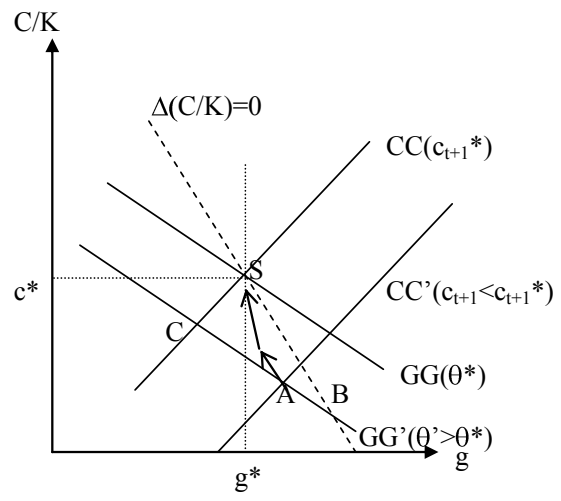

Equation (4.16b) represents the intertemporal consumption smoothing objective of households, which we represent as the $C C$ curve. Since higher growth raises the absolute level of future consumption given $C / K$, the curve is upward sloping in in the $(C / K, g)$-plane. Furthermore, a change in future $C / K$, shifts the curve upward. Finally, as in a standard model, the real interest rate plays a role in intertemporal consumption substitution. The real interest rate depends on next period's return to capital, which in turn depends positively on labour supply and therefore negatively on consumption. Therefore, the $C C$ curve in the flexible price model can be

\footnotetext{
${ }^{6}$ It is actually possible for the $G G$ curve to shift to the right upon a government spending increase when output increases by more than government spending. This is the case when $\frac{1-\theta}{\theta} \frac{\gamma}{1-\gamma}\left(1+c_{1}\right)>1$. However, Chapter 3 made clear that this is unrealistic.
} 
represented as depending only positively on future consumption. ${ }^{7}$

An increase in productive government expenditures raises the return to capital, thereby increasing the real interest rate and shifting the $C C$ curve down, ceteris paribus. When government spending is not productive, it does not directly affect the $C C$ curve.

The steady state relationship for a stable consumption path is defined by setting $\Delta \frac{C}{K}=0$ in equation $(4.16 \mathrm{~b})$, which yields:

$$
\frac{C}{K}=\left(\frac{\frac{\alpha}{\mu}\left(\frac{1-\alpha}{\mu}\right)^{c_{1}}\left(A \theta^{\gamma}\right)^{\frac{1}{1-\gamma}\left(1+c_{1}\right)}}{\frac{g}{\beta}-1+\delta}\right)^{\frac{1}{c_{1}}} .
$$

The $\Delta(C / K)=0$ curve shows possible combinations of consumption level and growth consistent with a constant level of consumption per unit of capital on the steady state growth path. The slope of the $\Delta(C / K)=0$ curve shows the reaction of the real interest rate to a change in consumption via the labour supply response. Note that a higher rate of growth requires a higher real interest rate for households to save sufficiently. In case of elastic labour supply the return to capital increases upon a fall in consumption, inducing higher growth. As a consequence the $\Delta(C / K)=0$ curve is downward sloping, but it is steeper that the $G G$ curve. ${ }^{8}$ When labour supply is inelastic, the $\Delta(C / K)=0$ curve is vertical.

Similar to the $C C$ curve, the $\Delta(C / K)=0$ curve will shift to the right when government expenditures increase, as long as government expenditures are productive. The more productive government expenditures are, the stronger the curve will shift to the right.

In steady state the consumption growth trade-off given by the $\Delta(C / K)=$ 0 curve has to be consistent with the resource constraint given by the the $G G$ curve. Therefore, their intersection $S$ in Figure 4.1a determines the steady state equilibrium. The instantaneous equilibrium is always given by the intersection of the $C C$ and the $G G$ curves. When this intersection is

\footnotetext{
${ }^{7}$ Under sticky prices, with the interest rate not directly connected to consumption and labour supply, the real interest rate enters as an additional argument in the $C C$ curve.

${ }^{8}$ Proof: For $\Delta \frac{C}{K}=0: \frac{d(C / K)}{d g}=-\frac{1}{c_{1} \frac{(1-\theta) Y / K}{C / K} \frac{1}{a_{2}}}$. For GG: $\frac{d(C / K)}{d g}=-\frac{1}{c_{1} \frac{(1-\theta) Y / K}{C / K}+1}$. Since $a_{2}>1$, the latter slope is clearly flatter.
} 
at point $S$, then by construction $\Delta(C / K)=0$.

For a given set of parameters that keep the position of the $G G$ curve unchanged, the model will always be on its steady state growth path. A hypothetical intersection of $C C$ and $G G$ at any other point than $\mathrm{S}$, like A in Figure 4.1a, implies $\Delta(C / K)>0$, meaning that households expect an upward sloping consumption path when normalised for capital growth. Since this is inconsistent with the required movement to point $S$, point $A$ cannot be a rational expectations equilibrium and households will choose consumption and growth so that the economy is at point $S$ when there is no expected shift of the $G G$ curve. The immediate jump onto the steady state growth path is a feature that is found in the simple $A K$ model (see Barro and Sala-i-Martin, 1995) as well as in models with endogenous labour supply (Turnovsky, 2000).

\subsubsection{The Impact of Increased Government Spending}

We model a temporary government spending shock as an autoregressive shock to the share of government spending in output, $\theta$, so that

$$
\hat{\theta}_{t}=\rho_{\theta} \hat{\theta}_{t-1} \quad 0 \leq \rho_{\theta} \leq 1 .
$$

Graphically, this implies an immediate shift of the $G G$ curve to $G G^{\prime}$ in Figure $4.1 \mathrm{~b}$ - where for the sake of exposition we assume $\gamma=0$ - and thereafter a gradual shift back to the original position $G G$ over time. Due to the negative wealth effect on future consumption induced by a persistent $\left(\rho_{\theta}>0\right)$ shock the $C C$ curve also shifts down. The more persistent the shock is, the larger is the shift. A permanent shock shifts it to point $B$, while a one period shock does not shift it, implying a short run equilibrium at point $C$. The actual intersection point $A$, and therefore the question whether growth increases or decreases, depends on a number of parameters. As the government spending shock fades away, the economy returns along the arrows back to the steady state.

To analyse under what conditions a temporary government spending shock increases growth we linearise the model around its steady state using a first order Taylor approximation. The resulting equations can be seen in Appendix 4.B. We use the method of undetermined coefficients to solve 
the model analytically.

Lemma 2. A temporary government spending shock temporarily increases growth and thus induces a permanent positive level effect on $C, Y$ and $K$ if either labour supply is sufficiently elastic, or government spending is sufficiently productive, or a combination of both.

(a). When government spending is unproductive, meaning $\gamma=0$, then the inverse elasticity of labour supply needs to fulfill the condition

$$
\sigma<(1-\alpha) \frac{\rho_{\theta}}{1-\rho_{\theta}}\left(1-\beta \frac{1-\delta}{g}\right)-\alpha
$$

to allow higher temporary growth.

(b). When labour supply is exogenous, meaning $\sigma \rightarrow \infty$, then government spending productivity needs to fulfill the following condition

$$
\frac{\gamma}{1-\gamma}>\frac{\left(1-\rho_{\theta}\right) a_{2}}{\left(a_{2}-\rho_{\theta}\right)\left(1-\rho_{\theta} \frac{1-\delta}{g}\right)+\rho_{\theta}\left((1-\beta) a_{2}+\left(1-\rho_{\theta}\right)\right) \frac{1-\delta}{g}} \frac{\theta}{1-\theta}
$$

to allow a higher temporary growth.

Proof. We define $\hat{c}_{t}=\varphi_{1} \hat{\theta}_{t}$ and $\hat{g}_{t+1}=\varphi_{2} \hat{\theta}_{t}$. We specify the government spending shock according to equation (4.18). The impact responses of $C$ and $g$ to a shock in $\theta$ are defined by

$$
\begin{aligned}
\varphi_{1} & =-\frac{A_{12}}{A_{11}-\rho_{\theta}} \\
\varphi_{2} & =\frac{\left(a_{1} a_{2}\left(1+c_{1}\right)-\frac{g+\delta}{1+g}\right) \rho_{\theta} a_{1} c_{2} \frac{\gamma}{1-\gamma}}{\left(A_{11}-\rho_{\theta}\right)\left(c_{2}-\left(1-a_{1}\right)\right)} \\
& +\frac{\left(\rho_{\theta} a_{1} c_{1}-\left(1-\rho_{\theta}\right)\right) a_{1} a_{2}\left(\frac{\theta}{1-\theta}\left(c_{2}-1\right)-\frac{\gamma}{1-\gamma} c_{2}\right)}{\left(A_{11}-\rho_{\theta}\right)\left(c_{2}-\left(1-a_{1}\right)\right)}
\end{aligned}
$$

where all parameters are defined and derived in Appendix 4.B. 
Conditions (4.19) and (4.20) follow directly from equation (4.21b) by setting $\gamma=0$ or $\sigma \rightarrow \infty$, respectively. Furthermore, it can be shown that ${ }^{9}$

$$
\frac{\partial \varphi_{2}}{\partial \gamma}>0
$$

We find that the effect depends on the duration of the shock, its productiveness and on the labour supply response, which is similar to the finding of Chang (1999) concerning capital accumulation in a standard RBC model without endogenous growth. Figure 4.2 illustrates how an increase in $\gamma$ increases the range of allowable $\sigma$ for a positive reaction of growth to the temporary government spending shock. The intercepts with $\gamma=0$ and $\sigma \rightarrow \infty$ are given by conditions (4.19) and (4.20).

\section{Regions of Crowding In}

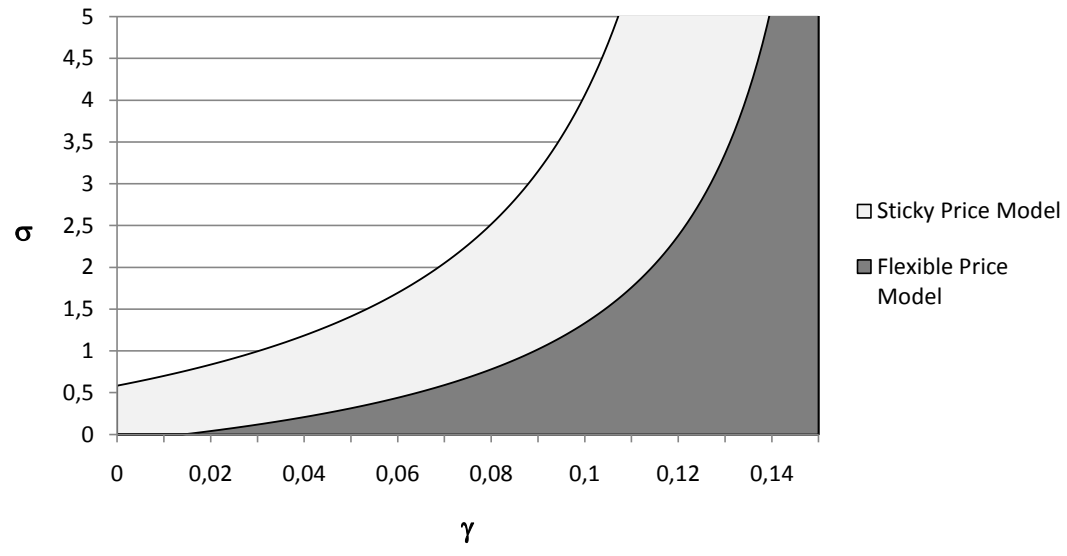

Figure 4.2: The shaded area represent the regions of parameter combinations of $\gamma$ and $\sigma$ where growth increases following a temporary government spending shock. An increase in $\sigma$ requires an increase in $\gamma$ to counter the lower labour supply effect. The calculation was made with parameters from Table 4.1, page 80 .

A temporary government spending shock primarily induces households

\footnotetext{
${ }^{9}$ The derivation is in Appendix 4.B.
} 
to reduce saving since they want to smooth consumption over this temporary fall in resources. The more persistent the government spending shock (higher $\rho_{\theta}$ ), the less strong this consumption smoothing motive will be, since next period's consumption is lower as well. The loss in resources leads to a fall in consumption possibilities, which then induces agents to work more. ${ }^{10}$ The increase in labour supply on one hand increases the return to capital, and thus the real interest rate, which increases saving desire, and on the other hand directly increases output and thus resources available for investment. This potentially allows higher growth.

In Figure 4.1b, the intersection of $C C^{\prime}$ and $G G^{\prime}$ at point $A$ lies further to the right the more persistent the shock is, which can easily be seen in equation (4.21b). A higher responsiveness of labour supply to a fall in consumption makes the $\Delta C / K=0$ curve flatter and thus moves point $B$ right. This implies that there is a larger range for point $A$ to be above $g^{*}$. Intuitively, the larger the increase in labour supply, the larger the increase in output allowing directly more investment, and the larger the increase in the real interest rate, leading to more saving and investment. Both mechanisms combined can increase growth. When labour supply is inelastic, then both of these mechanisms fall away and growth decreases when government spending is not productive.

When government spending is productive $(\gamma>0)$, two effects are at work. The first is the direct positive effect on output and thus investment possibilities, thus shifting $G G^{\prime}$ right. The second is the positive effect on the return to capital, which increases the interest rate and induces higher saving and investment. This shifts both the $\Delta(C / K)=0$ right as well as the $C C^{\prime}$ curve further down. Both of these effects increase the growth inducing effect of the increase in labour supply caused by higher government spending. When labour supply is inelastic, then the productive effect of government spending has to be larger in order to induce more growth.

\footnotetext{
${ }^{10}$ Chapter 2 shows that the increase in output in response to a government spending shock is accompanied by an increase in labour supply.
} 


\subsubsection{Discussion}

The discussion in Section 3.4 of the previous chapter made clear that a positive long-run effect of government spending on consumption is required to obtain short-run consumption crowding-in. This implies that the growth rate of capital accumulation has to increase temporarily. The analysis presented thus far makes clear that an increase in the growth rate requires households to increase their private savings to finance both the additional government spending as well as the additional investment. Additionally, government spending increases output via its productiveness as well as its labour supply effect. While these could be sufficient to induce higher growth, they will not be sufficient to induce consumption crowding in under flexible prices.

The solution is to allow additional deviations of output from steady state using sticky prices. In Figure $4.1 \mathrm{~b}$ the idea is to obtain a right-shift of the $G G$-curve caused by the additional labour supply effect in a New Keynesian model. In such a case growth will increase. While this implies an increase of consumption eventually, the immediate response also depends on the shift of the $C C$-curve relative to the shift of the $G G$-curve.

The basic idea of New Keynesian models is to have shocks which cause excess demand and thereby move the economy away from its flexible price equilibrium, usually through movements in labour supply caused by changes in the real wage. This results in inflation, which is the basis of the monetary policy reaction.

An inspection of equations (4.13a) to (4.13f) reveals that in an endogenous growth model investment is in fact determined as a residual from households' saving desire. Ex post, capital does not face decreasing returns. Therefore, any level of investment satisfies equation (4.6a). Thus, the introduction of price stickiness in an endogenous growth model does not produce a true New Keynesian model featuring excess demand. Nevertheless, the analysis will provide insights into the supply of resources necessary for growth, which is savings.

The key variable now lies with the reaction of the central bank to the temporary government spending shock. The government spending shock leads to a change in the return to capital. The next section argues that 
this change has to be taken into account in a Taylor rule since it is a change in the natural real rate of interest. Thereby, a rationale for the use of the output gap in the Taylor rule is provided. Section 4.5 uses this Taylor rule to show how an endogenous growth model with deviations of output from its flexible price level reacts to a temporary government spending shock.

\subsection{Why inflation targeting central banks seem to follow a standard Taylor rule}

Section 2.5.1 made clear that knowledge of the natural real rate of interest (NRRI) is important for monetary policy conduct in search of inflation stability. ${ }^{11}$ However, it also made clear that timely information about the NRRI is very hard to obtain. This section argues that by taking the output gap into account, central banks can already capture some of the movements in the NRRI, thereby making the use of a time-varying intercept unnecessary. Regarded from another angle, this means that even central banks only targeting inflation stability will seem to follow a standard Taylor rule with weight on the output gap.

\subsubsection{The Natural Real Rate of Interest}

Woodford (2003) defines the Wicksellian natural real rate of interest $r^{n}$ as the equilibrium real rate of interest that guarantees price stability. It is the real interest rate that aligns saving with investment and thereby demand with the flexible price level of output. Crucially, the NRRI is varying with exogenous demand and supply shocks (Woodford, 2003).

In an endogenous growth model the NRRI is the interest rate that aligns household savings with the investment required to generate the desired rate of growth. This implies that household's return on savings, given by the real interest rate $r$, has to equal the return on investment, which is the flexible price return on capital $r^{k^{f}}$ net of depreciation. ${ }^{12}$ Therefore, the

\footnotetext{
${ }^{11}$ We thank Bertrand Candelon, Julio Carillo, Lenard Lieb and Tom van Veen for valuable feedback.

${ }^{12}$ For clarity of exposition, we assume no depreciation.
} 
natural real rate of interest is given by

$$
r^{n}=r=r^{k^{f}} .
$$

Using this chapter's model, equation (4.6a) actually determines the flexible price return to capital. Therefore, we have

$$
r_{t}^{k^{f}}=\frac{\alpha}{\mu}\left(\frac{Y_{t}}{K_{t}}\right)^{n}
$$

From the discussion above, it follows that equation 4.23 represents the natural real rate of interest in an endogenous growth model, where $\left(\frac{Y_{t}}{K_{t}}\right)^{n}$ is the natural (flexible) price output capital ratio. When return to capital $r_{t}^{k}$ differs from the NRRI, marginal costs are not at their flexible price level.

\subsubsection{Monetary Policy}

As Woodford (2003) noted, changes in the NRRI have to be mirrored by changes in the actual real rate to maintain price stability. Under flexible prices, a model without a central bank automatically reaches that equilibrium through adjustments on the bond market, and thus via the nominal interest rate, without effects on the inflation rate $\pi$.

Monetary policy and an interest rule only make sense in a sticky price model like Calvo (1983) staggered price setting. Sticky prices cause deviations in real wages from their flexible price level, which lead to deviations of marginal costs as well as labour supply and thus output from their flexible price level. Furthermore, inflation increases when marginal costs rise above their flexible price level. Inflation stability requires that the real interest rate equals the NRRI, otherwise marginal costs are not at their flexible price level and induce a change in inflation.

Arbitrage ensures that the return to capital $r^{k}$ equals the real interest rate on other assets like bonds. The Fisher equation

$$
r_{t}=i_{t}-\pi_{t}^{e}
$$

relates the real interest rate to the nominal interest $i$ rate and expected inflation $\pi^{e}$. Assuming rational expectations, inflation stability requires 
that the nominal interest rate minus the desired inflation equals the NRRI at all times. Therefore, changes in the NRRI have to be matched by changes in the nominal interest rate. Otherwise, inflation will react and lead to an adjustment.

If monetary policy were to follow an interest rate rule that only reacts to inflation deviations, a rise in the NRRI following a supply shock will initially not be accommodated by a rise in the nominal interest rate. There is a disequilibrium on the financial markets, where capital earns a higher return than bonds $\left(r^{k}>r\right)$. Firms now face a cost of borrowing lower than their return on investment, which lowers their cost of capital. Due to their optimality condition (the ratio of equations $4.6 \mathrm{a}$ and $4.6 \mathrm{~b}$ ), firms are required to lower labour costs by lowering real wages and labour demand. This leads to lower labour supply and output.

Furthermore, lower capital and labour costs lower marginal costs, which lowers inflation. Determinacy, implying the equalisation of returns $\left(r^{k}=\right.$ $r=i-\pi)$, requires a passive interest response to inflation by the central bank so that the real interest rate rises as inflation falls. ${ }^{13}$ Hence, the rise in the NRRI is accommodated by a fall in actual return to capital and a rise in the central bank real interest rate.

Section 2.5.2 discussed the issue of an active or passive monetary policy with respect to determinacy of the model and concluded that in discrete time models, a backward looking interest rate rule can react actively to inflation. In fact, such a backward looking rule is passive in the context described here: inflation is falling in the period of the impact of the NRRI shock, but the nominal interest rate is not, thereby causing a rise in the real interest rate to accommodate the rise in the NRRI.

This analysis shows that the point made by Woodford (2003), which requires the central bank to react to changes in the NRRI to stabilise inflation, also holds for endogenous growth models.

\footnotetext{
${ }^{13} \mathrm{An}$ active interest response raises the nominal interest rate by more than one for one with inflation, a passive interest response by less.
} 


\subsubsection{The Taylor Rule}

The monetary policy rule followed by the FED was estimated by Taylor (1993) as

$$
i_{t}=0.04+1.5\left(\pi_{t}-0.02\right)+0.5\left(\frac{y_{t}-\bar{y}_{t}}{\bar{y}_{t}}\right)
$$

where $y_{t}-\bar{y}_{t}$ is the output gap. Woodford (2001) argues that such a Taylor rule can be obtained by minimising a central bank loss function of output and inflation. He noted that $\bar{y}_{t}$ should be replaced by the natural output and the intercept, representing the NRRI, should also take into account changes in this rate.

The Taylor rule should therefore be specified as

$$
i_{t}=r_{t}^{n}+\bar{\pi}+\rho_{\pi}\left(\pi_{t}-\bar{\pi}\right)+\rho_{y}\left(\frac{y_{t}-y_{t}^{n}}{y_{t}^{n}}\right)
$$

where $\bar{\pi}$ represents the target for inflation and $y^{n}$ natural output. Such a policy requires a correct estimation of the current flexible price output as well as the NRRI.

Using the definition of the NRRI, equation (4.23), in (4.25) we obtain

$$
i_{t}=\frac{\alpha}{\mu}\left(\frac{Y_{t}}{K_{t}}\right)^{n}+\bar{\pi}+\rho_{\pi}\left(\pi_{t}-\bar{\pi}\right)+\rho_{y}\left(\frac{y_{t}-y_{t}^{n}}{y_{t}^{n}}\right) .
$$

Since the capital stock is predetermined, the output gap approximations

$$
\frac{\frac{Y_{t}}{K_{t}}-\overline{\left(\frac{Y}{K}\right)}}{\overline{\left(\frac{Y}{K}\right)}}=\frac{y_{t}-\bar{y}}{\bar{y}} \text { and } \frac{\frac{Y_{t}}{K_{t}}-\left(\frac{Y_{t}}{K_{t}}\right)^{n}}{\left(\frac{Y_{t}}{K_{t}}\right)^{n}}=\frac{y_{t}-y_{t}^{n}}{y_{t}^{n}},
$$

where $\overline{\left(\frac{Y}{K}\right)}$ is an estimate of the steady state output capital ratio, are reasonable. 
Equation 4.26 can then be rewritten to

$$
i_{t}=i^{*}+\rho_{\pi}\left(\pi_{t}-\bar{\pi}\right)+\rho_{y}^{*}\left(\frac{y_{t}-\bar{y}}{\bar{y}}\right)
$$

with

$$
\begin{aligned}
\rho_{y}^{*} & =\frac{\alpha}{\mu} \overline{\left(\frac{Y}{K}\right)}, \\
i^{*} & =\frac{\alpha}{\mu} \overline{\left(\frac{Y}{K}\right)}+\bar{\pi},
\end{aligned}
$$

where $i^{*}$ is the nominal target interest rate corresponding to the steady state NRRI and we impose $\rho_{y}=\frac{\alpha}{\mu}\left(\frac{Y_{t}}{K_{t}}\right)^{n}$.

Equation (4.27) is equivalent to the original Taylor rule (4.24) and proves that the use of a fixed intercept and output target in the Taylor rule is equivalent to the use of a flexible NRRI and a flexible price output target. This is supported by Giammarioli and Valla (2003), who find using a standard New Keynesian model that "accounting for the fluctuations of $r^{*}$ over time only slightly improves the stability of the economy, mostly through a better stabilisation of the output gap."

A central bank reaction function where only inflation stabilisation is part of the objective function should have the form

$$
i_{t}=r_{t}^{n}+\bar{\pi}+\rho_{\pi}\left(\pi_{t}-\bar{\pi}\right) .
$$

Using the notation from above, this can be rewritten to

$$
i_{t}=i^{*}+\rho_{\pi}^{\prime}\left(\pi_{t}-\bar{\pi}\right)+\rho_{y}^{*}\left(\frac{y_{t}-\bar{y}}{\bar{y}}\right)
$$

with

$$
\rho_{\pi}^{\prime}=\rho_{\pi}-\rho_{y}^{*} \frac{\left(y_{t}-y_{t}^{n}\right) / \bar{y}}{\pi_{t}-\bar{\pi}} .
$$


Since $\frac{\left(y_{t}-y_{t}^{n}\right) / \bar{y}}{\pi_{t}-\bar{\pi}}>0^{14}, \rho_{\pi}^{\prime}$ is adjusted downward to account for the central bank reaction to the inflation inducing part of the output gap already embedded in the $\rho_{y}$-part of equation 4.29. The size of the adjustment is in principle unknown but could be approximated with the response of inflation to the output gap, which is assumed to be stable over time. Note that in standard New Keynesian models with cost push shocks the output gap also enters as an indicator of inflationary pressures.

A central bank only caring for inflation stability should use the policy rule equation 4.28. However, this requires timely information on the NRRI, which might not be available. Our analysis shows that the conventional Taylor rule, which uses a constant intercept, takes these fluctuations in the natural real rate of interest into account (see equation 4.29). Therefore, even central banks which supposedly only care about inflation will act in line with the standard Taylor rule - that is take the output gap into account when setting the interest rate. This might explain why many studies (e.g. Gorter et al., 2008) also find that the ECB follows the standard Taylor rule.

Furthermore, we highlight the importance for central banks to take the output gap into account when setting monetary policy due to the difficulty of obtaining a direct reliable measure of the NRRI. Finally, the unavailability of measures of the NRRI and natural output are not problematic for central banks following a standard Taylor rule with fixed intercept and output target, as such a Taylor rule takes these fluctuations into account.

\subsection{The Sticky Price Model}

The previous section highlighted the importance of the output parameter in the Taylor rule when using a sticky price model. This section introduces price stickiness and the Taylor rule into the endogenous growth model presented in Section 4.2 to show the impact sticky prices have on the

${ }^{14}$ The ratio of actual to flexible price output is

$$
\frac{Y_{t}}{K_{t}} /\left(\frac{Y_{t}}{K_{t}}\right)^{n}=\left(\mu m c_{t}\right)^{1-\alpha}
$$

Higher marginal costs, as they occur when $y_{t}>y_{t}^{n}$, induce inflation. 
response of growth to temporary government spending.

\subsubsection{Sticky Price Extension}

To introduce price stickiness, we assume a Calvo (1983) pricing mechanism, implying that only a certain share, $1-\phi$, of firms can reset their price at the desired mark-up $\mu$ in every period. Since the other firms cannot set their price at the desired constant mark-up above marginal costs, the mark-up and real marginal costs become variable over time. Combining equations (4.6a) and (4.6b) by substituting away labour $L$, we can represent real marginal cost of producing one extra unit of output as

$$
m c_{t}=\frac{\left(r_{t}^{k}\right)^{\frac{\alpha-\gamma}{1-\gamma}} w_{t}^{\frac{1-\alpha}{1-\gamma}}}{\left(A \theta^{\gamma}\right)^{\frac{1}{1-\gamma}} \alpha^{\frac{\alpha-\gamma}{1-\gamma}}(1-\alpha)^{\frac{1-\alpha}{1-\gamma}} K_{t}^{\frac{1-\alpha}{1-\gamma}} .}
$$

Higher marginal costs will lead to higher inflation $\pi$, as shown by the New Keynesian Phillips curve derived in Appendix 4.A.

$$
\hat{\pi}_{t}=\beta g \hat{\pi}_{t+1}+\chi \widehat{m c}_{t}
$$

where $\chi=(1-\phi)(1-\beta \phi g) / \phi$ and $\phi$ is the share of firms not able to reset price in a certain period and $\hat{x}$ denotes the percentage deviation of a variable $x$ from its steady state value.

There are two changes in the New Keynesian Phillips curve due to the presence of endogenous growth. The first one is that $\chi$ becomes smaller, meaning that inflation is less responsive to deviations in marginal costs. However, the second change increases the coefficient on future inflation, which increases the response of inflation if the shock is persistent. In practice, the difference turns out to be very small.

We furthermore assume a central bank setting the interest rate on the bonds market in reaction to deviations of output and inflation from their flexible price level in a Taylor rule fashion. Section 2.5.2 made clear that a model without capital adjustment costs or a backward looking interest rate rule will have the Taylor principle reversed. This means, that the coefficient on inflation has to be small, $\rho_{\pi} \leq 1$. The aim of this chapter is to provide an analytical solution. For this reason, the forward looking Taylor rule has 
to be used despite the apparent contradiction of the inflation parameter setting with actually observed values. This is not problematic considering the aims of this chapter in providing an analysis of what growth response the sticky price endogenous growth model is capable of showing. Chapter 5 provides a simulated solution to a model with both capital adjustment costs as well as a backward looking Taylor rule.

The Taylor rule to be used is therefore

$$
R_{t}=R^{*}+\rho_{\pi}\left(\pi_{t+1}-\bar{\pi}\right)+\rho_{y}\left(\frac{\frac{Y_{t+1}}{K_{t+1}}-\overline{\left(\frac{Y}{K}\right)}}{\overline{\left(\frac{Y}{K}\right)}}\right)
$$

where $R^{*}$ is the nominal target interest rate corresponding to the steady state natural real rate plus target inflation $\bar{\pi}$ and $\overline{\left(\frac{Y}{K}\right)}$ is the target steady state output capital ratio. The output gap is expressed relative to capital, in line with the tradition of endogenous growth models.

\subsubsection{The Full Model}

The full model is similar to the flexible price model of section 4.2.5. There are two differences, however. First, the process for real marginal costs (equation 4.30) replaces equation (4.13f). Second, the nominal interest rate is set by the central bank. This means that we additionally have to state equation (4.11b) explicitly as (4.33f), which we implicitly used in the flexible price model through its substitution into equation (4.11a). The full model is therefore:

$$
\begin{aligned}
\frac{Y_{t}}{K_{t}} & =m c_{t}^{c_{1}}(1-\alpha)^{c_{1}}\left(A \theta_{t}^{\gamma}\right)^{\frac{1}{1-\gamma}\left(1+c_{1}\right)}\left(\frac{C_{t}}{K_{t}}\right)^{-c_{1}}, \\
\frac{C_{t}}{K_{t}} & =\frac{C_{t+1}}{K_{t+1}} g_{t+1} \frac{1}{\beta} \frac{1}{1-\delta+r_{t+1}^{k}}, \\
g_{t+1} & =\frac{I_{t}}{K_{t}}+1-\delta \\
\frac{I_{t}}{K_{t}} & =\left(1-\theta_{t}\right) \frac{Y_{t}}{K_{t}}-\frac{C_{t}}{K_{t}},
\end{aligned}
$$




$$
\begin{aligned}
m c_{t} & =\left(r_{t}^{k}\right)^{\frac{1}{1+c_{1}}}\left(\frac{C_{t}}{K_{t}}\right)^{\frac{c_{1}}{1+c_{1}}} \alpha^{-\frac{1}{1+c_{1}}}(1-\alpha)^{-\frac{c_{1}}{1+c_{1}}}\left(A \theta_{t}^{\gamma}\right)^{-\frac{1}{1-\gamma}} \\
r_{t+1}^{k} & =\frac{R_{t}}{\pi_{t+1}}+\delta-1 \\
\hat{\pi}_{t} & =\beta \hat{\pi}_{t+1}+\chi \widehat{m c}_{t}, \\
R_{t} & =R^{*}+\rho_{\pi}\left(\pi_{t+1}-\bar{\pi}\right)+\rho_{y}\left(\frac{\frac{Y_{t+1}}{K_{t+1}}-\overline{\left(\frac{Y}{K}\right)}}{\overline{\left(\frac{Y}{K}\right)}}\right)
\end{aligned}
$$

with

$$
c_{1}=\frac{1-\alpha}{\sigma+\alpha-\gamma(1+\sigma)}>0
$$

\subsubsection{Sticky Price Dynamics}

To analyse the effects of a temporary government spending shock we linearise the model around its steady state using a first order Taylor approximation. The resulting equations can be seen in Appendix 4.C. We use the method of undetermined coefficients to solve the model analytically. Again we use the government spending process from equation 4.18.

Lemma 3. Given a central bank reaction function that perfectly accommodates the nominal interest rate to changes in the natural real rate as they are caused by a change in government spending, implying $\rho_{y}=r^{k} \bar{\pi}$, the New Keynesian model behaves like the flexible price model.

Proof. We define $\hat{c}_{t}=\varphi_{1} \hat{\theta}_{t}, \hat{g}_{t+1}=\varphi_{2} \hat{\theta}_{t}$ and $\hat{\pi}_{t}=\varphi_{3} \hat{\theta}_{t}$. The impact responses of these variables to a shock in $\theta$ are defined by

$$
\begin{aligned}
\varphi_{1} & =-\frac{B_{13}}{B_{11}-\rho_{\theta}} \frac{u}{u-v}+\frac{B_{23} A_{12}}{u-v} \\
\varphi_{2} & =\frac{a_{2} a_{3}}{c_{2}-a_{4}} \varphi_{3}-\left(\frac{a_{1} a_{2}}{c_{2}-a_{4}}+a_{1} a_{2}-\frac{g+\delta}{1+g}\right) \varphi_{1} \\
& -\frac{a_{1} a_{2}}{c_{2}-a_{4}}\left(\frac{\theta}{1-\theta}\left(c_{2}-a_{4}\right)-\frac{\gamma}{1-\gamma} c_{2}\right)
\end{aligned}
$$




$$
\varphi_{3}=-\frac{B_{23}}{B_{22}-\rho_{\theta}} \frac{u}{u-v}+\frac{B_{13} B_{21}}{u-v}
$$

with

$$
\begin{aligned}
& u=\left(B_{11}-\rho_{\theta}\right)\left(B_{22}-\rho_{\theta}\right) \\
& v=B_{12} B_{21}
\end{aligned}
$$

Appendix 4.C defines the parameters and also discusses the signs of $\varphi_{1}$ and $\varphi_{3}$.

When $\rho_{y}=r^{k} \bar{\pi}$ and thus $a_{4}=1$, then the model can be reduced to its flexible price counterpart, since $B_{21}=0$. This implies that equations (4.34a) and (4.34b) are equivalent to equations (4.21a) and (4.21b).

The economic intuition is that a government spending shock directly affects the flexible price real rate of interest. Since the endogenous growth model does not feature excess demand, full accommodation of a change in the flexible price real interest rate by the central bank leaves actual marginal costs of firms and all other variables at their flexible price level. This implies setting $\rho_{y}=\rho_{y}^{*}$ from Section 4.4.3. ${ }^{15}$ The response to a government spending shock is then described by Lemma 2 .

Graphically, the setting of the interest rate by the central bank removes the real interest rate effect due to labour supply changes from the $C C$ and the $\Delta(C / K)=0$ curves, making the latter vertical. For a change in government spending to have the same effect as under flexible prices, the central bank has to increase the interest rate as it would happen under flexible prices. In this case the intersection of the $G G$ curve and the $\Delta(C / K)=0$ curve traces the $\Delta(C / K)=0$ curve in Figure 4.1b.

Lemma 4. If the central bank reacts to deviations in output beyond pure adjustment of the natural real rate of interest $\left(\rho_{y}>r^{k} \pi\right.$, meaning $\left.a_{4}>1\right)$, a temporary government spending shock has more positive effect on growth than described in Lemma 2.

Proof. The grey area in Figure 4.2 shows how the parameter range of $\sigma$ and $\gamma$ allowing higher growth $\left(\varphi_{2}>0\right)$ increases when a central bank reaction

\footnotetext{
${ }^{15}$ The slight difference is due to the formulation as percentage deviations from steady state values.
} 
of $\rho_{y}=0.11$, implying $a_{4}>1$, is used. Further numerical simulations show that $\frac{\partial \varphi_{2}}{\partial a_{4}}>0$.

A strong response of the central bank to deviations in output from its target level $\left(a_{4}>1\right)$ also has the effect of increasing the interest rate and therefore the cost of capital, which increases, due to the capital labour ratio optimality condition $^{16}$, labour demand and thus output. Therefore, $a_{4}>1$ has the same effect on the curves in Figure 4.1b as $\gamma>0$. Both of these effects imply a more positive response of the growth rate to a temporary government spending shock.

The effects of $\rho_{y}$ on the growth response hinges on the validity of the Dupor (2001) conjecture. Chapter 5 will show that with a backward looking interest rule, capital adjustment costs as well as investment demand depending on the real interest rate these results are reversed: a lower $\rho_{y}$ will lead to a higher response of output. However, the basic conclusion from this chapter stays: in a sticky price endogenous growth model temporary government spending can increase growth since output above flexible price level directly provides resources for more growth and leads to a higher interest rate which increases saving, investment and growth.

\subsection{Simulation}

This section discusses numerical simulations with realistic parameter choices in order to visualise the effect temporary government spending has on private consumption. We simulate the model using the parameter set in Table 4.1 using quarterly periods.

These are mostly standard values in the literature. The exception is the Taylor rule parameter on inflation, which we have to set to a passive monetary policy for reasons explained before. An inverse elasticity of labour supply of $\sigma=1$ is used by Linnemann and Schabert in various of their papers dealing with consumption crowding in. The steady state growth rate is set to $2.1 \%$ annually, which implicitly defines $A$.

We present the results by showing the percentage difference in private consumption as compared to the baseline scenario of no change in

\footnotetext{
${ }^{16}$ Dividing (4.6b) by (4.6a) yields $\frac{K}{L}=\frac{\alpha}{1-\alpha} \frac{w}{r^{k}}$.
} 
Table 4.1: Calibrated Parameters for Quarterly Periods

\begin{tabular}{|r|c|l|}
\hline \hline Parameter & Value & Source \\
\hline Standard Parameters & \\
time discount $\beta$ & 0.99 & standard \\
capital share $\alpha$ & 0.33 & standard \\
depreciation $\delta$ & 0.025 & standard \\
inverse $L^{S}$ elasticity $\sigma$ & 1 & Linnemann and Schabert (2003a) \\
markup $\mu$ & 1.2 & standard \\
government share $\theta$ & 0.2 & Baxter and King (1993) \\
government prod $\gamma$ & $0 ; 0.1$ & Romp and de Haan (2007) \\
shock autocorrelation $\rho^{\varepsilon}$ & 0.9 & Galí et al. (2007) \\
steady state growth $g$ & 1.006 & $2.1 \%$ annual growth \\
\hline New Keynesian Parameters & \\
price stickiness $\phi$ & 0.75 & Linnemann and Schabert (2003a) \\
Taylor rule $\rho_{\pi}$ & 0.95 & \\
Taylor rule $\rho_{y}$ & 0.11 & Coenen and Straub (2005) \\
inflation target $\bar{\pi}$ & 1.005 & ECB target \\
\hline \hline
\end{tabular}

government spending, both scaled by baseline GDP, in Figure 4.3. When temporary government spending increases growth, then the long run response of consumption will be positive. The scale is from $-1.5 \%$ to $2 \%$ in all Figures.

When government spending is not productive, growth is reduced upon a temporary government spending shock of $2 \%$ of GDP. The fall in resources does induce higher labour supply and thus output. However, the dissaving motive of households is too strong, thereby leading to lower growth. The introduction of productive effects of government spending changes that result. In combination with price stickiness significant growth effects occur that increase consumption above its original level within 1 year. When labour supply is fixed, growth falls, showing the importance of the labour supply channel to provide resources for higher growth. 


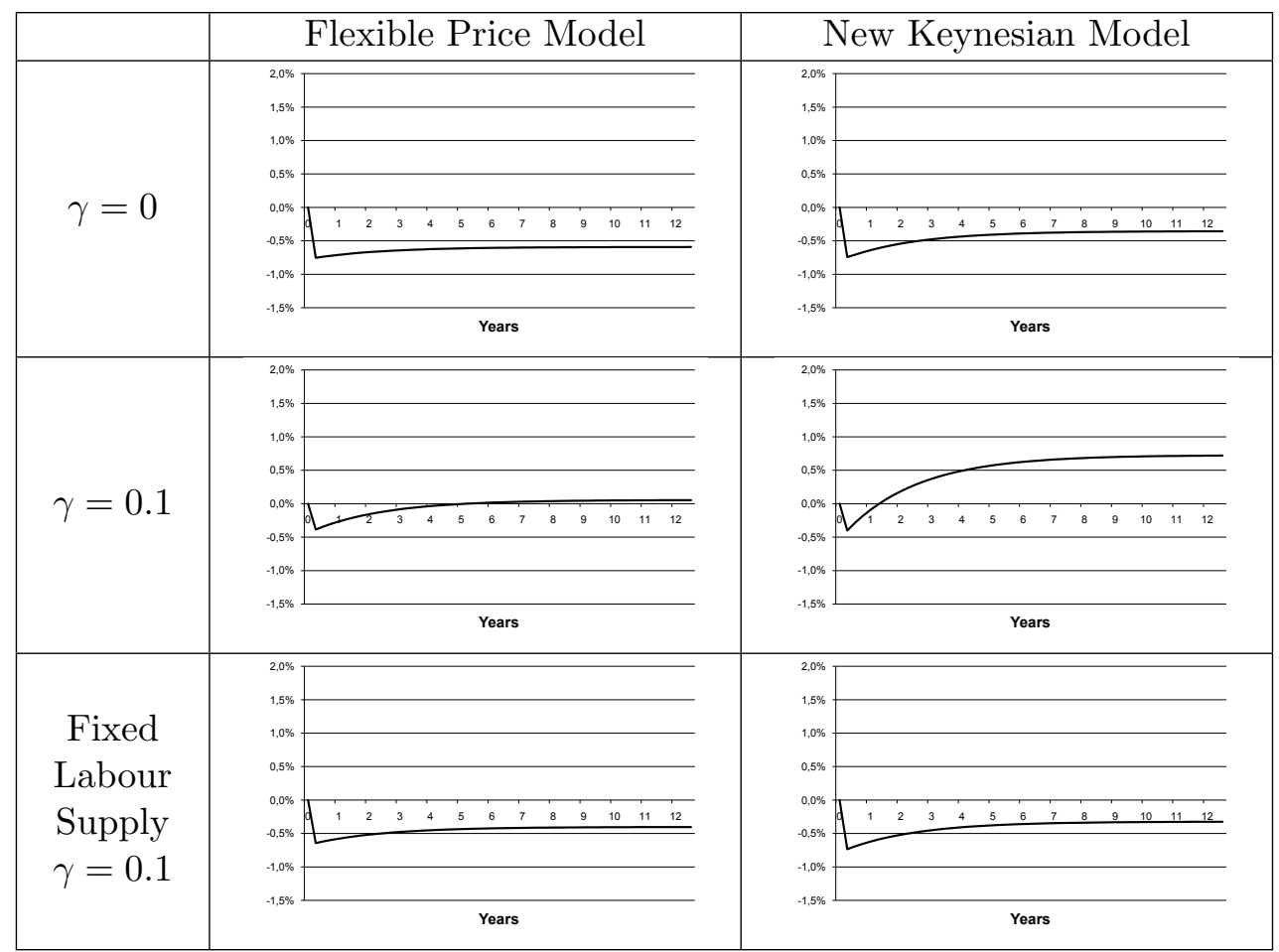

Figure 4.3: Model with (productive) government flow spending. Development of private consumption as a difference to the baseline scenario of no change in government spending, both scaled by baseline GDP. The shock is a $10 \%$ increase in government spending, corresponding to a $2 \%$ of total GDP. 


\subsection{Conclusion}

This chapter analyses the conditions under which a temporary government spending shock increases an economy's rate of growth. Since growth is determined using a learning-by-doing technology based on capital usage, the question boils down to when a temporary government spending shock increases investment.

Investment in this chapter's model is determined, in growth model tradition, by household saving. Thus, this chapter analyses the supply side of growth: how much resources are available after a temporary government spending shock for investment and growth. Chapter 5 additionally introduces the demand side by explicitly allowing investment demand.

A temporary government spending shock produces a temporary negative wealth effect, which households would generally like to smooth by dissaving, thereby reducing investment. This chapter finds 4 channels which might counter this dissaving effect and lead to an increase in investment after all.

The first channel is an increase in output due to higher labour supply. The second channel is an increase in output due to productive government spending. The third channel is the increase in the real interest rate due to an increase in labour supply or productive government spending. The first two channels increase available resources to allow higher investment despite higher government spending, while the last channel induces households to save more, thereby increasing investment. It turns out that under flexible prices the combination of all these channels is just enough to obtain a small increase in investment.

The fourth channel the chapter uncovers works via sticky prices and monetary policy. When output rises above its flexible price level due to price stickiness and the real interest rate is raised above its flexible price level, then both households desire to save as well as the available resources for investment increase. 


\section{A Derivation of the New Keynesian Phillips Curve for a Growing Economy}

The economy consists of a continuum of firms indexed by $i \in[0,1]$ who are all monopolistic competitors producing their good $Y_{i t}$, selling it at price $P_{i t}$, facing a demand function

$$
Y_{i t}=\left(\frac{P_{i t}}{P_{t}}\right)^{-\epsilon} Y_{t} .
$$

$Y_{t}$ and $P_{t}$ are the aggregate output and price level.

The firm wishes to maximise its profits subject to (4.35), meaning

$$
\max _{P_{i} t} \Pi_{t}=P_{i t} Y_{i t}-M C_{t} Y_{i t},
$$

where $M C_{t}=P_{t} m c_{t}$ are nominal marginal costs, which the firm takes as given since it is a price taker on the labour and capital market.

Under flexible prices, the optimality condition translates to

$$
P_{i t}=\frac{\epsilon}{\epsilon-1} M C_{i t}
$$

for all firms.

With the introduction of Calvo (1983) price stickiness firms have a probability $\phi$ of not being able to reset their price. They have to take this into account when setting their price, thus changing their maximisation problem to

$$
\max _{P_{i t}} E_{t} \sum_{j=0}^{\infty}(\beta \phi)^{j} V_{t, t+j}\left(\frac{P_{i t}}{P_{t+j}} Y_{i t+j}-\frac{M C_{t+j}}{P_{t+j}} Y_{i t+j}\right),
$$

subject to the demand equation (4.35). 
Solving for the first order condition, we obtain

$$
\begin{array}{r}
P_{i t} E_{t} \sum_{j=0}^{\infty}(\beta \phi)^{j} V_{t, t+j} \frac{Y_{t+j}}{T_{t+j}} \frac{T_{t+j}}{T_{t}} P_{t+j}^{\epsilon-1}= \\
\frac{\epsilon}{\epsilon-1} E_{t} \sum_{j=0}^{\infty}(\beta \phi)^{j} V_{t, t+j} \frac{Y_{t+j}}{T_{t+j}} \frac{T_{t+j}}{T_{t}} M C_{t+j} P_{t+j}^{\epsilon-1}
\end{array}
$$

The standard approach is to linearise the preceding equation around a steady state. To avoid complications, the usual approach is to assume a zero inflation steady state, meaning that marginal costs as well as the price level will always be around a steady state. In our case, output is growing, which requires us to divide by $T_{t}$. The term $\frac{T_{t+j}}{T t}$ can also be expressed in terms of variables having a steady state as

$$
\frac{T_{t+j}}{T_{t}}=\prod_{k=1}^{j} g_{t+k}
$$

For each $j$, a $g$-term will be included $j$ times, meaning that to obtain steady state deviations, it has to be divided by $g^{j}$. For this reason, and due to the fact that many terms on the LHS and RHS cancel after linearisation, the optimal reset price will be

$$
\hat{P}_{i t} \sum_{j=0}^{\infty}(\beta \phi g)^{j}=\sum_{j=0}^{\infty}(\beta \phi g)^{j} \widehat{M C}_{t+j},
$$

where a hat denotes steady state deviations. Using the formula for a geometric sequence, we can write

$$
\hat{P}_{i t}=(1-\beta \phi g) \sum_{j=0}^{\infty}(\beta \phi g)^{j} \widehat{M C}_{t+j}
$$

Furthermore,

$$
\hat{P}_{i t}=(1-\beta \phi g) \widehat{M C}_{t}+(1-\beta \phi g) \sum_{j=1}^{\infty}(\beta \phi g)^{j} \widehat{M C}_{t+j}
$$


holds. We also know that

$$
\hat{P}_{i t+1}=\frac{1-\beta \phi g}{\beta \phi g} \sum_{j=1}^{\infty}(\beta \phi g)^{j} \widehat{M C}_{t+j}
$$

holds. Combining these equations, we obtain

$$
\hat{P}_{i t}=(1-\beta \phi g) \widehat{M C}_{t}+\beta \phi g \hat{P}_{i t+1}
$$

To derive the Phillips curve, we first note that the aggregate price level is a weighted average of the past price level and the optimal reset price.

$$
\begin{aligned}
\hat{P}_{t} & =\phi \hat{P}_{t-1}+(1-\phi) \hat{P}_{i t} \\
\equiv & \hat{P}_{i t}=\frac{1}{1-\phi}\left(\hat{P}_{t}-\phi \hat{P}_{t-1}\right.
\end{aligned}
$$

Combining (4.44) with (4.45), and noting that $\hat{\pi}_{t}=\hat{P}_{t}-\hat{P}_{t-1}$ as well as that real marginal cost deviations are defined by $\widehat{m c}_{t}=\widehat{M C}_{t}-\hat{P}_{t}$, we obtain the New Keynesian Phillips curve for a growing economy.

$$
\hat{\pi}_{t}=\beta g \hat{\pi}_{t+1}+\chi \widehat{m c}_{t}
$$

where $\chi=\frac{(1-\beta \phi g)(1-\phi)}{\phi}$.

\section{B Appendix Flexible Price Model}

We make a first order Taylor approximation of the flexible price endogenous growth model of equations (4.13a) to (4.13f). We define the steady state percentage deviations of $C / K, g$ and $\theta$ as $\hat{c}, \hat{g}$ and $\hat{\theta}$. The linearised equations of (13a) to (13f) are

$$
\begin{aligned}
& \hat{y}_{t}=\frac{\gamma}{1-\gamma}\left(1+c_{1}\right) \hat{\theta}_{t}-c_{1} \hat{c}_{t} \\
& \hat{c}_{t}=\hat{c}_{t+1}+\hat{g}_{t+1}-\frac{r^{k}}{1+r^{k}-\delta} \hat{r}_{t+1}^{k}
\end{aligned}
$$




$$
\begin{aligned}
\hat{g}_{t+1} & =\frac{(1-\theta)}{g} \frac{Y}{K} \hat{y}_{t}-\frac{\theta}{g} \frac{Y}{K} \hat{\theta}_{t}-\frac{1}{g} \frac{C}{K} \hat{c}_{t} \\
\hat{r}_{t}^{k} & =\hat{y}_{t}
\end{aligned}
$$

From equation (13b) we know $\frac{g}{\beta}=1+r^{k}-\delta$. We also know $r^{k}=\frac{\alpha}{\mu} \frac{Y}{K}$. From these two equations we can derive

$$
\frac{1-\theta}{g} \frac{Y}{K}=\left(1-\beta \frac{1-\delta}{g}\right) \frac{\mu}{\alpha} \frac{1-\theta}{\beta}=a_{1} a_{2},
$$

where we defined $a_{1}=1-\beta \frac{1-\delta}{g}$ and $a_{2}=\frac{1-\theta}{\beta} \frac{\mu}{\alpha}>1$ for convenience. We can also derive

$$
\frac{r^{k}}{1+r^{k}-\delta}=a_{1} \text {. }
$$

Furthermore, using the resource constraint, we find

$$
\frac{1}{g} \frac{C}{K}=a_{1} a_{2}-\frac{g-(1-\delta)}{g} .
$$

Inserting (4.47), (4.49) and (4.50) in (4.48) we obtain

$$
\begin{aligned}
\left(1+a_{1} c_{1}\right) \hat{c}_{t+1} & =\left(1+a_{1} a_{2} c_{1}+a_{1} a_{2}-\frac{g-(1-\delta)}{g}\right) \hat{c}_{t} \\
& +a_{1} a_{2}\left(\frac{\theta}{1-\theta}-\left(1+c_{1}\right) \frac{\gamma}{1-\gamma}\right) \hat{\theta}_{t} \\
& +a_{1} \frac{\gamma}{1-\gamma}\left(1+c_{1}\right) \hat{\theta}_{t+1} .
\end{aligned}
$$

We can write our model in the reduced form matrix notation as $X_{t+1}^{f}=$ $A X_{t}^{f}$, where $X^{f}=\left[\begin{array}{ll}\hat{c} & \hat{\theta}\end{array}\right]^{\prime}$. The $2 \times 2$ transition matrix $A$ has the elements

$$
\begin{aligned}
A_{11} & =\frac{\frac{1-\delta}{g}\left(c_{2}-1\right)+a_{1} a_{2} c_{2}}{c_{2}-\left(1-a_{1}\right)} \\
A_{12} & =\frac{a_{1} a_{2}\left(\frac{\theta}{1-\theta}\left(c_{2}-1\right)-\frac{\gamma}{1-\gamma} c_{2}\right)+\rho_{\theta} a_{1} \frac{\gamma}{1-\gamma} c_{2}}{c_{2}-\left(1-a_{1}\right)} \\
A_{21} & =0 \\
A_{22} & =\rho_{\theta}
\end{aligned}
$$


with

$$
\begin{aligned}
& a_{1}=1-\beta \frac{1-\delta}{g} \\
& a_{2}=\frac{1-\theta}{\beta} \frac{\mu}{\alpha}>1 . \\
& c_{2}=\frac{1}{c_{1}}+1=\frac{(1+\sigma)(1-\gamma)}{1-\alpha}>1
\end{aligned}
$$

Determinacy requires that $A_{11}>1$, which always holds.

\section{Proof of Equation $4.21 \mathrm{~b}$}

Setting $\hat{c}_{t}=\varphi_{1} \hat{\theta}_{t}$ and $\hat{\theta}_{t+1}=\rho_{\theta} \hat{\theta}_{t}$, we obtain

$$
\rho_{\theta} \varphi_{1} \hat{\theta}_{t}=A_{11} \varphi_{1} \hat{\theta}_{t}+A_{12} \hat{\theta}_{t}
$$

which solves to equation (4.21a).

Using (4.47) in (4.49) we obtain

$$
\hat{g}_{t+1}=-\left[\left(a_{1} a_{2}\left(1+c_{1}\right)-\frac{g-(1-\delta)}{g}\right) \hat{c}_{t}+a_{1} a_{2}\left(\frac{\theta}{1-\theta}-\left(1+c_{1}\right) \frac{\gamma}{1-\gamma}\right) \hat{\theta}_{t}\right]
$$

Rewrite this to

$$
\begin{aligned}
\varphi_{2}= & \frac{\left(a_{1} a_{2}\left(1+c_{1}\right)-\frac{g-(1-\delta)}{g}\right) A_{12}}{A_{11}-\rho_{\theta}} \\
- & \frac{a_{1} a_{2}\left(\frac{\theta}{1-\theta}-\left(1+c_{1}\right) \frac{\gamma}{1-\gamma}\right)\left(A_{11}-\rho_{\theta}\right)}{A_{11}-\rho_{\theta}} \\
\varphi_{2} & =\frac{\left(a_{1} a_{2}\left(1+c_{1}\right)-\frac{g-(1-\delta)}{g}\right)\left(a_{1} a_{2}\left(\frac{\theta}{1-\theta}\left(c_{2}-1\right)-\frac{\gamma}{1-\gamma} c_{2}\right)+\rho_{\theta} a_{1} c_{2} \frac{\gamma}{1-\gamma}\right)}{\left(A_{11}-\rho_{\theta}\right)\left(c_{2}-\left(1-a_{1}\right)\right)} \\
- & \frac{\left(a_{1} a_{2} c_{2}+\frac{1-\delta}{g}\left(c_{2}-1\right)-\rho_{\theta}\left(c_{2}-\left(1-a_{1}\right)\right)\right) a_{1} a_{2} c_{1}\left(\frac{\theta}{1-\theta}\left(c_{2}-1\right)-\frac{\gamma}{1-\gamma} c_{2}\right)}{\left(A_{11}-\rho_{\theta}\right)\left(c_{2}-\left(1-a_{1}\right)\right)},
\end{aligned}
$$

which solves to (4.21b). 


\section{Proof of Claim 4.22}

We take the derivative given a certain steady state growth rate, as this is also how we calibrate and simulate the model. This means, that we ignore $\partial g / \partial \gamma$ terms.

The denominator's (D) derivative of $\varphi_{2}$ with respect to $\gamma$ is

$$
\begin{aligned}
\frac{\partial D}{\partial \gamma} & =\left(a_{1} a_{2}+\frac{1-\delta}{g}-\rho_{\theta}\right) \frac{\partial c_{2}}{\partial \gamma} \\
& =\left(a_{2}-\rho_{\theta}-\frac{1-\delta}{g}\left(a_{2} \beta-1\right)\right) \frac{\partial c_{2}}{\partial \gamma}
\end{aligned}
$$

where $\frac{\partial c_{2}}{\partial \gamma}<0$. The term in the bracket is positive since $a_{2}>1$ and $\rho_{\theta}<1$. This means that the denominator becomes smaller as $\gamma$ increases.

The numerator's $(\mathrm{N})$ derivative with respect to $\gamma$ is

$$
\begin{aligned}
\frac{\partial N}{\partial \gamma} & =a_{1} a_{1} a_{2} \rho_{\theta} c_{2} \frac{\gamma}{1-\gamma} \frac{\partial c_{1}}{\partial \gamma}+\left(a_{1} a_{2}\left(1+c_{1}\right)-\frac{g-(1-\delta)}{g}\right) \rho_{\theta} a_{1} \frac{1+\sigma}{1-\alpha} \\
& +\rho_{\theta} a_{1} a_{1} a_{2}\left(\frac{\theta}{1-\theta}\left(c_{2}-1\right)-\frac{\gamma}{1-\gamma} c_{2}\right) \frac{\partial c_{1}}{\partial \gamma} \\
& -\left(\rho_{\theta} a_{1} c_{1}-\left(1-\rho_{\theta}\right)\right) a_{1} a_{2} \frac{1}{1-\theta} \frac{1+\sigma}{1-\alpha} \\
& =\left(a_{2}-1-\left(a_{2} \beta-1\right) \frac{1-\delta}{g}\right) \rho_{\theta} a_{1} \frac{1+\sigma}{1-\alpha}+\left(1-\rho_{\theta}\right) a_{1} a_{2} \frac{1+\sigma}{1-\alpha} \frac{1}{1-\theta}>0
\end{aligned}
$$

The numerator's derivative is positive. This proves the claim (4.22) made in the paper.

\section{C Appendix Sticky Price Model}

The linearised equations of (26a) to (26h) are

$$
\begin{aligned}
& \hat{y}_{t}=c_{1} \widehat{m c}_{t}+\frac{\gamma}{1-\gamma}\left(1+c_{1}\right) \hat{\theta}_{t}-c_{1} \hat{c}_{t} \\
& \hat{c}_{t}=\hat{c}_{t+1}+\hat{g}_{t+1}-\frac{r^{k}}{1+r^{k}-\delta} \hat{r}_{t+1}^{k}
\end{aligned}
$$




$$
\begin{aligned}
\hat{g}_{t+1} & =\frac{(1-\theta)}{g} \frac{Y}{K} \hat{y}_{t}-\frac{\theta}{g} \frac{Y}{K} \hat{\theta}_{t}-\frac{1}{g} \frac{C}{K} \hat{c}_{t} \\
\widehat{m c}_{t} & =\frac{1}{1+c_{1}} \hat{r}_{t}^{k}+\frac{c_{1}}{1+c_{1}} \hat{c}_{t}-\frac{\gamma}{1-\gamma} \hat{\theta}_{t} \\
\hat{r}_{t}^{k} & =\frac{1}{a_{1}}\left(\hat{R}_{t}-\hat{\pi}_{t}\right) \\
\hat{R}_{t} & =\frac{\rho_{\pi}}{1+r^{k}-\delta} \hat{\pi}_{t}+a_{4} a_{1} \hat{y}_{t} \\
\hat{\pi}_{t} & =\beta g \hat{\pi}_{t+1}+\chi \widehat{m c}_{t}
\end{aligned}
$$

Combining (4.57e) and (4.57f) yields

$$
\hat{r}_{t}^{k}=\frac{a_{3}}{a_{1}} \hat{\pi}_{t}+a_{4} \hat{y}_{t}
$$

where

$$
\begin{aligned}
& a_{3}=\frac{\rho_{\pi}}{1+r^{k}-\delta}-1 \\
& a_{4}=\frac{\rho_{y}}{r^{k} \pi}
\end{aligned}
$$

Using this and $(4.57 \mathrm{~d})$ in $(4.57 \mathrm{a})$ yields

$$
\hat{y}_{t}=\frac{a_{3}}{a_{1}} \frac{c_{1}}{1-c_{1}\left(a_{4}-1\right)} \hat{\pi}_{t}-\frac{c_{1}}{1-c_{1}\left(a_{4}-1\right)} \hat{c}_{t}+\frac{1+c_{1}}{1-c_{1}\left(a_{4}-1\right)} \frac{\gamma}{1-\gamma} \hat{\theta}_{t}
$$

Using (4.59) in (4.57c) gives

$$
\begin{aligned}
\hat{g}_{t+1} & =\frac{a_{2} a_{3}}{c_{2}-a_{4}} \hat{\pi}_{t}-\left(\frac{a_{1} a_{2}}{c_{2}-a_{4}}+a_{1} a_{2}-\frac{g-(1-\delta)}{g}\right) \hat{c}_{t} \\
& -\frac{a_{1} a_{2}}{c_{2}-a_{4}}\left(\frac{\theta}{1-\theta}\left(c_{2}-a_{4}\right)-\frac{\gamma}{1-\gamma} c_{2}\right) \hat{\theta}_{t}
\end{aligned}
$$


Using (4.60 as well as (4.58) in (4.57b) yields

$$
\begin{aligned}
\left(c_{2}-a_{4}\left(1-a_{1}\right)\right) \hat{c}_{t+1} & =\left(\frac{1-\delta}{g}\left(c_{2}-a_{4}\right)+a_{1} a_{2}\left(c_{2}-a_{4}+1\right)\right) \hat{c}_{t}-a_{2} a_{3} \hat{\pi}_{t} \\
& +a_{1} a_{2}\left(\frac{\theta}{1-\theta}\left(c_{2}-a_{4}\right)-c_{2} \frac{\gamma}{1-\gamma}\right) \hat{\theta}_{t} \\
& +a_{1} a_{4} c_{2} \frac{\gamma}{1-\gamma} \hat{\theta}_{t+1}+a_{3} c_{2} \hat{\pi}_{t+1}
\end{aligned}
$$

Using (4.59) in (4.58), this in (4.57d) and this in (4.57g) yields

$$
\hat{\pi}_{t+1}=\left(\frac{1}{\beta g}-\frac{\chi}{\beta g} \frac{a_{3}}{a_{1}} \frac{c_{2}-1}{c_{2}-a_{4}}\right) \hat{\pi}_{t}+\frac{\chi}{\beta g} \frac{a_{4}-1}{c_{2}-a_{4}} \hat{c}_{t}-c_{2} \frac{\gamma}{1-\gamma} \frac{\chi}{\beta g} \frac{a_{4}-1}{c_{2}-a_{4}} \hat{\theta}_{t}
$$

Substituting (4.62) in (4.61), we can derive matrix $B$.

We write the model as

$$
X_{t+1}^{N K}=B X_{t}^{N K}
$$

where $X_{t}^{N K}=\left[\begin{array}{lll}\hat{c} & \hat{\pi} & \hat{\theta}\end{array}\right]^{\prime}$ and the transition matrix $\mathrm{C}$ is a $3 \times 3$ matrix with the elements

$$
\begin{aligned}
B_{11} & =\frac{\frac{1-\delta}{g}\left(c_{2}-a_{4}\right)+a_{1} a_{2}\left(c_{2}-a_{4}+1\right)+a_{3} c_{2} B_{21}}{c_{2}-a_{4}\left(1-a_{1}\right)} \\
B_{12} & =\frac{a_{3}\left(c_{2} B_{22}-a_{2}\right)}{c_{2}-a_{4}\left(1-a_{1}\right)} \\
B_{13} & =\frac{a_{1} a_{2}\left(\frac{\theta}{1-\theta}\left(c_{2}-a_{4}\right)-c_{2} \frac{\gamma}{1-\gamma}\right)+a_{3} c_{2} B_{23}+a_{1} a_{4} c_{2} \frac{\gamma}{1-\gamma} \rho_{\theta}}{c_{2}-a_{4}\left(1-a_{1}\right)} \\
B_{21} & =\frac{\chi}{\beta g} \frac{a_{4}-1}{c_{2}-a_{4}} \\
B_{22} & =\frac{1}{\beta g}-\frac{\chi}{\beta g} \frac{a_{3}}{a_{1}} \frac{c_{2}-1}{c_{2}-a_{4}} \\
B_{23} & =-c_{2} \frac{\gamma}{1-\gamma} B_{21} \\
B_{33} & =\rho_{\theta}
\end{aligned}
$$


with

$$
\begin{aligned}
& a_{1}=1-\beta \frac{1-\delta}{1+g}>0 \\
& a_{2}=\frac{1-\theta}{\beta} \frac{\mu}{\alpha}>1 \\
& a_{3}=\frac{\rho_{\pi}}{1+r^{k}-\delta}-1 \\
& a_{4}=\frac{\rho_{y}}{\pi} \frac{\mu}{\alpha} \\
& c_{2}=\frac{(1+\sigma)(1-\gamma)}{1-\alpha}>1 .
\end{aligned}
$$

\section{Prove of Signs of $\varphi_{1}$ and $\varphi_{3}$}

Using the method of undetermined coefficients, we can derive

$$
\begin{aligned}
\varphi_{1} & =-\frac{B_{13}}{B_{11}-\rho_{\theta}} \frac{u}{u-v}+\frac{B_{23} B_{12}}{u-v} \\
\varphi_{2} & =\frac{a_{2} a_{3}}{c_{2}-a_{4}} \varphi_{3}-\left(\frac{a_{1} a_{2}}{c_{2}-a_{4}}+a_{1} a_{2}-\frac{g+\delta}{1+g}\right) \varphi_{1} \\
& -\frac{a_{1} a_{2}}{c_{2}-a_{4}}\left(\frac{\theta}{1-\theta}\left(c_{2}-a_{4}\right)-\frac{\gamma}{1-\gamma} c_{2}\right) \\
\varphi_{3} & =-\frac{B_{23}}{B_{22}-\rho_{\theta}} \frac{u}{u-v}+\frac{B_{13} B_{21}}{u-v}
\end{aligned}
$$

with

$$
\begin{aligned}
& u=\left(B_{11}-\rho_{\theta}\right)\left(B_{22}-\rho_{\theta}\right) \\
& v=B_{12} B_{21}
\end{aligned}
$$

We introduce the $2 \times 2$ matrix $B^{\prime}$ with the elements $B_{11}, B_{12}, B_{21}$ and $B_{22}$ and the Eigenvalues $\lambda_{1,2}$. The function $u-v$ can be rewritten as

$$
\begin{aligned}
& u-v=\rho_{\theta}^{2}-\rho_{\theta} \underbrace{\left(B_{11}+B_{22}\right)}_{\text {trace }\left(B^{\prime}\right)}+\underbrace{\left(B_{11} B_{22}-B_{12} B_{21}\right)}_{\left|B^{\prime}\right|} \\
& u-v=\rho_{\theta}^{2}-\rho_{\theta}\left(\lambda_{1}+\lambda_{2}\right)+\lambda_{1} \lambda_{2}
\end{aligned}
$$

$u-v$ is a quadratic function in $\rho_{\theta}$ with two nulls at $\lambda_{1}$ and $\lambda_{2}$. Since determinacy requires $\lambda_{1,2}>1$ (according to the Blanchard-Kahn conditions 
(Blanchard and Kahn, 1980)), while $\rho_{\theta}<1, u-v$ is clearly positive.

We can rewrite

$$
\begin{aligned}
\varphi_{1} & =-\frac{B_{22}-\rho_{\theta}}{u-v} \frac{a_{1} a_{2}\left(\frac{\theta}{1-\theta}\left(c_{2}-a_{4}\right)\right)}{c_{2}-a_{4}\left(1-a_{1}\right)} \\
& +\frac{B_{22}-\rho_{\theta}}{u-v} c_{2} \frac{\gamma}{1-\gamma}\left[\frac{B_{21} a_{3}\left(a_{2}-c_{2} \rho_{\theta}\right)}{\left(B_{22}-\rho_{\theta}\right)\left(c_{2}-a_{4}\left(1-a_{1}\right)\right)}+\frac{a_{1}\left(a_{2}-a_{4} \rho_{\theta}\right)}{c_{2}-a_{4}\left(1-a_{1}\right)}\right]
\end{aligned}
$$

The first term is definitely negative. The second term is most positive when $\rho_{\theta}=0$.

The sign of $\varphi_{1}$ then depends negatively on the sign of

$$
\left(\frac{\theta}{1-\theta}\left(c_{2}-a_{4}\right)-c_{2} \frac{\gamma}{1-\gamma}\right)-\frac{a_{3}}{a_{1}} \frac{B_{21}}{B_{22}} c_{2} \frac{\gamma}{1-\gamma}
$$

The first bracket is negative when the GG curve shifts right. In this case the direct productivity effect of government spending is stronger than the negative resource effect. The second term shows the New Keynesian effect of output being possibly above its steady state level, which requires $a_{4}>$ 1. This additionally shifts the GG-curve. Since under $\rho_{\theta}=0$ the CCcurve does not shift down, $\varphi_{1}>0$ is possible. However, we use realistic parameterisations where the direct productivity effect is not that big, as well as where government spending shocks are persistent. Therefore, $\varphi_{1}<0$ will hold.

We can rewrite

$$
\begin{aligned}
\varphi_{3} & =\frac{B_{21}}{u-v}\left(c_{2} \frac{\gamma}{1-\gamma}\left(B_{11}-\rho_{\theta}\right)+B_{13}\right) \\
\varphi_{3} & =\frac{B_{21}}{u-v} \frac{c_{2}-a_{4}}{c_{2}-a_{4}\left(1-a_{1}\right)}\left[a_{1} a_{2} \frac{\theta}{1-\theta}+c_{2} \frac{\gamma}{1-\gamma}\left(a_{1} a_{2}+\frac{1-\delta}{g}-\rho_{\theta}\right)\right]
\end{aligned}
$$

Since the bracket is always positive, the sign of $\varphi_{3}$ depends on the sign of $B_{21}$ and thus on the sign of $a_{4}-1$. 


\section{Equation $4.34 \mathrm{~b}$}

Using the method of undetermined coefficients, we can derive

$$
\begin{gathered}
\rho_{\theta} \varphi_{1} \hat{\theta}_{t}=B_{11} \varphi_{1} \hat{\theta}_{t}+\varphi_{3} B_{12} \hat{\theta}_{t}+B_{13} \hat{\theta}_{t} \\
\rho_{\theta} \varphi_{3} \hat{\theta}_{t}=B_{21} \varphi_{1} \hat{\theta}_{t}+\varphi_{3} B_{22} \hat{\theta}_{t}+B_{23} \hat{\theta}_{t},
\end{gathered}
$$

which solves to equations (4.34a) and (4.34c). Equation (4.34b) is simply (4.60) in the notation of the method of undetermined coefficients. 



\section{5}

\section{Persistence of Shocks using a New Keynesian Endogenous Growth Model}

\subsection{Introduction}

Traditional New Keynesian models deal with temporary fluctuations of economic variables around a steady state. The effects of monetary and fiscal policy on these fluctuations are well known. Once these fluctuations fade away, the economy returns to its predetermined steady state. Thus, both shocks and policy don't have persistent effects.

Section 2.4 of the literature review made clear that this is inappropriate. Temporary fluctuations in output have persistent effects. This implies that policy choices do not only have short run but also long run consequences. To our knowledge, the only existing paper discussing this aspect using a New Keynesian model is Rannenberg (2009) in the context of the impact of monetary policy on the NAIRU.

This chapter presents a New Keynesian endogenous growth model, where the source as well as the degree of endogenous growth is adaptable. Crucially, it also features investment demand, thereby extending the supply-based determination of growth from Chapter 4. We refrain from any further rigidities besides price stickiness in order to show as clearly as possible the additional value of endogenous growth in the New Keynesian 
model. However, this model can be extended by any rigidities the standard New Keynesian model knows.

Chapter 3 concluded that positive long run effects of government spending on private consumption can increase current consumption demand so far that consumption is actually crowded in. While the previous chapter could not show this due to the absence of investment, and thus excess demand, this chapter will show that consumption is actually crowded in by government spending if learning-by-doing depends sufficiently on current economic conditions.

Endogenous growth adds an additional determinant to consumption and investment demand. During favourable current economic conditions learning-by-doing is enhanced, thereby increasing future output and current demand. Therefore, similar sized shocks have a larger short run consequence compared to the exogenous growth model. Moreover, shocks also have persistent effects due to the presence of the endogenous growth channel. We will show these short and long run consequences for a variety of shocks. We can furthermore confirm the result by Rannenberg (2009) that a larger weight of monetary policy on the output gap leads to a smaller long-run output loss in face of an adverse productivity shock.

We furthermore extend the model by a zero bound constraint of the nominal interest rate. While the general consequences are the same as in an exogenous growth New Keynesian model, endogenous growth amplifies these effects somewhat due to the depressing effect of adverse current economic conditions on demand. Furthermore, the inability of monetary policy to react to deflationary conditions also leads to a permanent output loss. However, the fiscal multiplier, which is large under a zero bound to begin with, also increases with endogenous growth. This is in line with the finding of Christiano et al. (2009) (see Section 2.3.3). Finally, we can also show that the paradox of thrift, where a higher savings desire will actually lead to lower savings and investment, can actually be present in the New Keynesian endogenous growth model.

This chapter first presents the New Keynesian endogenous growth model. Section 5.3 presents our approach to simulate the model. Afterwards, Section 5.4 presents the results. Finally, Section 5.5 concludes. 


\subsection{The Model}

The model employed in this chapter is to a large part similar to the one in the previous chapter. Nevertheless, we restate the complete model derivation to avoid confusion. However, a crucial difference lies in the specification of the endogenous growth process itself.

\subsubsection{Investment Demand in Endogenous Growth Models}

In the textbook Solow growth model household saving is the primary determinant of investment and the rate of growth. This is no different in endogenous growth models. Installed capital delivers a certain rate of return, which households use in their savings decision, thereby providing funds for investment. Therefore, a higher interest rate will increase savings and growth. The previous chapter showed that an endogenous growth model with sticky prices as well as a monetary policy rule also adheres to that logic. A higher interest rate set by the central bank will increase saving, investment and growth, as well as it leads to some deviations of output from its flexible price level since the interest rate is not at the NRRI.

The fact that a higher interest rate set by the central bank increases investment runs against the intuition of New Keynesian models. One would expect the reverse to occur since a higher interest rate increases the required return to capital and therefore lowers the required future capital stock. However, this logic is not present in the endogenous growth model of Chapter 4, since installed capital on the aggregate does not face diminishing returns. This is crucial for steady state endogenous growth, but leads to strange results when looking at deviations from a steady state, from a New Keynesian perspective. Therefore, the challenge is to construct a knowledge creation process that allows constant returns to capital on the steady state growth path but allows decreasing returns when dealing with deviations from that steady state path. 


\subsubsection{The Endogenous Growth Specification}

The knowledge creation process is a learning-by-doing specification and is given by

$$
\begin{aligned}
& T_{t+1}=B X_{t}^{\eta_{1}} T_{t}^{\left(1-\eta_{1}\right)} \varepsilon_{t}^{T}, \\
& \text { with } \\
& \qquad X_{t}=K_{t}^{\eta_{2}} Y_{t}^{\left(1-\eta_{2}\right)} .
\end{aligned}
$$

$T$ is the level of technology used in a Cobb-Douglas production function (specified in Section 5.2.4). $B$ is a scaling parameter, $X$ is the level of economic activity relevant for learning-by-doing, $K$ is the capital stock, $Y$ is output and $\eta_{1}$ and $\eta_{2}$ are parameters which will be explained in more detail later. $\varepsilon_{t}^{T}$ is a research shock.

Defining the gross growth rate of technology by $g_{t+1}=\frac{T_{t+1}}{T_{t}},(5.1)$ can be rewritten as

$$
g_{t+1}=\frac{T_{t+1}}{T_{t}}=B\left(\frac{K_{t}}{T_{t}}\right)^{\eta_{1} \eta_{2}}\left(\frac{Y_{t}}{T_{t}}\right)^{\eta_{1}\left(1-\eta_{2}\right)} e^{\varepsilon_{t}^{T}}
$$

An inspection of (5.3) reveals that given a steady state level of $\frac{K}{T}$ and $\frac{Y}{T}$, technology growth will also be constant. Therefore, it fulfills the requirement for providing endogenous growth. At the same time, it should be clear that a change in capital does not lead to a 1-to-1 change in technology, thereby allowing decreasing returns to capital in the short run.

While the technology specification (5.1) looks ad-hoc, it isn't. Romer (2006) shows in a textbook treatment the endogenous growth properties of a technology accumulation function of the general form

$$
\dot{A}(t)=B\left[a_{K} K(t)\right]^{\beta}\left[a_{L} L(t)\right]^{\gamma} A(t)^{\theta},
$$

where $a_{K}$ and $a_{L}$ are the proportions of the resource used in knowledge production, $A$ is technology, and $K$ and $L$ are capital and labour. Romer (2006) also treats the case of learning-by-doing, where labour and capital is not deliberately used in knowledge production, thus having $a_{K}=a_{L}=1$, 
and shows that the endogenous growth properties do not change. ${ }^{1}$ A close inspection reveals that our knowledge creation funcion (5.1) is simply a discrete time special case of (5.4) with according parameter restrictions. Furthermore, Comin and Gertler (2006) use a similar knowledge creation function where last period's technology also determines knowledge.

In steady state all growing variables grow at rate $g$. All growing variables are therefore represented in terms of $T$ in order to be able to analyse deviations from steady states using the usual methodology.

\subsubsection{Source and Strength of Endogenous Growth}

The knowledge creation function (5.1) contains 2 parameters $\eta_{1}$ and $\eta_{2}$ which determine the strength and the source of endogenous growth. Chapter 4 uses capital as the source for learning by doing, therefore implying $\eta_{2}=1$. In such a case path dependence of economic variables is determined by deviations of investment from steady state. A temporary fall in investment will lower the capital/technology ratio and thus technological progress, thereby leading to a negative level effect for all growing variables.

On the other hand, the case of $\eta_{2}=0$ implies that output is the source for learning by doing. This means that, next to capital, variations in labour supply cause a path dependence of the economy. As Section 5.4 will show, this specification will lead to stronger permanent effects of temporary shocks that affect labour demand or supply. This chapter will illustrate the effects of choosing $\eta_{2}=0$ as well as $\eta_{2}=1$ as extreme cases. However, any choice of $\eta_{2}$ is possible.

Setting $\eta_{1}=0$ transforms the model to an exogenous growth model growing at rate $B$. Due to the easy implementation of this case this will be our benchmark specification in the simulations in Section 5.4. The opposing case would be $\eta_{1}=1$. In this case, current technology level depends on past periods capital stock or output. Given capital stock as a source of endogenous growth $\left(\eta_{2}=1\right)$, this case comes quite close to the Romer (1986) AKL model under the assumption that used capital takes one period to become general knowledge. Thus, this is still not the model setup used

\footnotetext{
${ }^{1}$ This should be no surprise as technically the $a_{K}$ and $a_{L}$ terms go into the scaling parameters of the production and the knowledge accumulation function.
} 
in Chapter 4. However, simulations with $\eta_{1}=1$ produced a wave pattern in the impulse response function, hinting at an instability, probably due to the weak investment demand present in such a model. We therefore will use $\eta_{1}=0.5$ as an illustrative case for an endogenous growth model. Varying the degree of $\eta_{1}$ changes the relative size of path dependence of the economy. The exact determination of $\eta_{1}$ and $\eta_{2}$ is an empirical question.

\subsubsection{Firms}

The production function for firm $i$ in period $t$ is specified as a Cobb-Douglas function

$$
Y_{t}^{i}=A\left(K_{t}^{i}\right)^{\alpha}\left(L_{t}^{i}\right)^{1-\alpha} G_{t}^{\gamma} T_{t}^{1-\alpha-\gamma} e^{\varepsilon_{t}^{A}}
$$

The variables $Y_{t}^{i}, K_{t}^{i}$ and $L_{t}^{i}$ represent output, capital and employment, respectively. $G_{t}$ is productive government spending and is not firmspecific. $A_{t}$ is a productivity shift parameter and $\varepsilon^{A}$ is a productivity shock. Furthermore, $T_{t}$ is defined in Section 5.2.2, eq. (5.1), and is also not firm-specific.

Aggregating across all identical firms and dividing by $T$, we obtain

$$
\frac{Y_{t}}{T_{t}}=A\left(\frac{K_{t}}{T_{t}}\right)^{\alpha} L_{t}^{1-\alpha}\left(\frac{G_{t}}{T_{t}}\right)^{\gamma} e^{\varepsilon_{t}^{A}}
$$

This shows that given government spending is growing with $T$ in a steady state, and given a steady state labour supply, output relative to $T$ will also be in a steady state. In equation (5.18) we propose a government spending rule where steady state spending is a constant share of output, thus fulfilling this condition.

Each firm i minimises costs $r_{t}^{k} K_{t}^{i}+w_{t} L_{t}^{i}$ subject to output produced. The variables $r_{t}^{k}$ and $w_{t}$ represent the return on capital in use and the wage rate, respectively, in period $t$. The firm takes $r_{t}^{k}$ and $w_{t}$ as given. Solving the Lagrangian and interpreting the Lagrange multiplier as real marginal 
cost $m c_{t}$, we obtain the first order conditions:

$$
\begin{aligned}
r_{t}^{k} & =m c_{t} \alpha \frac{Y_{t}^{i}}{K_{t}^{i}}, \\
w_{t} & =m c_{t}(1-\alpha) \frac{Y_{t}^{i}}{L_{t}^{i}} .
\end{aligned}
$$

Aggregating across all identical firms, equations (5.7a) and (5.7b) become

$$
\begin{aligned}
& r_{t}^{k}=m c_{t} \alpha A\left(\frac{K_{t}}{T_{t}}\right)^{-(1-\alpha)} L_{t}^{1-\alpha}\left(\frac{G_{t}}{T_{t}}\right)^{\gamma} e^{\varepsilon_{t}^{A}}, \\
& \frac{w_{t}}{T_{t}}=m c_{t}(1-\alpha) A\left(\frac{K_{t}}{T_{t}}\right)^{\alpha} L_{t}^{-\alpha}\left(\frac{G_{t}}{T_{t}}\right)^{\gamma} e^{\varepsilon_{t}^{A}} .
\end{aligned}
$$

Equation (5.8a) shows that the steady state return to capital will be constant given that $\frac{K}{T}, \frac{G}{T}$ and $L$ are constant in steady state, thus fulfilling the conditions for endogenous growth. It furthermore shows that productive government spending will increase the return to both capital and labour, since it increases output without receiving factor payment.

Substituting away labour from (5.8a) and (5.8b) yields the equation for real marginal costs

$$
m c_{t}=\frac{\left(r_{t}^{k}\right)^{\alpha}\left(\frac{w_{t}}{T_{t}}\right)^{1-\alpha}}{A\left(\frac{G_{t}}{T_{t}}\right)^{\gamma} \alpha^{\alpha}(1-\alpha)^{1-\alpha} e^{\varepsilon_{t}^{A}} .}
$$

We assume a standard set-up of monopolistic competition where firms face a finite elasticity of demand and absent of rigidities set their price at a desired mark-up $\mu>1$ above nominal marginal costs. We introduce Calvo (1983) price rigidities, where a fraction $\phi$ cannot reset its price optimally in a certain period. Therefore, the aggregate mark-up in the economy does not necessarily equal the desired mark-up, so that real marginal costs can differ from their flexible price level. For a detailed derivation, see for example Woodford (2003).

Higher marginal costs will lead to higher inflation $\pi$, as shown by the 
New Keynesian Phillips curve. ${ }^{2}$

$$
\hat{\pi}_{t}=\beta \hat{\pi}_{t+1}+\chi \widehat{m c}_{t}
$$

where $\chi=\frac{(1-\phi)(1-\beta \phi)}{\phi}, \phi$ is the percentage of firms not re-optimising their price, $\beta$ is the time discount factor and $\hat{x}$ denotes the percentage deviation of a variable $x$ from its steady state value.

\subsubsection{Households}

The representative household maximises its intertemporal utility over consumption $C$ and leisure $\Lambda$ subject to a budget constraint and a capital accumulation equation. This can be specified as follows:

$$
\max _{C, \Lambda} \sum_{t=0}^{\infty} \beta^{t} u_{t}(C, \Lambda),
$$

where $\beta<1$ is the time discount factor.

We restrict our attention to the commonly used CES function with logutility for consumption. We furthermore use the common specification of introducing labour supply $L$ directly in the utility function, where $L=1-\Lambda$ when we normalise total available time to unity. We thus obtain

$$
u_{t}=e^{\left(\varepsilon_{t}^{C}\right)}\left(\log \left(C_{t}\right)-\frac{L_{t}^{1+\sigma}}{1+\sigma}\right)
$$

where $\sigma>0$ is the inverse of the intertemporal elasticity of labour supply and $\varepsilon_{t}^{C}$ is a preference shock.

Utility is maximised subject to the budget constraint and the capital accumulation identity

$$
\begin{aligned}
w_{t} L_{t}+R_{t-1} B_{t} / P_{t}+r_{t}^{k} K_{t}+\kappa_{t} & \geq C_{t}+B_{t+1} / P_{t}+I_{t}+\tau_{t} \\
K_{t+1}-(1-\delta) K_{t} & =I_{t}-\frac{\sigma_{I}}{2}\left(e^{\varepsilon_{t}^{I}} \frac{I_{t}}{K_{t}}-\overline{\left(\frac{I}{K}\right)}\right)^{2} K_{t},
\end{aligned}
$$

where $\kappa_{t}$ are profits from firm ownership of households and $\tau_{t}$ are lump sum

\footnotetext{
${ }^{2}$ The derivation is shown in Appendix 4.A.
} 
taxes. $R_{t-1}$ is the gross nominal interest rate for bonds held from period $t-1$ to $\operatorname{period}^{3} t$ and $\delta$ is the capital depreciation rate. $C_{t}$ is consumption, $I_{t}$ is investment, $P_{t}$ is the price level and $B_{t}$ is the stock of bonds in period $t$. As usual in the New Keynesian literature we introduce quadratic capital adjustment cost in deviation from the steady state investment-capital ratio, which is given by $\frac{I}{K}=(g-1)+\delta$. $e^{\varepsilon_{t}^{I}}$ is a shock to the costs of investment.

Household optimisation leads to the following first order conditions:

$$
\begin{aligned}
C_{t} & =C_{t+1} \frac{1}{\beta} \frac{\pi_{t+1}}{R_{t}} e^{\varepsilon_{t}^{C}-\varepsilon_{t+1}^{C}} \\
r_{t+1}^{k} & =\frac{R_{t}}{\pi_{t+1}} \frac{1}{1-\sigma_{I} e^{\varepsilon_{t}^{I}}\left(e^{\varepsilon_{t}^{I}} \frac{I_{t}}{K_{t}}-\overline{\left(\frac{I}{K}\right)}\right)}-\frac{1-\delta+\frac{\sigma_{I}}{2}\left(\left(e^{\varepsilon_{t+1}^{I}} \frac{I_{t+1}}{K_{t+1}}\right)^{2}-\overline{\left(\frac{I}{K}\right)}^{2}\right)}{1-\sigma_{I} e^{\varepsilon_{t+1}^{I}}\left(e^{\varepsilon_{t+1}^{I}} \frac{I_{t+1}}{K_{t+1}}-\overline{\left(\frac{I}{K}\right)}\right)} \\
w_{t} & =L_{t}^{\sigma} C_{t}
\end{aligned}
$$

Equation (5.14a) is the standard Euler equation, showing the intertemporal consumption path depending on the real interest rate on bonds, $\frac{R}{\pi}$, as well as a preference shock $\varepsilon_{t}^{C}-\varepsilon_{t+1}^{C}$.

Equation (5.14b) relates the return to capital to the real interest rate. Without capital adjustment costs, $\sigma_{I}=0$, the return on capital net of depreciation equals the real interest rate. Current higher investment increases required next period's return to capital due to the cost incurred of installing the capital. Higher future cost of installing capital lowers required return. The intuition is indirect since more installed capital in period $t+1$ will lower future adjustment costs. An investment shock (a positive $\varepsilon_{t}^{I}-\varepsilon_{t+1}^{I}$ ) raises the required return to capital, thereby lowering investment. The last condition shows the equality between the marginal utility of consumption and leisure, where the relative price of leisure in terms of consumption is the real wage.

\footnotetext{
${ }^{3}$ This timing is also used in Smets and Wouters (2003) and Galí et al. (2007).
} 


\subsubsection{Equilibrium}

The full model is a collection of above equations as well as the resource constraint.

$$
\begin{aligned}
\frac{Y_{t}}{T_{t}} & =\frac{C_{t}}{T_{t}}+\frac{I_{t}}{T_{t}}+\frac{G_{t}}{T_{t}} \\
\frac{Y_{t}}{T_{t}} & =A\left(\frac{K_{t}}{T_{t}}\right)^{\alpha} L_{t}^{1-\alpha}\left(\frac{G_{t}}{T_{t}}\right)^{\gamma} e^{\varepsilon_{t}^{A}} \\
\frac{C_{t}}{T_{t}} & =\frac{C_{t+1}}{T_{t+1}} g_{t+1} \frac{1}{\beta} \frac{\pi_{t+1}}{R_{t}} e^{\varepsilon_{t}^{C}-\varepsilon_{t+1}^{C}} \\
\frac{I_{t}}{T_{t}} & =\frac{K_{t+1}}{T_{t+1}} g_{t+1}-(1-\delta) \frac{K_{t}}{T_{t}} \\
g_{t+1} & =B\left(\frac{K_{t}}{T_{t}}\right)^{\eta_{1} \eta_{2}}\left(\frac{Y_{t}}{T_{t}}\right)^{\eta_{1}\left(1-\eta_{2}\right)} e^{\varepsilon_{t}^{T}} \\
\frac{K_{t}}{T_{t}} & =\frac{\alpha}{1-\alpha} L_{t} \frac{w_{t}}{T_{t}} \frac{1}{r_{t}^{k}} \\
r_{t+1}^{k} & =\frac{R_{t}}{\pi_{t+1}} \frac{1-\sigma_{I} e^{\varepsilon_{t}^{I}}\left(e^{\varepsilon_{t}^{I}} \frac{I_{t}}{K_{t}}-\overline{\left(\frac{I}{K}\right)}\right)}{1-\delta+\frac{\sigma_{I}}{2}\left(\left(e^{\varepsilon_{t+1}^{I}} \frac{I_{t+1}}{K_{t+1}}\right)^{2}-\overline{\left(\frac{I}{K}\right)^{2}}\right)} \\
\frac{w_{t}}{T_{t}} & =L_{t}^{\sigma} \frac{C_{t}}{T_{t}} \\
m c_{t} & =\frac{\left(r_{t}^{k}\right)^{\alpha}\left(\frac{w_{t}}{T_{t}}\right)^{1-\alpha}}{\left.A\left(\frac{G_{t}}{T_{t}}\right)^{\gamma} \alpha^{\alpha}(1-\alpha)^{1-\alpha} e^{\varepsilon_{t} \varepsilon_{t+1}^{I}} \frac{I_{t+1}}{K_{t+1}}-\overline{\left(\frac{I}{K}\right)}\right)}
\end{aligned}
$$

The New Keynesian Phillips curve (5.10) translates marginal costs to inflation. All that is needed to close the model are the policy processes for the interest rate, government spending and taxes. 


\subsubsection{Policy}

The central bank follows a Taylor rule to determine the notational interest rate.

$$
R_{t}^{n o t}=R^{*}+\rho_{\pi}\left(\pi_{t}-\bar{\pi}\right)+\rho_{y}\left(\frac{\frac{Y t}{T_{t}}-\overline{\left(\frac{Y}{T}\right)}}{\overline{\left(\frac{Y}{T}\right)}}\right)+\varepsilon_{t}^{R},
$$

where $R^{*}$ is the target rate implied by the steady state return to capital, $\bar{\pi}$ is the target inflation rate, and $\overline{\left(\frac{Y}{T}\right)}$ is the target output-technology ratio. The inclusion of the output gap in this manner follows Section 4.4 and allows a simple linearisation around the steady state.

The actual interest rate is determined by

$$
R_{t}=\max \left(0, R_{t}^{n o t}\right)
$$

This introduces a non-linearity into the model, as sometimes the interest rate setting might be restricted by the zero bound. This requires special attention in the solution procedure, shown in Appendix 5.A.

The government finances all its spending using lump-sum taxation. Government spending on the steady state growth path is a fraction $\theta$ of output. $\varepsilon_{t}^{G}$ is a shock to government spending.

$$
\frac{G_{t}}{T_{t}}=\left(\theta \frac{Y}{T}\right) e^{\varepsilon_{t}^{G}} .
$$

The absence of a time subscript on $\frac{Y}{T}$ is deliberate. This specification implies that government spending does not fluctuate with output when it moves away from its steady state level, but is allowed to grow with output at the steady state pace. When written in a form as deviation from steady state, we obtain a standard formulation of the spending process.

\subsubsection{Steady State}

In steady state, $m c=1 / \mu$ holds. Furthermore, we can drop time subscripts. From the Euler equation (imposing steady state $\frac{C}{T}$ ) and the equality of net 
returns to capital and bonds we can obtain

$$
g-1+\delta=\beta r^{k}-(1-\beta)(1-\delta)
$$

We also know steady state investment to be

$$
\frac{I}{T}=\frac{K}{T}(g-1+\delta)
$$

We furthermore know from 5.7a that

$$
r^{k}=\frac{\alpha}{\mu} \frac{Y}{T}\left(\frac{K}{T}\right)^{-1}
$$

Steady state consumption is

$$
\frac{C}{T}=(1-\theta) \frac{Y}{T}-\frac{I}{T}
$$

Steady state output is given by

$$
\frac{Y}{T}=\left(A \theta^{\gamma}\left(\frac{K}{T}\right)^{\alpha} L^{1-\alpha}\right)^{\frac{1}{1-\gamma}}
$$

Combining (5.8b) and (5.14c) we obtain steady state labour supply

$$
L=\left[\frac{\left(\frac{1-\alpha}{1-\gamma} \frac{1}{\mu}\right)^{1-\gamma} A \theta^{\gamma}\left(\frac{K}{T}\right)^{\alpha}}{\left(\frac{C}{T}\right)^{1-\gamma}}\right]^{\frac{1}{\sigma+\alpha-\gamma(1+\sigma)}}
$$

To determine the steady state, one has to analyse the labour supply - growth tradeoff, as described in Chapter 4 and in Turnovsky (2000). A precise solution can be derived using equations (5.19a) to (5.19f) when regarding $\frac{K}{T}(1-\beta)(1-\delta) \approx 0$. Then we obtain

$$
L \approx\left(\frac{\frac{1-\alpha}{\alpha} \frac{1}{\beta}}{\frac{(1-\theta) \mu}{\alpha \beta}-1}\right)^{\frac{1}{1+\sigma}}
$$

The return to capital is then determined, using labour supply, by the 
equation

$$
\left(\frac{\beta\left(1+r^{k}-\delta\right)}{B}\right)^{\frac{1-\alpha}{\alpha+(1-\alpha) \eta_{2}}}\left(r^{k}\right)^{\eta_{1}}=\left(\frac{\alpha}{\mu}\right)^{\eta_{1}}\left(A \theta^{\gamma} L^{1-\alpha}\right)^{\frac{\eta_{1}}{\alpha+(1-\alpha) \eta_{2}}} .
$$

Using (5.19a), this translates directly into growth. When $\eta_{1}=0, g=$ $B$ holds, consistent with an exogenous growth rate. When $\eta_{1}>0$, all other factors influence the return to capital and thus growth is determined endogenously.

\subsection{Methodology}

All variables shown in equations (5.15a) to (5.15i) possess a steady state. These equations are linearised around that steady state using a first order Taylor approximation. Afterwards, the model dynamics are simulated using the $P-Q$ approach. Appendix 5.A shows the solution strategy used for when the zero bound holds. The simulation requires a whole range of parameters. Since the aim is to illustrate the additional value of endogenous growth, we calibrate the parameters using existing literature.

\subsubsection{Calibration}

We simulate the model for quarterly periods. Table 5.1 shows the parameters chosen to simulate the model. Most of them are standard parameters with little importance to this paper's results. While Galí et al. (2007) choose an inverse elasticity of labour supply of $\sigma=0.2$, this value is estimated by Smets and Wouters (2003) to $\sigma=2.1$. A lower parameter increases the labour supply response to shocks, and thereby increases the chances for consumption crowding-in to government spending. $\sigma=1$ is the value chosen by Linnemann and Schabert in various papers for representative purposes. The capital adjustment cost parameter is set to $\sigma_{I}=\frac{\delta}{0.06(g-1+\delta)} \approx 14$, following the logic in Christiano et al. (2009). We simulate the model with both productive and unproductive government spending to illustrate its contribution.

The price stickiness parameter is rather high. However, Hall (2009) argues that a very high degree of price stickiness is needed for a realistic 
Table 5.1: Calibrated Parameters for Quarterly Periods

\begin{tabular}{|r|c|l|}
\hline \hline Parameter & Value & Source \\
\hline Standard Parameters & & \\
time discount $\beta$ & 0.99 & standard \\
capital share $\alpha$ & 0.33 & standard \\
depreciation $\delta$ & 0.025 & standard \\
inverse $L^{S}$ elasticity $\sigma$ & 1 & Linnemann and Schabert (2003a) \\
markup $\mu$ & 1.2 & standard \\
capital adj. cost $\sigma_{I}$ & $\approx 14$ & Christiano et al. (2009) \\
government share $\theta$ & 0.2 & Baxter and King (1993) \\
shock autocorrelation $\rho^{\varepsilon}$ & 0.9 & Galí et al. (2007) \\
\hline New Keynesian Parameters & \\
price stickiness $\phi$ & 0.85 & Hall (2009) \\
Taylor rule $\rho_{\pi}$ & 1.7 & Smets and Wouters (2003) \\
Taylor rule $\rho_{y}$ & 0.11 & Smets and Wouters (2003) \\
inflation target $\bar{\pi}$ & 1.005 & ECB target \\
scaling parameter $B$ & 1.006 & Comin and Gertler (2006) \\
endog. growth strength $\eta_{1}$ & $0 ; 0.5$ & \\
source of endog. growth $\eta_{2}$ & $1 ; 0$ & \\
government prod $\gamma$ & $0 ; 0.1$ & Romp and de Haan (2007) \\
\hline \hline
\end{tabular}

variability of the mark-up. In this model, all rigidity and thus mark-up variability has to come from $\phi$, thus justifying this choice. The output parameter on monetary policy is sometimes set to zero by authors that try to show crowding in of consumption (Linnemann and Schabert, 2003a; Galí et al., 2007). The reason is simply that higher interest rates lower consumption demand. We will use the parameters found by Smets and Wouters (2003), but we will also show the effect of having a strong reaction to the output gap by using $\rho_{y}=0.5$.

There is no reference paper for our technology evolution function. We set $B=1.006$ to obtain an annualised steady state growth of $2.1 \%$ in the exogenous growth model (used in Comin and Gertler, 2006). We furthermore use this steady state growth rate to define the steady state values of $r^{k}, Y / T$ and so forth. This implicitly defines A, since A scales the 
model's return to capital and steady state growth (see (5.21)). We simulate the model for exogenous growth $\left(\eta_{1}=0\right)$ as well as for endogenous growth $\left(\eta_{1}=0.5\right)$. This value is arbitrary. However, this model's results are not sensitive to the exact choice of $\eta_{1}$. Section 5.4.6 shortly discusses the implication of $\eta_{1}=0.1$. Different sources of endogenous growth, output or capital, are also shown using $\eta_{2}=0$ and $\eta_{2}=1$. Any intermediate combination is possible as well, with predictable results.

Finally, we specify that shocks $\varepsilon^{x}$ develop according to the process

$$
\varepsilon_{t}^{x}=\rho^{\varepsilon} \varepsilon_{t-1}^{x} \quad x \in[A, G, C, I, T],
$$

where we use an autocorrelation coefficient for shocks of $\rho^{\varepsilon}=0.9$. Note that these are not stochastic but deterministic shocks. For the interest rate shock the interest rate is set discretely to $1 \%$ below steady state for one year. When simulating the effect of government spending while the zero bound on the interest rate holds, we set government spending to a $10 \%$ increase for the duration of the zero bound and zero thereafter.

\subsubsection{Analysed Scenarios}

We present a number of scenarios in order to highlight the valuable additions endogenous growth makes to a New Keynesian model. The first two scenarios (Section 5.4.1) are meant to illustrate in what way the New Keynesian model changes when endogenous growth is introduced. To that aim we simulate a negative investment shock, an increase in capital adjustment $\operatorname{costs} \varepsilon_{t}^{I}$, as well as a negative research shock, a fall in $B$.

In Section 5.4.2, we show the consumption crowding-in potential of the New Keynesian endogenous growth model. To that aim, we introduce a government spending shock, $\varepsilon_{t}^{G}$, in the size of $2 \%$ of GDP. We furthermore show the impact of having productive government spending by applying the government spending shock when spending is unproductive $(\gamma=0)$ and productive $(\gamma=0.1)$.

Section 5.4.3 shows that monetary policy has not only short run but also long run consequences in a New Keynesian endogenous growth model. To that aim, we first subject the model to a simple interest rate shock, where the nominal interest rate is set at $1 \%$ below its steady state value 
for 1 year. Afterwards, we show the short and long run consequences of alternative monetary policy rules in face of a negative productivity shock. This requires the simulation of a negative productivity shock $\left(\varepsilon_{t}^{A}\right)$ with a Taylor rule parameter on output of $\rho_{y}=0.11$ (baseline) as well as $\rho_{y}=0.5$

In a liquidity trap monetary policy looses its power to influence the economy. We simulate the effect of such a liquidity trap by subjecting the model to a simultaneous negative investment $\left(\varepsilon_{t}^{I}\right)$ and consumption $\left(\varepsilon_{t}^{C}\right)$ shock (Section 5.4.4). This lowers demand so much that deflation occurs and the nominal interest rate should be set at a below zero value. In this case, the zero interest rate becomes binding. We show the net effect of this zero bound by subtracting the response of the economy with a zero bound from the response when monetary policy could set below zero interest rate, thus follow the Taylor rule normally. We furthermore show the effect of government spending in the presence of a zero bound. Due to the linearity of our model, we can simulate this as a discrete government spending shock of $2 \%$ of GDP for 4 quarters while holding the nominal interest rate fixed.

The final case studied in Section 5.4.5 concerns the paradox of thrift. We introduce a savings shock, in form of a negative consumption preference shock $\left(\varepsilon_{t}^{C}\right)$. We will show that such a shock can reduce demand so far that investment actually falls.

\subsection{Results}

We present the effect of a shock as a percentage deviation to a scenario without a shock occurring. We therefore calculate the path of the actual growing variables by multiplying with $T$, and then by taking the percentage deviation to a baseline scenario without any shocks. In this way we see long run effects caused by short run deviations in the growth rate, something which a standard New Keynesian model cannot show. All graphs show years on the $\mathrm{x}$-axis (even though the model is simulated with quarterly periods) and percentage difference from the baseline scenario (output and consumption) or percentage value (inflation, interest rate) on the y-axis.

The solid line represents the exogenous growth model, the dashed line an $A K$ type endogenous growth model where capital determines learningby-doing, and the dotted line an endogenous growth model where output 
determines learning-by-doing, thus featuring the highest path dependence.

\subsubsection{Illustration of Exogenous versus Endogenous Growth}

The definition of an exogenous growth model is that the underlying rate of growth is determined exogenously and that any other economic fluctuations don't have an impact on the long run. In contrast, an endogenous growth model is characterised by having the rate of growth determined endogenously, so that economic fluctuations do have an impact on long run variables. This contrast is nicely illustrated by comparing a negative investment shock with a negative research shock. Figure 5.1 shows the response of output in these two cases.

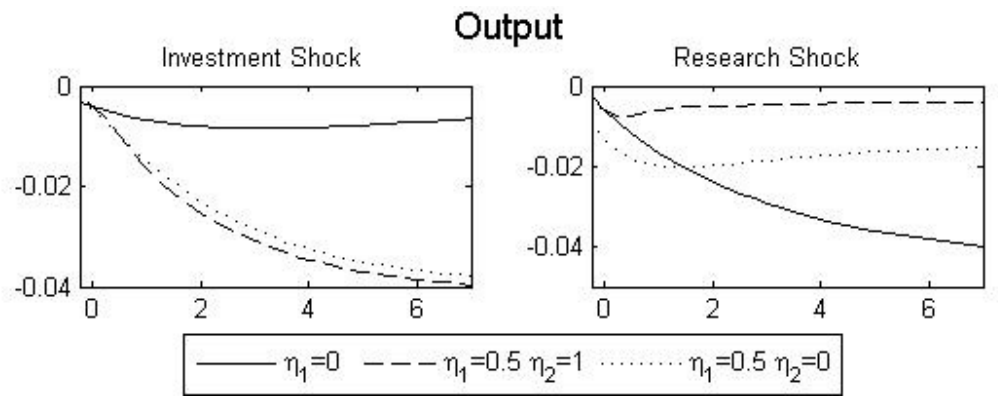

Figure 5.1: The response of output to an investment shock and a research shock.

The negative investment shock is introduced as a shock to cost of investment, which requires the return to capital increase, thereby lowering investment. In the exogenous growth model, it leads to a long-lasting fall in output by about half a percent. Eventually, output will return to its baseline level despite this long-lasting performance of the economy below its potential. In an endogenous growth model, the lower capital stock lowers learning-by-doing, and thus technological progress. Figure 5.1 shows the continuous decline in output. Technically, the capital technology stock is below its steady state value the whole time since the investment shock is so persistent, thereby lowering the growth rate. The response of the two sources of endogenous growth is so similar since the labour supply hardly changes, thereby making capital the driving force of learning-by-doing even 
in the output case.

The negative research shock is implemented as a persistent fall in $B$. In the exogenous growth model, this leads to a continuous decline in technology relative to the baseline case. Therefore, output is lost permanently, without any chance for policy to interact. In the endogenous growth model, technological progress is determined endogenously, represented by the quick stabilisation of the output path in Figure 5.1. Technically, the initial fall in $B$ lowers the growth rate. However, when $T$ falls, the ratio $\frac{X}{T}$ rises, thereby reinstating the original growth rate. The consequence is therefore only an initial loss in output that persists. The higher $\eta_{1}$, the larger will be the initial fall in output, and the faster will be the transition back to the steady state growth.

To conclude, the growth rate falls in an endogenous growth model, leading to a permanent loss in output, when there is a shock to the accumulation of productive resources, while in an exogenous growth model such a permanent effect has to be introduced exogenously. The following sections show that this endogenous determination of growth leaves room for policy to have permanent implications.

\subsubsection{Consumption Crowding-in}

Chapter 2 shows the empirical finding that private consumption increases in response to a government spending shock. Chapter 3 discusses extensively the failure of New Keynesian models to generate this effect, thereby revealing the consumption crowding-in puzzle. The chapter furthermore proposes long run demand effects as a source of consumption demand to induce short run consumption crowding-in. Figure 5.2 shows that this channel works as expected when output is the source of learningby-doing $\left(\eta_{2}=0\right)$. The government spending shock is introduced as an autoregressive shock.

Government spending leads to an increase in demand. This increase in demand increases labour demand, which increases real wages, and thus labour supply. Furthermore, it leads to inflation, which in turn causes the central bank to increase the interest rate, reducing consumption demand. Under exogenous growth, the rise in demand by government spending has 

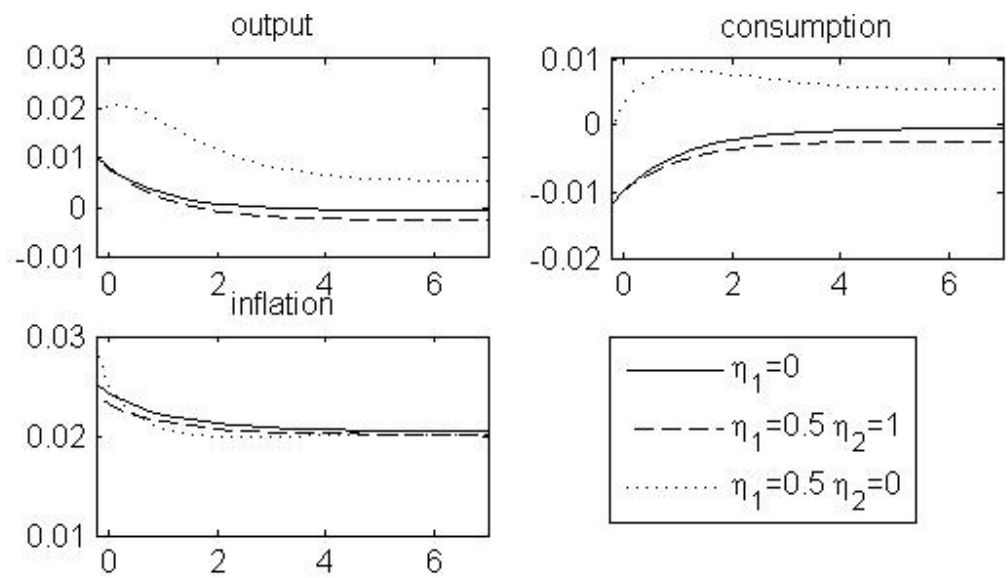

Figure 5.2: The response to a government spending shock using $\gamma=0$.

to be met by the increase in output and the fall in consumption demand, causing crowding out. Under endogenous growth, the increased economic activity causes learning-by-doing, which increases the underlying growth rate of the economy. This in turn increases consumption demand, which again raises labour demand, output and inflation. Due to higher output, consumption does not have to fall.

Chapter 3 made clear that to obtain consumption crowding-in, government spending needs to cause additional positive effects for private consumption demand to shift the $I S$ curve right. This demand is created by the higher economic activity that is caused by government spending. We can calculate the output multiplier of government spending by $m=\frac{1}{\theta} \frac{\% Y}{\%}$, which yields an output multiplier of $m=0.95$. Furthermore, the path dependence implied by an endogenous growth model causes this increased activity to also have a positive long run effect on output.

When looking at the cases of $\eta_{1}=0$ and $\eta_{2}=1$ in Figure 5.2, one can see that inflation hardly rises. The reason lies in the output response of the central bank reaction function, so that interest rates increase without large inflationary effects. This increase in the interest rate lowers investment demand and capital accumulation. Even though this effect is not large, it causes a loss in long run output when capital is the source of learning by doing. 
The output multiplier for the exogenous growth model is only $m=0.52$. This is very small, due to the degree of price stickiness used. Hall (2009) shows that to obtain a multiplier close to unity, one needs a quarterly probability of sticky prices of $\phi=0.89$. This chapter shows that in an endogenous growth model government spending produces more demand and thus a higher output multiplier without the need to induce a higher degree of price stickiness.

Chapter 3 also proposed to use productivity effects of government spending to increase the response of private consumption after a government spending shock. Chapter 4 shows that productive government spending has large supply side effects that increase the growth rate significantly. As it turns out, this effect is not too significant when investment is also determined by the interest rate.

Figure 5.3 shows the effect of having productive government spending. The productivity effect directly increases output but also lowers marginal costs, thereby lowering the inflation effect of government spending in all cases. The output multipliers are $m=0.61$ and $m=1.11$. The main driver of consumption crowding-in is therefore the demand effect of government spending, and not the productivity effect.
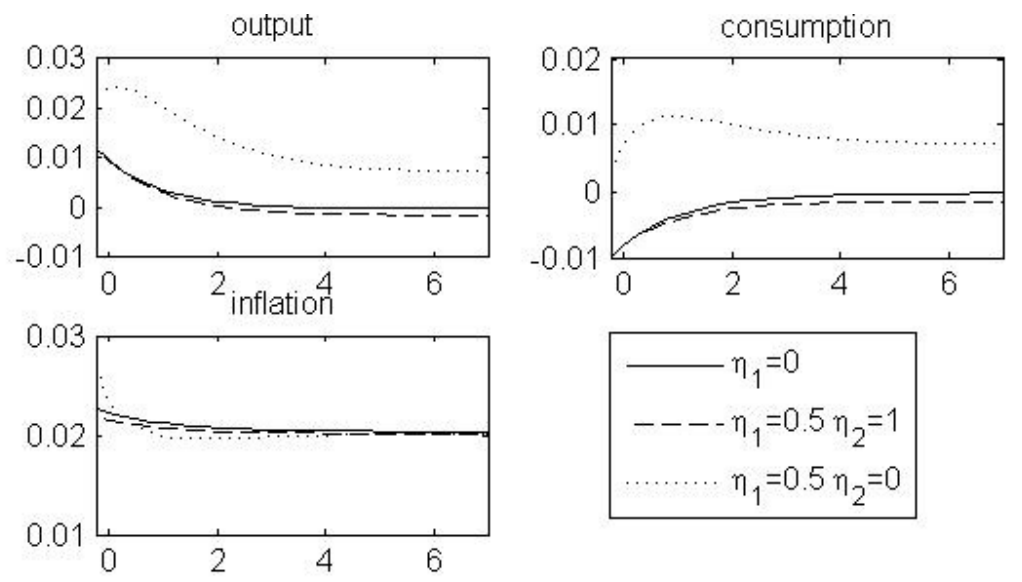

Figure 5.3: The response to a government spending shock using $\gamma=0.1$.

Chapter 4 shows that in an endogenous growth model with learningby-doing determined by capital accumulation the simultaneous presence of 
productive government spending and price stickiness significantly increases growth, and thereby increases consumption above its baseline level. As Figure 5.3 shows, this effect cannot be reproduced here. The reason lies in the determination of investment. While in Chapter 4 investment was entirely determined by household savings, it is also determined by the real interest rate in this chapter. A significant rise in investment is only possible with a fall in the real interest rate or a rise of future capital productivity. For these reasons, investment does not rise, thereby disallowing more growth when learning-by-doing depends on capital.

This section shows that endogenous growth effects are an important transmission channel for government spending. Not only do they increase the multiplier without the need to increase price stickiness, they also allow consumption crowding-in, a puzzle often discussed in recent literature.

Does this mean that the government should have high spending? Clearly, the drawback in this model is the absence of potential distortionary taxation. A policy prescription about optimal steady state government spending needs to take potential distortionary taxes into account. Considering government spending as a tool next to monetary policy to respond to business cycle fluctuations, the assumption of debt financed spending is realistic. Spending can be cut in times of boom and increased in recessions. When used in such situations, this section shows that government spending not only increases short run, but also long run output when learning-bydoing depends sufficiently on current economic conditions.

\subsubsection{Long Run Policy Implications of Monetary Policy}

A standard phrase in undergraduate textbooks is that money is neutral in the long run. The idea behind that is that in the long run output is determined by supply factors, while potential demand effects induced by money in the short run disappear through adjustments in the price level. We will show that this is only partly correct in an endogenous growth setting. While long run output is indeed determined by supply factors, these can be influenced by short run monetary policy.

Figure 5.4 shows the response of output to the central bank setting the interest rate at $1 \%$ below steady state for one year. The lower interest rate 


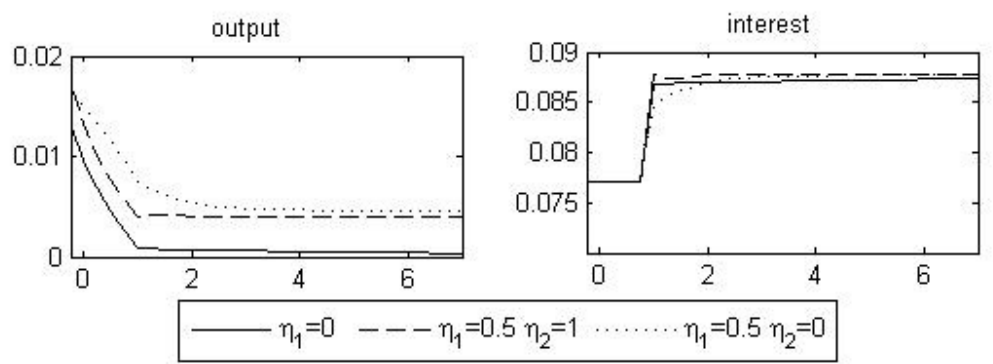

Figure 5.4: The response of output to a negative interest rate shock.

raises both consumption and investment demand. This increases labour demand, real wages, inflation and output. Higher output as well as a higher capital stock lead via learning-by-doing to higher technology growth, and thereby lead to a permanent increase of output. This means that short run demand induced by monetary policy has real long run effects.

Rannenberg (2009) simulates an endogenous growth model with a Taylor rule and a time-varying NAIRU and claims that the inflation averse policy of European central banks following the oil price shocks of the 70's caused large increases in the NAIRU. He claims that a monetary policy rule with a larger weight on the output gap could have reduced that increase in the NAIRU and thus increased output.

Even though our model does not contain a NAIRU, we are able to reproduce the effects on long run output found by Rannenberg (2009). The model is subjected to a negative productivity shock, which reduces output given the amount of resources used and also increases marginal costs. Thus, it is similar to an oil price shock. Figure 5.5 shows the response of output, inflation and the interest rate to that shock.

Inflation rises for two reasons. The first is the direct increase in marginal costs of production. The second is that consumers want to smooth the temporary fall in consumption due to the temporary fall in output, thereby creating excess demand. The rise in inflation forces the central bank to increase the nominal interest rate.

In an endogenous growth model another effect gains importance. The negative productivity shock adversely affects learning-by-doing, though the effect is much stronger in the output case $\left(\eta_{2}=0\right)$. This adverse shock to 

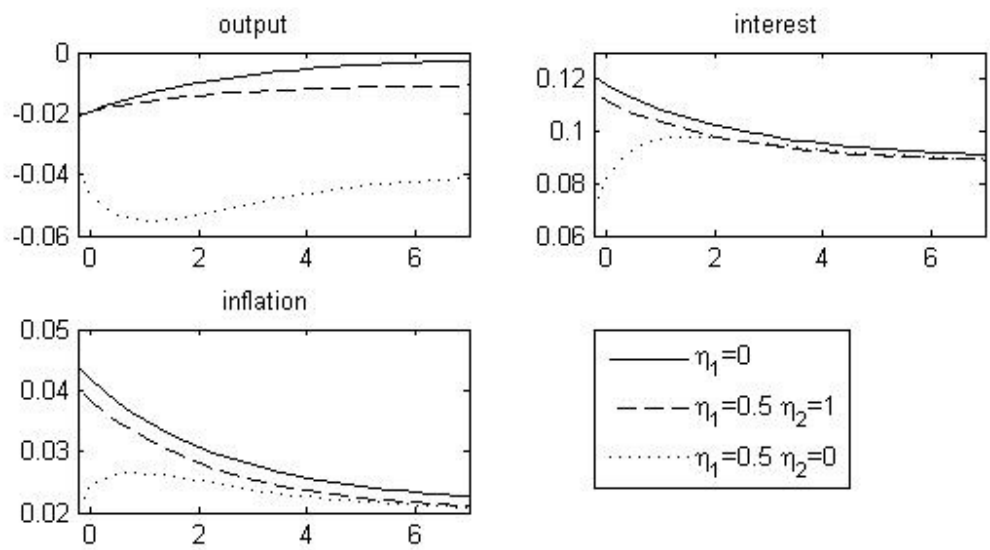

$$
\begin{aligned}
& -\eta_{1}=0 \\
& ---\eta_{1}=0.5 \eta_{2}=1 \\
& \cdots \cdots \cdots \eta_{1}=0.5 \eta_{2}=0
\end{aligned}
$$

Figure 5.5: The response of output, inflation and the interest rate to a negative productivity shock with a monetary policy reaction of $\rho_{y}=0.1$.

growth reduces current consumption demand, which lowers excess demand and explains the lower response of inflation in the endogenous growth cases. However, the lower amount of excess demand also lowers output further. Given the presence of the output gap in the Taylor rule, the fall in output and the rise in inflation almost cancel out in the case of $\eta_{2}=0$ given our parameter set.

Figure 5.5 makes clear that the adverse effect on learning-by-doing caused by the negative productivity shock has significant long run consequences for output. Rannenberg (2009) suggests that these consequences can be reduced by following a monetary policy with a larger weight on the output gap. We reproduce such a scenario in Figure 5.6, where we impose the same negative productivity shock but assume an output gap parameter of $\rho_{y}=0.5$ in the Taylor rule. This should partially offset the increase in interest rates due to higher inflation.

The policy of lower real interest rates leads to more consumption and investment demand. The expected effect will be a higher inflation rate as monetary policy sets lower interest rates for any given inflation due to the negative output gap. The fact that nominal interest rates rise has to do with the strong rise in inflation. ${ }^{4}$ Higher demand also increases

\footnotetext{
${ }^{4}$ A long-lasting negative shock in the Taylor rule will actually lead to increasing
} 

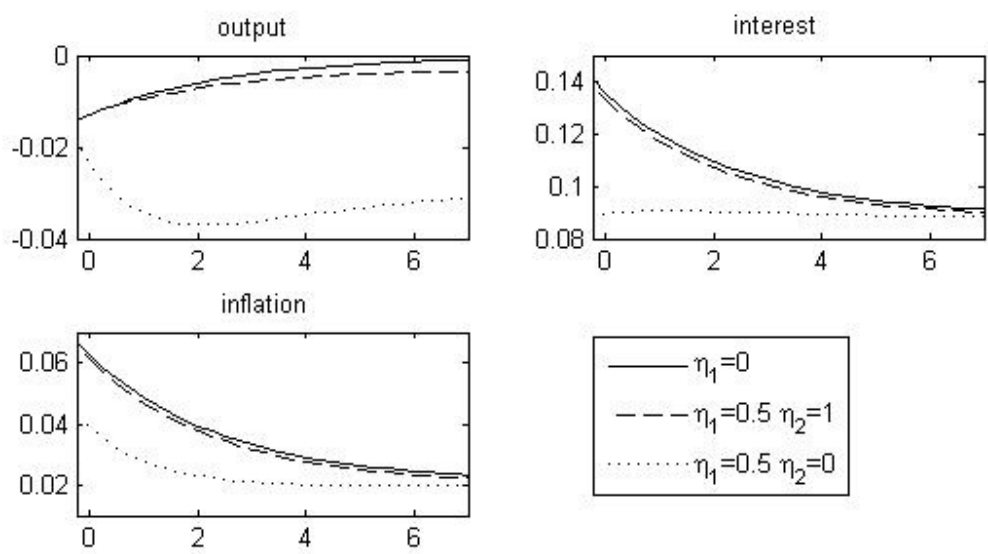

Figure 5.6: The response of output, inflation and the interest rate to a negative productivity shock with a monetary policy reaction of $\rho_{y}=0.5$.

the output response of the economy. Thus, higher investment and higher output increase learning-by-doing and thereby lower the adverse long run consequence of the temporary fall in productivity. Therefore, we can confirm the result found by Rannenberg (2009).

The analysis of the impact of monetary policy on short and long run output suggests that short term inflationary policy is a viable tool to increase long run output. However, the purely forward looking specification of inflation implies a costless inflationary period to boost output, which might not be realistic in reality. While low interest rates will boost output and thus learning-by-doing, the following disinflationary period might diminish these effects. Thus, this question requires further research using a richer model. The final conclusion concerning monetary policy remains unchanged: through its influence on current economic conditions monetary policy has real effects on long run variables. These should be taken into account in the pursuit of monetary policy.

nominal interest rates. This is why we set a discretionary interest rate shock in that scenario. 


\subsubsection{The Zero Bound: One's Losses, Other's Gains}

The recent economic crisis has brought interest rates down to very low levels, fuelling fears of a liquidity trap like Japan has seen it. At the same time, huge fiscal stimulus packages have been implemented. The literature review already pointed out that optimal monetary policy in periods of a zero bound should create additional inflation expectations to alleviate the situation. Without it, the economy faces a spiral of a shortage of demand, leading to deflation, higher real interest rates and more demand shortage.

The literature review also showed that fiscal policy in times of a zero bound is a lot more powerful due to the demand creation effect of government spending. In fact, Christiano et al. (2009) show that fiscal policy becomes more powerful in situations when the deflationary spiral of a zero bound is more severe. This chapter will confirm this result.

We subject the model to a simultaneous negative shock to investment and consumption. This large fall in demand leads to deflation. When the nominal interest rate hits zero, monetary policy looses its power to react appropriately to the deflationary situation. The consequences are a higher real interest rate, even more loss in demand, and finally in output. Figure 5.7 shows the net effect of the central bank's loss in power. This is calculated as the difference between a scenario where the central bank could set below zero interest rates and a scenario where it can't.

The implications are clear. The zero bound holds for approximately one year, during which the nominal interest rate is too high and inflation is too low. Furthermore, output as well as investment are too low. This leads to a fall knowledge accumulation due to learning-by-doing. At this point, the endogenous growth model introduces another transmission channel into the zero bound deflationary spiral. Lower growth lowers households' consumption demand, which further worsens the deflationary spiral. Figure 5.7 clearly shows that. Furthermore, the loss of power of monetary policy causes significant long run losses in output. Since monetary policy is not able to avert this loss, fiscal policy has to come to the rescue.

To simulate a government spending shock while a zero bound holds, we introduce it as a shock the size of $2 \%$ of GDP lasting 4 quarters while at 

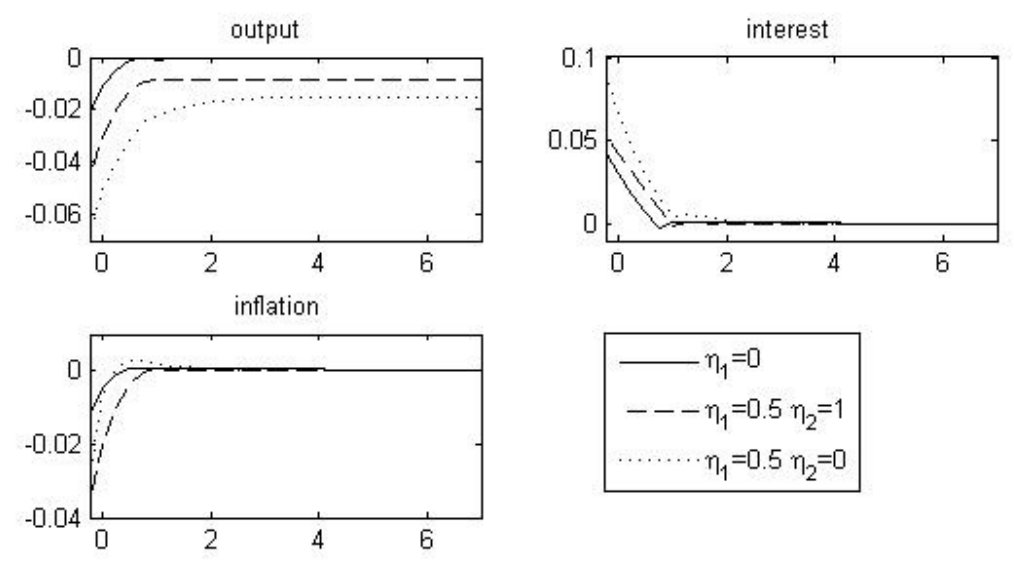

Figure 5.7: The net effect of output, inflation and the interest rate due to the inability of monetary policy to follow the Taylor rule in response to a simultaneous negative consumption and investment shock.

the same time keeping the interest rate fixed, in line with the finding of Christiano et al. (2009). Figure 5.8 shows that the government spending shock increases inflation, thereby countering the deflationary spiral that leads to large output losses. The net effect is a very large increase in output. The government spending multipliers are $m=1.22, m=1.33$ and $m=1.57$. Notably, consumption also increases.

We showed that the loss of power of monetary policy leads to larger adverse effects in an endogenous growth model due to the additional effect of growth on consumption demand. By the same token, this channel also increases the government spending multiplier, thus confirming Christiano et al. (2009). This means that fiscal policy becomes even more important in the presence of a zero interest rate when endogenous growth effects are relevant. When comparing Figures 5.7 and 5.8, it is striking to see that the government spending increase can actually offset the adverse consequences of the loss of power of monetary policy. This shows that government spending is a very important tool in the hands of policy makers, especially in times when monetary policy becomes powerless. 

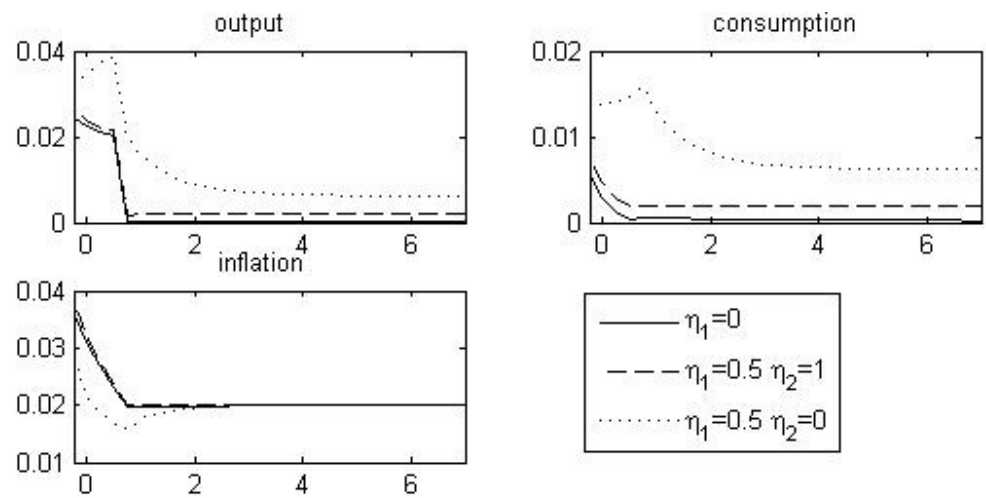

$$
\begin{aligned}
& -\eta_{1}=0 \\
& ---\eta_{1}=0.5 \quad \eta_{2}=1 \\
& \cdots \cdots \cdots \eta_{1}=0.5 \eta_{2}=0
\end{aligned}
$$

Figure 5.8: The response to a government spending shock in the presence of a zero bound using $\gamma=0$.

\subsubsection{The Paradox of Thrift}

The paradox of thrift was popularised by Keynes and states that the desire of the economy as a whole to save more may be detrimental to its well-being as the fall in demand may decrease incomes so much that the economy actually saves less in the end. The primary criticism to that theory is the fact that additional savings enter the loans market, lowering the interest rate and thereby raise investment.

We introduce a savings shock as a negative time preference shock for households. Figure 5.9 shows that the criticism to the paradox of thrift is indeed valid: investment increases in response to such a shock. In the exogenous growth model, output temporarily falls and then rises to a level slightly above steady state due to the increased capital stock. In the long run, output will be back at its steady state level.

When learning-by-doing is determined by the capital stock, then the savings shock, by increasing investment, leads to a significant positive long run response of output. The growth rate will return to its steady state level, but output experiences a level shift. The fact that more saving increases growth in an endogenous growth model won't be any surprise.

The results change when current output is a strong determinant of the endogenous growth rate. The savings shock reduces demand, which in turn lowers output, the growth rate and leads to an even further fall in 


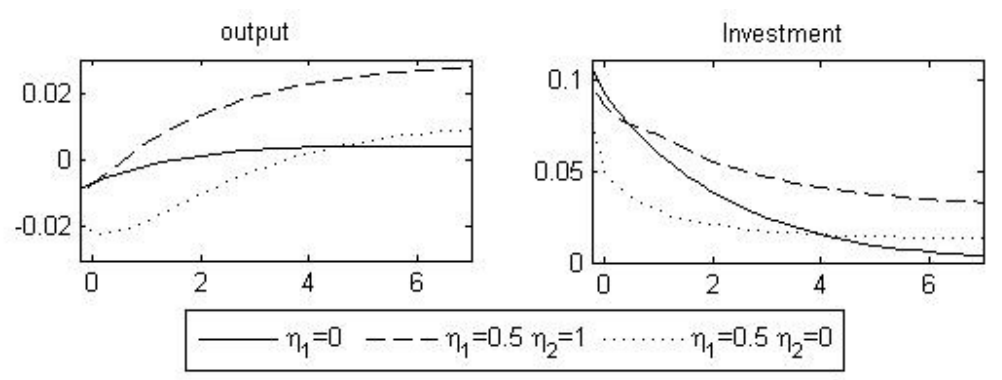

Figure 5.9: The response to a savings shock.

demand. These effects contribute to inducing a large initial fall of output. After a couple of periods, the output-technology ratio in the knowledge accumulation function is back at steady state, while investment is still above steady state since the savings shock is so persistent, and therefore capital, output and growth are increasing. As can be seen in Figure 5.9, output eventually increases above its baseline level.

When we reduce the persistence of the savings shock to $\rho=0.8$, Figure 5.10 shows that investment actually falls due to the large adverse effect on output. The real interest rate is still below steady state, thus inducing investment. However, the resources available for investment are simply lower due to the loss in output. Therefore, we can show a real paradox of thrift, where additional savings demand in an endogenous growth model actually leads to a fall in investment, and thus an adverse effect on short run and long run output.

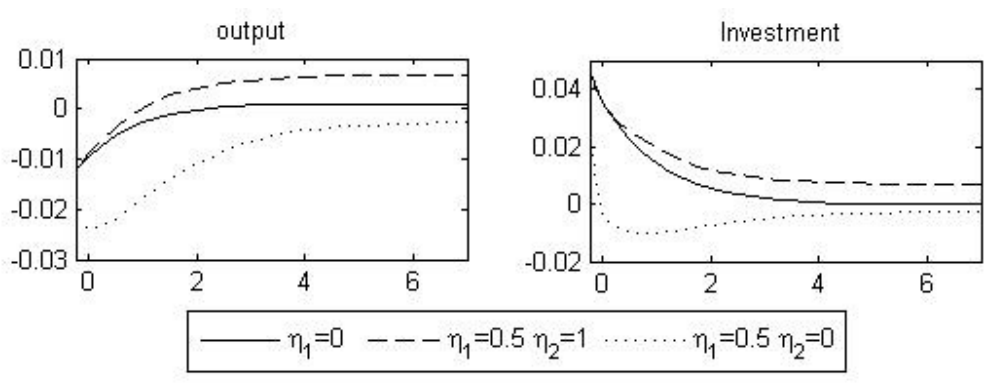

Figure 5.10: The response to a savings shock with persistence $\rho=0.8$. 


\subsubsection{Robustness}

The preceding analysis implies a pretty strong impact of current economic conditions on the growth rate of technology. A $1 \%$ difference in $X$ leads to a $0.5 \%$ change in growth, and thus technology. For the case where output determines learning-by-doing $\left(\eta_{2}=0\right)$, this implies very strong effects of output on growth and thus on demand. We also simulated all cases with $\eta_{1}=0.1$. There is hardly any difference for the case where capital determines learning by doing $\left(\eta_{2}=1\right)$. Since the capital stock adjusts slowly anyways, there are never any large immediate effects.

When $\eta_{2}=0$, changes are more apparent. The immediate impact of all shocks is smaller. The reason is that the growth rate does not react that strongly on impact, thereby lowering the second round effect from consumption demand. On the other hand, the growth rate takes longer until it reaches its steady state again. As equation 5.3 shows, a fall in $Y$ will lower $T$ until the ratio, and thus growth, is back at its steady state. This means that demand effects of below steady state output last longer.

Concerning the qualitative results obtained in this chapter, the only change concerns consumption crowding-in. Since the rise in output does not lead to such a strong growth effect anymore, consumption demand is also less. Therefore, consumption falls on impact, and we observe a J-curve effect where consumption only rises above its baseline level after 2 years. All other results, including the paradox of thrift, still hold.

\subsection{Conclusion}

This chapter achieves a number of important goals relevant in recent research. It derives a New Keynesian endogenous growth model featuring investment demand. In contrast to exogenous growth models, current economic conditions affect the economy's underlying technology growth rate, which leads to permanent level effects on variables. The model introduced allows a floating transition in the strength of this effect with the setting of one parameter, to range from exogenous growth to strong endogenous growth effects. Furthermore, the chapter considers two possibilities for the determination of technological progress: learning-by- 
doing from capital usage or from total production.

Endogenous growth adds two important channels to the standard New Keynesian model. The first is that temporary shocks or policy measures can have permanent effects. The second is that temporary deviations in the growth rate have an immediate effect on consumption demand. This causes similar sized shocks to have a larger immediate effect in an endogenous growth model than in an exogenous growth model.

The most important impact of these new transmission channels is the fact that government spending crowds in private consumption. While other authors have tried to construct a New Keynesian model that can achieve this using a variety of measures, our approach is unique in the literature.

A second conclusion from introducing endogenous growth into a New Keynesian model is that monetary policy actions not only have short run but also long run consequences. This seems to counter the argument that in the long run money is neutral. However, long run output is still purely determined by supply factors, with the difference being that these are influenced by the short run monetary policy choice.

Third, when the zero bound on the nominal interest rate binds in face of a negative demand shock, then the impact of the endogenous growth rate on demand worsens the deflationary spiral that an economy hits. In such a case, the loss of power of monetary policy leads to large negative short and long run effects on output. However, such a situation also makes fiscal policy a lot more powerful, allowing large multipliers.

Finally, the combination of an endogenous growth model with a New Keynesian model allows to show that a savings shock by households does not necessarily have to lead to an increase in investment. In fact, the paradox of thrift can occur. The fall in demand decreases output so much, that investment falls despite a falling real interest rate. This is another novel finding in New Keynesian models.

This chapter shows that the introduction of elements of endogenous growth into an otherwise standard New Keynesian model allows the analysis of persistent effects of temporary shocks. This persistence of effects introduces new channels through which policy can influence the economy. Specifically, it provides an opportunity for consumption crowding-in to exist that has not been found in the literature before. 


\section{A Lower Zero Bound: Solution Strategy}

A usual solution procedure to solve a model with backward and forward looking variables is to obtain the $P-Q$ approach. These matrices allow the construction of the time series of the variables according to

$$
s_{t}=P s_{t-1}+Q \varepsilon_{t}
$$

The $P$ matrix shows the computed backward dynamics of each variable, while the $Q$ matrix shows the impact of shocks.

When non-linearities are present, the $P-Q$ approach does not work that simple, as these matrixes can only be calculated for a stable system. An interest rate fixed at zero leads to an unstable system (Woodford, 2003). However, Bodenstein et al. (2009) present a piecewise approach based on Eggertsson and Woodford (2003) to solve a model with a non-linear monetary policy rule as it is present here.

They solve the model using the $P-Q$ approach, knowing that for periods $t \geq T+1$, where $T$ is the last period where the zero bound holds, the model can be solved using (5.23). All that remains to be done is to find transition matrices from period $t=0$ to period $t=T$ for $s_{t}$, knowing that $s_{0}=0$. These matrices are derived in Bodenstein et al. (2009), where we additionally allow for the shock term to have an autoregressive process. This adds (using the notation in Bodenstein et al. (2009))

$$
\begin{aligned}
F^{(1)} & =-\left(\bar{A} P+B^{*}\right)^{-1}\left(\bar{D}+Q \rho^{\varepsilon}\right) \\
F^{(T-t+1)} & =\left(I-A G^{(T-t)}\right)^{-1}\left(A F^{(T-t)} \rho^{\varepsilon}+D\right) \\
s_{1} & =h^{(T)}+F^{(T)} \varepsilon_{1} \\
s_{t} & =G^{(T-t+1)} s_{t-1}+h^{(T-t+1)}+F^{(T-t+1)} \rho^{\varepsilon} \varepsilon_{t}
\end{aligned}
$$

With this methodology the dynamic paths of the growing variables in terms of $T$ can be solved. This method, with appropriate adjustments, is also used to solve for the dynamic paths of variables when the interest rate is set discretely at $1 \%$ below its steady state level. 



\section{6}

\section{Implications}

\subsection{Implications for Future Research}

Traditional New Keynesian models were estimated by matching first and second moments of a simulated model to real data. However, real data first had to be de-trended in order to make it look like data that a New Keynesian model could generate, meaning as deviations of the variables around a steady state. This de-trending is done using methods ranging from a simple linear trend, over Hendrick-Prescott filters to stochastic trends. For all methods it holds that the New Keynesian literature assumes that the trend is unexplained, it is a movement outside the model. The New Keynesian literature only tries to explain the movements around that trend.

Without doubt, the much more interesting question is the explanation of the trend. While the explanation of the long run trend is the domain of the endogenous growth literature, this dissertation establishes that temporary movements in the long run trend can also be explained within the New Keynesian model. Therefore, a lot more information from empirical data can actually be used in the estimation procedure of the New Keynesian model.

Another field of application is a richer description of transition dynamics for policy changes affecting the endogenous rate of growth. While the solution procedure of New Keynesian models involves deviations around a certain steady state, one could simulate these transition dynamics by 
imposing shocks representing the old steady state in the initial period and then observing the transition dynamics, including the role of monetary and fiscal policy in that process.

Furthermore, future research can deal with a more sophisticated determination of the deviation of the endogenous growth rate from its trend. The endogenous growth literature provides a vast amount of possibilities. The decision as to which one of these is appropriate will have to be based on empirical estimation.

\subsection{Policy Implications}

Finally, the implications for optimal monetary and fiscal policy should be analysed using a formal welfare analysis. To this end, one first has to realise that the New Keynesian endogenous growth model does not add new insights concerning the determination of optimal policy along the steady state growth path. It allows the analysis of temporary deviations from that steady state growth path. This means that if any policy actions are taken, these have to be temporary measures. In the long run, policy should return to its optimal path. It is well known that a too high level of government spending requires too high distortionary tax rates, which will be detrimental to growth and welfare.

When looking at temporary policy measures, the fact that even these can permanently increase output is an intriguing idea. However, one has to realise that agents already trade off the decision of higher future utility (from higher consumption) versus the current disutility of higher labour supply. This is what determines the steady state growth rate. Therefore, one cannot generally state that any policy action increasing the rate of growth, even if only temporary, is welfare enhancing without first making a formal welfare analysis. Nevertheless, there are some policy conclusions to be drawn.

The first conclusion relates to the appropriateness of the large fiscal stimulus packages seen in world economies in the recent crisis. Interest rates as well as inflation fell to very low levels. This raised the question of whether we witnessed a liquidity trap, given the fact that monetary policy seemed unable to stimulate the economy further. The fact that the 
huge fiscal stimulus packages implemented did not induce inflation seem to confirm the theory that the economy is indeed in a liquidity trap. Chapter 5 shows that these packages made a lot of sense to prevent further current and future output losses.

The most important implication of the inclusion of endogenous technology into a New Keynesian model relates to the endogenous determination of the trend or target output. In an exogenous growth model, policy makers have to guess in face of a shock whether their output target has changed or not. This problem is especially severe following the latest recession. In countries all over the world policy makers are unsure of whether output is still far below trend or whether the actual trend output has fallen. This has important policy implications.

When using a well-estimated New Keynesian endogenous growth model the change in trend caused by shocks can be seen earlier, thereby allowing more appropriate policy responses. A direct application to the current crisis relates to the question of when budget deficits should be reversed. According to a standard New Keynesian model, economies are still far below their natural level, thus justifying aggressive countercyclical policy. However, a model with endogenous technology predicts that we are getting closer to the actual trend. In a sense, such a model leads to the conclusion that one should take one's losses and should not try to chase a target which does not actually exist anymore. This implies an earlier reduction of budget deficits. 



\section{Bibliography}

Alfonso, A. and J. G. Alegre (2008). Economic growth and budgetary components: A panel assessment for the EU. ECB Working Paper (848).

Altig, D., L. Christiano, M. Eichenbaum, and J. Lindé (2005). Firmspecific capital, nominal rigidities and the business cycle. NBER working paper (11034).

Amano, R. A. and T. S. Wirjanto (1998). Government expenditures and the permanent-income model. Review of Economic Dynamics 1(3), 719-730.

Aschauer, D. A. (1989). Is public expenditure productive? Journal of Monetary Economics 23, 177-200.

Barro, R. (1990). Government spending in a simple model of endogeneous growth. Journal of Political Economy 98(5), 103-125.

Barro, R. J. and H. I. Grossman (1971). A general disequilibrium model of income and employment. American Economic Review 61(1), 82-93.

Barro, R. J. and X. Sala-i-Martin (1995). Economic Growth. McGraw-Hill. 
Bartolomeo, G. D. and M. Manzo (2007). Do tax distortions lead to more indeterminacy? a New Keynesesian perspective. MPRA working paper (3549).

Bassetto, M. (2008). Fiscal theory of the price level. Available online http://www.nber.org/bassetto/research/palgrave/ftheorypost.pdf.

Baxter, M. and R. G. King (1993). Fiscal policy in general equilibrium. The American Economic Review 83(3), 315-334.

Bénassy, J.-P. (2007). IS-LM and the multiplier: A dynamic general equilibrium model. Economic Letters 96, 189-195.

Blanchard, O. and C. Kahn (1980). The solution of linear difference models under rational expectations. Econometrica 48(5), 1305-1311.

Blanchard, O. and R. Perotti (2002). An empirical characterization of the dynamic effects of changes in government spending and taxes on output. The Quarterly Journal of Economics 117(4), 1329-1368.

Blanchard, O. J. and D. Quah (1989). The dynamic effects of aggregate demand and supply disturbances. The American Economic Review 79(4), 655-673.

Bodenstein, M., C. J. Erceg, and L. Guerrieri (2009). Effects of foreign schocks when interest rates are zero. International Finance Discussion Papers (983).

Bom, P. R. and J. E. Lighthart (2008). How productive is public capital? A meta-analysis. CESifo Working Paper Series (2206).

Bouakez, H. and N. Rebei (2007, August). Why does private consumption rise after a government spending shock? Canadian Journal of Economics 40(3), 954-979.

Buiter, W. H. (2002). The fiscal theory of the price level: A critique. Th Economic Journal 112, 459-480.

Burnside, C., M. Eichenbaum, and J. Fisher (2004). Fiscal shocks and their concequences. Journal of Economic Theory 115, 89-117. 
Calvo, G. A. (1983). Staggered prices in a utility-maximizing framework. Journal of Monetary Economics 12, 383-398.

Campbell, J. Y. and N. G. Mankiw (1987). Are output fluctuations transitory? The Quarterly Journal of Economics 102, 857-880.

Candelon, B. and L. Lieb (2010). Fiscal policy in good and bad times. Meteor Research Memorandum.

Carlstrom, C. T. and T. S. Fuerst (2005). Investment and interest rate policy: A discrete time analysis. Journal of Economic Theory 123, 4-20.

Cassou, S. P. and K. J. Lansing (1998). Optimal fiscal policy, public capital, and the productivity slowdown. Journal of Economic Dynamics and Control 22, 911-935.

Castro, F. (2006). The macroeconomic effects of fiscal policy in Spain. Applied Economics 38, 913-924.

Chang, W.-Y. (1999). Government spending, endogenous labor, and capital accumulation. Journal of Economic Dynamics and Control 23, 12251242.

Christiano, L., M. Eichenbaum, and S. Rebelo (2009). When is the government spending multiplier large? NBER Working Paper (15394).

Coenen, G. and R. Straub (2005). Does government spending crowd in private consumption: Theory and empirical evidence for the Euro area. International Finance 8(3), 435-470.

Cogan, J. F., T. Cwik, J. B. Taylor, and V. Wieland (2010). New Keynesian verus old Keynesian government spending multipliers. Journal of Economic Dynamics and Control 34(7236), 281-296.

Colciago, A. (2005). Rule of thumb consumers meet sticky wages. Munich Personal RePEc Archive.

Comin, D. and M. Gertler (2006). Medium-term business cycles. The American Economic Review 96(3), 523-551. 
Devarajan, S., V. Swaroop, and H. fu Zou (1996). The composition of public expenditure and economic growth. Journal of Monetary Economics 37, $313-344$.

Devereux, M. B., A. C. Head, and B. J. Lapham (1996). Monopolistic competition, increasing returns and the effects of government spending. Journal of Money, Credit and Banking 28(2), 233-254.

Diebold, F. X. and G. D. Rudebusch (1989). Long memory and peristence in aggregate output. Journal of Monetary Economics 24, 189-209.

Drèze, J. and E. Malinvaud (1994). Growth and employment: the scope of a European initiative. European Economic Review 38(3-4), 489-504.

Dupor, B. (2001). Investment and interest rate policy. Journal of Economic Theory 98, 85-113.

Eggertsson, G. B. and M. Woodford (2003). The zero bound on interest rates and optimal monetary policy. Brookings Papers on Economic Activity 1, 139-233.

Evans, P. and G. Karras (1994a). Are government activities productive? Evidence from a panel of U.S. states. The Review of Economics and Statistics 76(1), 1-11.

Evans, P. and G. Karras (1994b). Is government capital productive? Evidence from a panel of seven countries. Journal of Macroeconomics 16, 271-279.

Fatas, A. and I. Mihov (2001). The effects of fiscal policy on consumption and employment: Theory and evidence. CEPR Discussion Paper (2760).

Furlanetto, F. and M. Seneca (2009). Fiscal shocks and real rigidities. The B.E. Journal of Macroeconomics 9(1), 1-33. Article 2.

Futagami, K., Y. Morita, and A. Shibita (1993). Dynamic analysis of an endogenous growth model with public capital. Scandinavian Journal of Economics 95, 607-625. 
Galí, J. (2008). Monetary Policy, Inflation, and the Business Cycle: An Introduction to the New Keynesian Framework. Princeton University Press.

Galí, J. and M. Gertler (1999). Inflation dynamics: A structural econometric analysis. Journal of Monetary Economics 44(2), 195-222.

Galí, J., J. D. López-Salido, and J. Valles (2007). Understanding the effects of government spending on consumption. Journal of the European Economic Association 5(1), 227-270.

García-Peñalosa, C. and S. J. Turnovsky (2007). Growth, income inequality, and fiscal policy: What are the relevant trade-offs? Journal of Money, Credit and Banking 39(2-3), 369-394.

Giammarioli, N. and N. Valla (2003). The natural real rate of interest in the EURO area. ECB working paper series (233).

Giammarioli, N. and N. Valla (2004). The natural real interest rate and monetary policy: A review. Journal of Policy Modeling 26, 641-660.

Giordano, R., S. Momigliano, S. Neri, and R. Perotti (2007). The effects of fiscal policy in Italy: Evidence from a VAR model. European Journal of Political Economy 23, 707-733.

Goodfriend, M. and R. G. King (1997). The new classical synthesis and the role of monetary policy. In B. Bernanke and J. Rotemberg (Eds.), NBER Macroeconomics Annual. MIT Press.

Gorter, J., J. Jacobs, and J. de Haan (2008). Taylor rules for the ECB using expectations data. Scandinavian Journal of Economics 110(3), 473-488.

Hall, R. E. (2009). By how much does GDP rise if the government buys more output? NBER Working Paper (15496).

Hiroki, A. (2009). Long-run relationship between inflation and growth in a New Keynesian framework. Munich Personal RePEc Achive (15205).

Irmen, A. and J. Kuehnel (2008). Productive government expenditure and economic growth. University of Heidelberg Discussion Paper Series (464). 
Jones, C. I. (1995a). R\&D based models of endogenous growth. The Journal of Political Economy 103(4), 759-784.

Jones, C. I. (1995b). Time series test of endogenous growth models. Quarterly Journal of Economics 110, 495-525.

Kamps, C. (2004). The Dynamic Macroeconomic Effects of Public Capital. Springer-Verlag.

Kneller, R., M. F. Bleaney, and N. Gemmell (1999). Fiscal policy and growth: Evidence from OECD countries. Journal of Public Economics 74, 171-190.

Kriwoluzky, A. (2009). Per-announcement and timing - the effects of a government expenditure shock. EUI Working Papers (40).

Kühn, S., J. Muysken, and T. van Veen (2010). The adverse effects of government spending on private consumption in New Keynesian models. Metroeconomica 61(4), 621-639.

Kurozumi, T. and W. V. Zandweghe (2008). Investment, interest rate policy, and equilibrium stability. Journal of Economic Dynamics and Control 32, 1489-1516.

Kwan, Y. K. (2006). The direct substitution between government and private consumption in East Asia. NBER Working Paper (W12431).

Kydland, F. E. and E. C. Prescott (1982). Time to build and aggregate fluctuations. Econometrica 50, 1345-1370.

Laubach, T. and J. C. Williams (2003). Measuring the natural rate of interest. The Review of Economics and Statistics 85(4), 1063-1070.

Lavoie, M. (2006). A Post-Keynesian ammendment to the new consensus on monetary policy. Metroconomica 57(2), 165-192.

Linnemann, L. (2004). Tax base and crowding-in effects of balanced budget fiscal policy. Scandinavian Journal of Economics 106, 273-297.

Linnemann, L. and A. Schabert (2003a). Can fiscal spending stimulate private consumption? Economic Letters 82, 173-179. 
Linnemann, L. and A. Schabert (2003b). Fiscal policy in the New Neoclassical Synthesis. Journal of Money, Credit and Banking 35(6), 911-930.

Linnemann, L. and A. Schabert (2006). Productive government expenditure in monetary business cycle models. Scottish Journal of Political Economy 53, 28-46.

Mankiw, N. (2000). The savers-spenders theory of fiscal policy. The American Economic Review 90(2), 120-125.

Mertens, K. and M. O. Ravn (2010). Measuring the impact of fiscal policy in the face of anticipation: A structural VAR approach. The Economic Journal 120, 393-413.

Mittnik, S. and T. Neumann (2001). Dynamic effects of public investment: Vector autoregressive evidence from six industrialized countries. Empirical Economics 26, 429-446.

Monacelli, T. and R. Perotti (2008). Fiscal policy, wealth effects, and markups. NBER Working Paper (14584).

Monacelli, T. and R. Perotti (2010, May). Fiscal policy, the real exchange rate, and traded goods. The Economic Journal 120, 427-461.

Mountford, A. and H. Uhlig (2009). What are the effects of fiscal policy shocks? Journal of Applied Econometrics 24, 960-992.

Msonnier, J.-S. and J.-P. Renne (2007). A time-varying "natural" rate of interest for the Euro area. European economic review 51, 1768-1784.

Murray, C. J. and C. R. Nelson (2002). The great depression and output persistence. Journal of Money, Credit and Banking 34, 1090-1098.

Nakov, A. (2008). Optimal and simple monetary policy rules with a zero floor on the nominal interest rate. International Journal of Central Banking 4, 73-127.

Nelson, C. R. and C. I. Plosser (1982). Trends and random walks in macroeconomic time series: Some evidence and implications. Journal of Monetary Economics 10, 139-162. 
Ni, S. (1995). An empirical analysis on the substitutability between private consumption and government purchases. Journal of Monetary Economics 36(3), 593-605.

Pappa, E. (2005). New-Keynesian or RBC transmission? The effects of fiscal shocks in labour markets. CEPR Discussion Paper (5313).

Peretto, P. F. (2003). Fiscal policy and long-run growth in R\&Dbased models with endogenous market structure. Journal of Economic Growth 8, 325-347.

Perotti, R. (2004). Estimating the effects of fiscal policy in OECD countries. IGIER Working Paper (276).

Perotti, R. (2007). In search of the transmission mechanism of fiscal policy. NBER Macroeconomics Annual 22, 169-249.

Ramey, V. and M. Shapiro (1998). Costly capital reallocation and the effects of government spending. NBER Working Paper 6283.

Ramey, V. A. (2009). Identifying government spending shocks: It's all in the timing. NBER Working Paper (15464).

Rannenberg, A. (2009). Explaining European unemployment with a New Keynesian new growth model. In E. Hein, T. Niechoj, and E. Stockhammer (Eds.), Macroeconomic Policies on Shaky Foundations - Whither Mainstream Economics? Metropolis.

Ravn, M., S. Schmitt-Grohé, and M. Uribe (2006). Deep habits. Review of Economic Studies 73, 195-218.

Reifschneider, D. and J. C. Williams (2000). Three lessons for monetary policy in a low-inflation era. Journal of Money, Credit and Banking 32, 936-966.

Romer, D. (2006). Advanced Macroeconomics, Chapter 3, pp. 100-170. McGraw-Hill.

Romer, P. (1986). Increasing returns and long-run growth. Journal of Political Economy 94(5), 1002-1037. 
Romer, P. M. (1990). Endogenous technological change. Journal of Political Economy 98, S71-S102.

Romp, W. and J. de Haan (2007). Public capital and economic growth: A critical survey. Perspektiven der Wirtschaftspolitik 8, 6-52.

Schumpeter, J. (1939). Business cycles: a theoretical, historical, and statistical analysis of the capitalist process. McGraw Hill.

Sims, C. A. (2008). Stepping on a rake: The role of fiscal policy in the inflation of the 1970's. Available online http://www.sims.princeton.edu/ yftp/FiscalTheoryGreatInflation/BOJpresentation.pdf.

Smets, F. and R. Wouters (2003). An estimated dynamic stochastic general equilibrium model of the Euro area. Journal of the European Economic Association 1(5), 1123-1175.

Smets, F. and R. Wouters (2007). Shocks and frictions in U.S. business cycles: A Bayesian DSGE approach. The American Economic Review 97(3), 506-606.

Stadler, G. W. (1990). Business cycle models with endogenous technology. The American Economic Review 80(4), 763-778.

Steindl, S. and G. Tichy (2009). Cycles and growth: An introduction. Empirica 36, 159-164.

Stock, J. H. and M. W. Watson (2001). Vector autoregressions. Journal of Economic Perspectives 15(4), 101-115.

Sturm, J. E. and J. de Haan (1995). Is public expenditure really productive? Economic Modelling 12, 60-72.

Taylor, J. B. (1993). Discretion verus policy rules in practice. CarnegieRochester Conference Series on Public Policy 39, 195-214.

Tenhofen, J. and G. B. Wolff (2007). Does anticipation of government spending matter? Evidence from an expectation augmented VAR. Deutsche Bundesbank Discussion Paper, Series 1: Economic Studies (14). 
Tervala, J. (2009). Productive government spending and private consumption: A pessimistic view. Economics Bulletin 29, 417-426.

Turnovsky, S. J. (1997). Fiscal policy in a growing economy with public capital. Macroeconomic Dynamics 1, 615-639.

Turnovsky, S. J. (2000). Fiscal policy, elastic labour supply and endogenous growth. Journal of Monetary Economics 45, 185-210.

Woodford, M. (2001). The Taylor rule and optimal monetary policy. The American Economic Review 91 (2), 232-237.

Woodford, M. (2003). Interest and Prices. Princeton University Press. 


\section{Nederlandse SAmenvatting (Summary in Dutch)}

Dit proefschrift behandelt de effecten die overheidsuitgaven in dynamische algemene evenwichtsmodellen (DGE) hebben. Dit soort modellen wordt over het algemeen gekarakteriseerd door huishoudens die hun nut niet alleen in elke periode maar ook tot in de toekomst optimaliseren. Het basis Nieuw-Keynesiaanse model, dat ook een DGE model is, voorspelt dat een stijging van de overheidsuitgaven een daling in de particuliere consumptie veroorzaakt. Echter, empirisch onderzoek van het afgelopen decennium dat gebruik maakt van vector-autoregressieve modellen was niet in staat om een dergelijke daling van consumptie te repliceren. Integendeel, het tegenovergestelde effect lijkt plaats te vinden: een stijging van particuliere consumptie wanneer de overheidsuitgaven toenemen. Er is dus een consumptie crowding-in puzzel in de literatuur over dynamische algemene evenwichtsmodellen. Dit proefschrift analyseert hoe de bestaande literatuur deze puzzel behandelt en stelt bovendien een nieuwe benadering voor dit probleem voor.

Hoofdstuk 2 geeft een uitgebreide literatuurstudie over alle aspecten van deze dissertatie. De overige hoofdstukken worden gemotiveerd door de 
bestaande behandeling, zowel theoretisch als empirisch, van de relevante onderwerpen in de literatuur te bespreken.

Hoofdstuk 3 biedt een systematische analyse van de effecten van de overheidsuitgaven met behulp van grafieken. De reden voor de vermindering van particuliere consumptie door overheidsuitgaven is het verbruik van goederen door de overheid. Huishoudens kiezen hoeveel ze werken, en daarmee bepalen zij de productie. Als de overheid meer verbruikt, zijn er gewoonweg minder producten beschikbaar voor hun eigen verbruik. In de loop van hun optimalisatie zullen ze hun verbruik van vrije tijd verminderen en meer werken, waardoor de productie wordt verhoogd. Wanneer het model prijsstarheid heeft, net als de Nieuw-Keynesiaanse modellen, kan deze verhoging van de productie nog groter zijn. Echter, de consumptie kan nooit stijgen in reactie op een schok in overheidsuitgaven, omdat de daling van consumptie de oorspronkelijke reden voor de stijging van de werktijd is.

Elk DGE-model dat een stijging van consumptie vertoont, heeft of een extra verhoging van de productie groter dan de overheidsuitgaven nodig, $\mathrm{f}$ moet een extra positief effect op de consumptie vraag hebben. Hoofdstuk 3 analyseert de bestaande literatuur, die consumptie crowding-in verklaart, langs deze lijnen. Het stelt vast dat geen van de ingevoerde maatregelen een voldoende stijging in consumptie verklaart. Voorts wordt een nieuwe methode ter verklaring van crowding-in voorgesteld. Als overheidsuitgaven een positief effect op de toekomstige consumptie hebben, dan wordt de huidige consumptieve vraag verhoogd, met het gevolg dat consumptie stijgt.

In een standaard Nieuw-Keynesiaans model zijn de lange termijn waarden van alle variabelen terug op hun oorspronkelijke steady-state niveau. Er is geen blijvend effect van een schok. Echter, een endogeen groeimodel, dat ook een DGE-model is, staat tijdelijk schokken om de groei te benvloeden toe die daardoor leiden tot blijvende effecten op de gemodelleerde variabelen. Aangezien het voorgestelde nieuwe mechanisme voor consumptie crowding-in is gebaseerd op een dergelijke lange termijn effect, combineert dit proefschrift een endogene groei en een NieuwKeynesiaans model. Hoofdstuk 4 analyseert, met hulp van een basis endogeen groeimodel, het effect van tijdelijke overheidsuitgaven voor groei en dus voor lange termijn consumptie. 
Het hoofdstuk vindt vier primaire kanalen waarmee tijdelijke overheidsuitgaven besparingen van huishoudens veroorzaken. Het eerste kanaal is het directe negatieve vermogenseffect, waardoor huishoudens minder besparen. Tegengesteld aan dit effect is de toename van het arbeidsaanbod, die in combinatie met productieve overheidsbestedingen een directe verhoging in de productie mogelijk maakt en daardoor meer middelen voor groei beschikbaar zijn. Bovendien verhogen deze twee effecten ook de reële rentevoet, waardoor besparingen stijgen. Het vierde kanaal is ontdekt bij de invoering van starre prijzen. Afwijkingen van de productie van het flexibele prijsniveau evenals een hogere rele rente leiden tot meer middelen voor groei.

Hoofdstuk 4 bevat ook een sectie die het gebruik van de Taylor-regel om de rentevoet vast te stellen in een endogeen groeimodel bespreekt. Deze sectie laat zien dat een Taylor-regel, gebruikt in een Nieuw-Keynesiaans model, daadwerkelijk een productie gat parameter vereist om de nominale rente aan te passen aan veranderingen in de natuurlijke reële rente. Zonder deze parameter is de stabiliteit van inflatie niet gegarandeerd. Verder wordt gesteld dat dit aspect de ogenschijnlijk bestaande aandacht op het productie gat door centrale banken, die zogenaamd alleen aandacht aan inflatie besteden, verklaren kan.

Hoofdstuk 5 laat zien dat het nieuwe mechanisme ter verklaring van de stijging van consumptie werkt. In een nieuw-Keynesiaans model met endogene groei, waar technologische vooruitgang voldoende afhangt van de huidige productie, leidt de stimulering van de economie door de huidige overheidsuitgaven tot een voldoende toekomstige stijging in consumptie, zodat de huidige consumptie stijgt, dus crowding-in vindt plaats.

Daarnaast is het model in hoofdstuk 5 in staat om een aantal andere relevante aspecten te verklaren. Het monetaire beleid heeft gevolgen op de lange termijn, en een te sterke reactie tegen inflatie bij een negatieve productiviteitsschok kan op lange termijn tot nadelige effecten leiden. Een andere bevinding is de mogelijke aanwezigheid van de spaarzaamheidsparadox. Terwijl men hogere investeringen en lange termijn productie door hogere besparingen zou kunnen verwachten, is het inderdaad mogelijk dat het aanvankelijke gebrek aan vraag de groei van de productie zo sterk verlaagd, dat het door hogere besparingen, als deze 
niet zo duurzaam zijn, niet meer ingehaald wordt. Ten slotte laat het hoofdstuk zien dat alle schokken een groter effect in aanwezigheid van een liquiditeitsfaciliteit hebben wanneer er endogene groei in een NieuwKeynesiaans model is. 


\section{Short Curriculum Vitae}

Stefan Kühn was born on the 21st of May 1981 in Berlin, Germany. He did his Master degree in International Economic Studies at the Faculty of Economics and Business of Maastricht University in 2005. Thereafter, he joined the Department of Economics to pursue his $\mathrm{PhD}$. He has presented his results at numerous international conferences. Furthermore, one of his articles is published in Metroeconomica. 